\title{
Um código LES de alta ordem para simulação de escoamentos turbulentos com desenvolvimento espacial
}

\author{
Patrícia Sartori
}



Data de Depósito:

Assinatura:

\section{Patrícia Sartori}

\section{Um código LES de alta ordem para simulação de escoamentos turbulentos com desenvolvimento espacial}

\footnotetext{
Tese apresentada ao Instituto de Ciências Matemáticas e de Computação - ICMC-USP, como parte dos requisitos para obtenção do título de Doutora em Ciências - Ciências de Computação e Matemática Computacional. VERSÃO REVISADA

Área de Concentração: Ciências de Computação e Matemática Computacional

Orientador: Prof. Dr. Leandro Franco de Souza
} 
Ficha catalográfica elaborada pela Biblioteca Prof. Achille Bassi e Seção Técnica de Informática, ICMC/USP, com os dados fornecidos pelo(a) autor(a)

Sartori, Patrícia
Um código LES de alta ordem para simulação de
escoamentos turbulentos com desenvolvimento espacial
/ Patrícia Sartori; orientador Leandro Franco
de Souza. - São Carlos - SP, 2016.
90 p.
Tese (Doutorado - Programa de Pós-Graduação em
Ciências de Computação e Matemática Computacional)
- Instituto de Ciências Matemáticas e de Computação,
Universidade de São Paulo, 2016.
1. Large Eddy Simulations. 2. Geração de condições
iniciais turbulentas. 3. Camada limite turbulenta.
4. Modelagem submalha. I. Souza, Leandro Franco de,
orient. II. Título.




\section{Patrícia Sartori}

\section{A high-order LES code for spatially developing turbulent flow simulations}

Doctoral dissertation submitted to the Instituto de Ciências Matemáticas e de Computação - ICMCUSP, in partial fulfillment of the requirements for the degree of the Doctorate Program in Computer Science and Computational Mathematics. FINAL VERSION

Concentration Area: Computer Science and Computational Mathematics

Advisor: Prof. Dr. Leandro Franco de Souza 

A minha família. 

Agradeço primeiramente a Deus pela força para vencer mais essa jornada.

Aos meus pais, Ricardo e Vanira, e ao meu irmão, Vinícius, e ao meu namorado, Erick, que sempre me apoiaram e acreditaram em mim.

Ao meu professor e amigo Dr. Leandro Franco de Souza pela orientação, incentivo e paciência no decorrer desses anos.

A todos os meus amigos e colegas do LMMAC pela amizade, companheirismo e grande ajuda. Em especial, agradeço ao Josuel Kruppa Rogenski, que sem ele não chegaria até aqui.

Ao apoio financeiro concedido nesse período pela Fundação de Amparo à Pesquisa do Estado de São Paulo por meio dos processos 2011/00647-9 e 2012/25121-2 (BEPE) para a realização desse projeto.

Por fim, a todos que direta ou indiretamente contribuíram para a realização desse trabalho. 

"São vencedoras e vivem uma existência feliz as pessoas que vencem os desafios que elas próprias lançaram."

(Daisaku Ikeda). 



\section{RESUMO}

SARTORI, P.. Um código LES de alta ordem para simulação de escoamentos turbulentos com desenvolvimento espacial. 2016. 90 f. Tese (Doutorado em Ciências - Ciências de Computação e Matemática Computacional) - Instituto de Ciências Matemáticas e de Computação (ICMC/USP), São Carlos - SP.

A metodologia LES (Large Eddy Simulation) é uma alternativa viável para a solução numérica de escoamentos de interesse prático em virtude da limitação computacional imposta pela resolução direta de todas as escalas presentes em escoamentos turbulentos. Entretanto, a compreensão detalhada do fenômeno da turbulência é ainda uma tarefa desafiadora em consequência do seu comportamento não linear e alta sensibilidade às condições iniciais e de contorno. Dessa forma, o sucesso de simulações LES está associado à utilização de um código computacional eficiente, com modelagem submalha que represente corretamente a dinâmica do escoamento, juntamente com a especificação de condições iniciais turbulentas fisicamente consistentes. Nesse contexto, o presente trabalho tem como objetivo o desenvolvimento de um código LES de alta ordem aliado a um método de geração de perturbações para o estudo de escoamentos turbulentos em camada limite sobre superfície plana. Foi adotada a formulação vorticidade-velocidade. A metodologia numérica baseia-se no método de diferenças finitas em malhas colocalizadas, onde as derivadas nas direções longitudinal e normal ao escoamento são aproximadas usando diferenças compactas de alta ordem. Esse estudo assume periodicidade na direção transversal do escoamento e então um método espectral é adotado nessa direção. A integração temporal é feita através do método Runge-Kutta de $4^{a}$ ordem e a solução da equação de Poisson se dá por meio de um método multigrid. Para a modelagem submalha é adotado o modelo WALE (Wall-Adapting Local Eddy-viscosity). O método RFG (Random Flow Generation) foi responsável pela geração das flutuações de velocidade. Os resultados obtidos mostraram-se em boa concordância com os dados DNS (Direct Numerical Simulation) e LES presentes na literatura.

Palavras-chave: Large Eddy Simulations, Geração de condições iniciais turbulentas, Camada limite turbulenta, Modelagem submalha. 



\section{ABSTRACT}

SARTORI, P.. Um código LES de alta ordem para simulação de escoamentos turbulentos com desenvolvimento espacial. 2016. 90 f. Tese (Doutorado em Ciências - Ciências de Computação e Matemática Computacional) - Instituto de Ciências Matemáticas e de Computação (ICMC/USP), São Carlos - SP.

LES methodology is a viable alternative for the numerical solution of practical interest flows due to the computational limitations imposed by the direct resolution of all scales presented in turbulent flow. However, the detailed understanding of the turbulence phenomenon is still a challenging task as a result of its non-linear behavior and high sensitivity to initial and boundary conditions. Thus, the success of LES simulations is associated with the use of an efficient computational code, wherein the subgrid scale modeling accurately represents the flow dynamics, together with the specification of realistic inicial boundary conditions. In this context, this study aims to develop a high-order LES code combined with a method for generating velocity fluctuations to compute turbulent boundary layer flows over a flat plate. The vorticity-velocity formulation was adopted. The numerical scheme is based on the finite difference method in collocated grid, where the derivatives in the streamwise and wall-normal are approximated using high order compact finite difference schemes. We also assume periodicity in spanwise direction therefore it is adopted a spectral method in this direction. The method chosen for the temporal evolution is the $4 t h$ order Runge-Kutta method and the solution of Poisson equation solution is accessed via a multigrid algorithm. For subgrid modelling it is adopted the Wall-Adapting Local Eddy-viscosity (WALE) model. The RFG (Random Flow Generation) method was responsible for the generation of unsteady turbulent velocity signal. The results obtained were in good agreement with DNS (Direct Numerical Simulation) and LES from the literature.

Key-words: Large eddy simulations, Inflow modelling, Turbulent boundary layer, Subgrid-scale modelling. 

Re - número de Reynolds

$U_{\infty}$ - velocidade do escoamento livre

$\delta$ - espessura da camada limite

$\delta^{*}$ - espessura de deslocamento

$\theta$ - espessura de quantidade de movimento

$\tau_{w}$ - tensão de cisalhamento na parede

$C_{f}$ - coeficiente de atrito

$H$ - fator de forma

$x_{2}^{+}$- menor distância adimensional à parede

$u_{\tau}$ - velocidade de cisalhamento

$v$ - viscosidade cinemática

$\kappa$ - constante de von Kárman

$u_{i}$ - componentes do vetor velocidade

$x_{i}$ - componentes do vetor posição

$P$ - pressão

$\rho_{0}$ - densidade

$\Delta-$ tamanho característico do filtro em LES

$\bar{u}_{i}$ - componentes do vetor velocidade filtrada

$\tau_{i j}$ - tensor de Reynolds submalha

$v_{t}-$ viscosidade turbulenta

$\delta_{i j}$ - delta de Kronecker

$\bar{S}_{i j}$ - tensor de deformação filtrado

$\bar{P}_{\text {mod }}$ - pressão modificada

$\bar{f}_{i}$ - termo que inclui $v_{t}$ no espaço de Fourier

$\nabla^{2}$ - operador Laplaciano 
$L$ - comprimento de referência

$U_{\infty}-$ velocidade de referência

$C_{s}$ - constante de Smagorinsky

$|\bar{S}|$ - magnitude do tensor de deformação

$C_{\mathrm{W}}$ - constante do modelo WALE

$\omega_{i}-$ componentes do vetor vorticidade

$\varepsilon_{i j k}$ - tensor permutação

$a_{i}$ - termos não lineares no espaço físico

$k-$ modos de Fourier

$K$ - número total de modos de Fourier

$i$ - unidade imaginária

$\beta_{k}-$ número de onda na direção transversal

$\lambda_{3}$ - comprimento de onda do modo de Fourier fundamental na direção transversal

$\pi$ - número pi

$\bar{\Omega}_{i k}$ - componentes do vetor vorticidade filtrado no espaço de Fourier

$\bar{U}_{i k}$ - componentes do vetor velocidade filtrado no espaço de Fourier

$\bar{A}_{i k}$ - termo nao linear no espaço de Fourier

$\bar{F}_{i k}$ - termo $\bar{f}_{i}$ no espaço de Fourier

st $f$ - fator de stretching

$\operatorname{Re}_{\theta}$ - número de Reynolds baseado na espessura de quantidade de movimento e na velocidade do escoamento livre

$\Delta_{x_{1}}$ - espaçamento entre dois pontos de malha na direção $x_{1}$

$\Delta_{x_{2}}$ - espaçamento entre dois pontos de malha na direção $x_{2}$

$\Delta_{t}$ - passo de tempo 
$1 \quad$ INTRODUÇÃO $\ldots \ldots \ldots \ldots \ldots$

$1.1 \quad$ Estrutura do trabalho $\ldots \ldots \ldots \ldots \ldots$

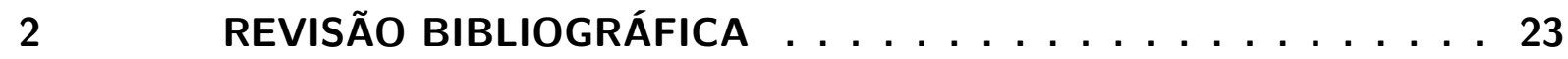

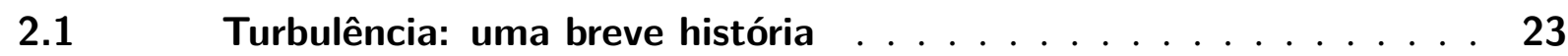

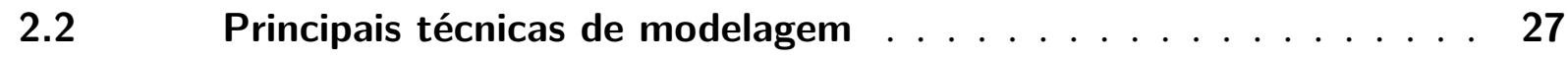

$2.3 \quad$ Geração de condições de entrada turbulentas $\ldots \ldots \ldots . \ldots 28$

$2.4 \quad$ Camada limite laminar e turbulenta . . . . . . . . . . . . . 30

3 FORMULAÇÃO MATEMÁTICA $\ldots \ldots \ldots \ldots \ldots \ldots$

$3.1 \quad$ LES: uma breve introdução $\ldots \ldots \ldots \ldots \ldots \ldots$

$3.2 \quad$ Filtragem das equações $\ldots \ldots \ldots \ldots \ldots \ldots$

$3.3 \quad$ Modelagem submalha $\ldots \ldots \ldots \ldots \ldots$

$3.3 .1 \quad$ Modelo de Smagorinsky _. . . . . . . . . . . . . . . . . 39

3.3 .2 Modelo WALE . . . . . . . . . . . . . . . . . . . . . 40

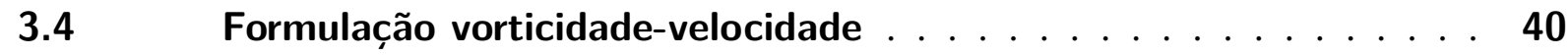

$3.5 \quad$ Condição de entrada turbulenta - método RFG . . . . . . . . . . 41

$3.6 \quad$ Domínio de integração $\ldots \ldots \ldots \ldots \ldots \ldots \ldots$

$3.7 \quad$ Condições de contorno $\ldots \ldots \ldots \ldots \ldots$

4 METODOLOGIA NUMÉRICA . . . . . . . . . . . . . . . 47

$4.1 \quad$ Método espectral $\ldots \ldots \ldots \ldots \ldots \ldots \ldots$

$4.2 \quad$ Decomposição do domínio . . . . . . . . . . . . . . . . . . 49

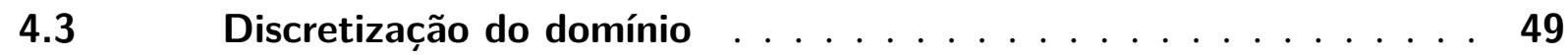

$4.3 .1 \quad$ Derivadas temporais $\ldots \ldots \ldots \ldots$

$4.3 .2 \quad$ Derivadas espaciais . . . . . . . . . . . . . . . . . 50

$4.3 .3 \quad$ Discretização da equação de Poisson . . . . . . . . . . . . 53

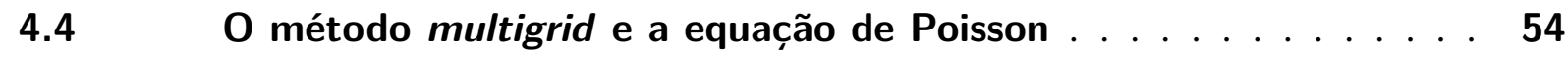

$4.5 \quad$ Relaminarização do escoamento . . . . . . . . . . . . . . 55

$4.6 \quad$ Filtragem espacial . . . . . . . . . . . . . . . . . 55

$4.7 \quad$ Verificação do código $\ldots \ldots \ldots \ldots \ldots \ldots \ldots$

5 CAMADA LIMITE TURBULENTA EM PLACA PLANA . . . . . 59

$5.1 \quad$ Influência da modelagem submalha $\ldots \ldots \ldots \ldots$ 
$5.2 \quad$ Estudo de convergência de malha $\ldots \ldots \ldots \ldots$

$5.2 .1 \quad$ Resolução transversal . . . . . . . . . . . . . . . . . . . . 64

$5.2 .2 \quad$ Resolução longitudinal e normal . . . . . . . . . . . . . . 65

$5.3 \quad$ Influência das condições iniciais $\ldots \ldots \ldots \ldots \ldots$

$5.3 .1 \quad O$ parâmetro $\tau \ldots \ldots \ldots \ldots \ldots \ldots$

$5.3 .2 \quad$ A influência do parâmetro $\tau \ldots \ldots \ldots \ldots$

$5.4 \quad$ Cálculo dos parâmetros integrais da camada limite $\ldots \ldots \ldots 76$

$5.5 \quad$ Visualização das estruturas turbulentas $\ldots \ldots \ldots \ldots \ldots$

$5.6 \quad$ Comentários do capítulo $\ldots \ldots \ldots \ldots \ldots$

$6 \quad$ CONCLUSÕES $\ldots \ldots \ldots \ldots \ldots$

$6.1 \quad$ Trabalhos futuros $\ldots \ldots \ldots \ldots \ldots$. . . . . . . . . 84

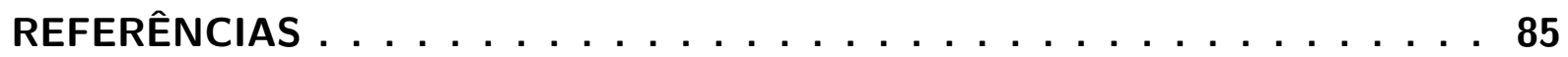


A turbulência é ainda um dos problemas sem solução completa na dinâmica dos fluidos e, certamente, a compreensão detalhada do seu comportamento traria inúmeros benefícios nas mais diversas áreas da ciência.

Uma das características mais importantes da turbulência é a diversidade de escalas, as quais aumentam rapidamente com o número de Reynolds (WILCOX, 1994; SAGAUT, 2006). Como consequência imediata, a resolução numérica de escoamentos de relevância prática definitivamente não é nada simples e impõe um alto custo computacional.

A metodologia LES (Large Eddy Simulation) surgiu como uma alternativa viável para contornar a perda de informações advindas da aplicação da média temporal na abordagem RANS (Reynolds-Averaged Navier-Stokes) e para o custo computacional exorbitante imposto pela resolução de todas as escalas da turbulência em simulações DNS (Direct Numerical Simulation). Como o nome já diz, essa metodologia consiste em resolver diretamente as maiores estruturas turbulentas e modelar as menores. De acordo com Pope (2000), os menores vórtices, que são mais caros de serem simulados, são modelados ao invés de resolvidos, o que então reduz o custo computacional da simulação. O que justifica a ideia por trás dessa metodologia é que as maiores estruturas do movimento contem mais energia e são diretamente afetadas pelas condições de contorno, enquanto que as menores escalas tendem a ser mais homogêneas e isotrópicas, tornando-se mais passíveis de modelagem (WILCOX, 1994; LESIEUR; MÉTAIS, 1996).

Um dos principais obstáculos para o sucesso de simulações LES de escoamentos com altos números de Reynolds está na correta imposição de condições iniciais (KEATING et al. 2004; SAGAUT, 2006). Em situações com desenvolvimento espacial como a camada limite turbulenta sobre placa plana, as condições não homogêneas ao longo da direção principal do escoamento não permitem o uso de condições de periodicidade nessa direção. Ao invés disso, torna-se necessário a geração de um perfil de flutuações turbulentas transiente que represente o campo turbulento na entrada do domínio. Ainda, a alta sensibilidade às condições iniciais torna 
indispensável a especificação detalhada e precisa de flutuações turbulentas que assegurem que todas as propriedades físicas do escoamento sejam bem representadas na entrada.

Segundo Smirnov, Shi e Celik (2001) e Keating et al. (2004), a geração de condições realistas deve satisfazer correlações espaciais e características da turbulência - momentos de primeira e segunda ordem, bem como o espectro de energia e as fases entre os modos das flutuações de velocidade geradas. A maneira mais comum de construir um campo de flutuação dessa forma é baseada em métodos espectrais, onde funções harmônicas são geradas com estatísticas apropriadas e então reunidas em um campo de escoamento randômico.

Baseado no trabalho de Kraichnan (1970), o método RGF proposto por Smirnov, Shi e Celik (2001) pode ser adotado para especificar condições iniciais/entrada para escoamentos turbulentos não homogêneos e anisotrópicos com desenvolvimento espacial. O campo de flutuações é gerado através de superposição de funções harmônicas com fases e amplitudes randômicas.

Nesse sentido, o objetivo dessa pesquisa é desenvolver e validar um código LES combinado com o método RFG (Random Flow Generation) para simulação de escoamentos com desenvolvimento espacial, em particular, escoamentos turbulentos em camada limite sobre placa plana. Desde que modelagem submalha é responsável pela introdução dos efeitos das pequenas escalas na solução filtrada final, torna-se também essencial levar em conta um modelo submalha que forneça um perfil adequado de viscosidade turbulenta próxima a parede. Para tanto adota-se o modelo WALE (Wall-Adapting Local Eddy-viscosity).

Para minimizar as perdas de informação inerentes à discretização numérica, as aproximações espaciais foram realizadas através de diferenças finitas compactas de alta ordem de precisão. Para o avanço temporal adotou-se o método Runge-Kutta clássico de $4^{a}$ ordem de precisão. A paralelização do código é feita por meio da decomposição do domínio na direção principal do escoamento. Ainda, objetivando uma redução do custo computacional e melhor resolução próximo aos contornos rígidos, utilizou-se uma técnica de estiramento de malha (stretching) na direção normal do escoamento. Os testes numéricos realizados para uma faixa de $\operatorname{Re}_{\theta}$ entre 900 até 1300 mostraram boa concordância com dados DNS e LES da literatura.

\subsection{Estrutura do trabalho}

O restante do texto está organizado da seguinte forma:

- O próximo capítulo é dedicado à revisão dos conceitos fundamentais para a solução numérica de escoamentos turbulentos. Nesse sentido, apresentam-se as principais características e avanços históricos relacionados a turbulência em fluidos, bem como as principais metodologias usadas para sua solução numérica desse tipo de problema. Ainda, uma discussão sobre a desafiadora questão relacionada a geração de condições iniciais turbulentas e uma descrição das regiões características de uma camada limite turbulenta são abordados. 
- O Capítulo 3 apresenta a formulação matemática para simulação LES de escoamentos turbulentos, juntamente com a modelagem submalha e a técnica adotada nesse estudo para a especificação de condições iniciais turbulentas. A formulação vorticidade-velocidade das equações governantes LES e as condições de contorno adotadas para os resultados obtidos nesse trabalho também são exibidas.

- Destina-se o Capítulo 4 para a descrição da metodologia computacional, onde são abordadas as discretizações e os métodos numéricos utilizados para a resolução numérica das equações governantes.

- O Capítulo 5 engloba os resultados numéricos e discussões acerca das simulações de escoamentos em camada limite turbulenta em placa plana de forma a validar o código LES desenvolvido nesse trabalho.

- E, finalmente, o Capítulo 6 contém as considerações finais e sugestões para trabalhos futuros. 



\section{REVISÃO BIBLIOGRÁFICA}

Seja por ser característica inerente aos escoamentos reais ou pela importância das aplicações industriais, o estudo da turbulência ainda é um tema atual de pesquisa. Com efeito, em virtude da sua complexidade, ainda não é possível entender detalhadamente seu comportamento e isso tem impulsionado o crescimento de pesquisas voltadas à compreensão e controle de escoamentos turbulentos.

Como o foco dessa pesquisa é a simulação de escoamentos turbulentos em camada limite, essa seção traz uma breve revisão sobre os principais pontos para o estudo numérico da turbulência: história da turbulência, as técnicas de modelagem mais utilizadas, geração de condições de contorno turbulentas e camada limite turbulenta.

\subsection{Turbulência: uma breve história}

A compreensão do comportamento dos movimentos turbulentos é um dos mais intrigantes e desafiadores problemas da mecânica dos fluidos computacional (POPE, 2000). Este tipo de escoamento vem sendo estudado pelos maiores fisicistas e engenheiros dos séculos 19 e 20, mas ainda assim, não é possível entendê-lo por completo e nem predizer o seu comportamento com total certeza, mesmo para casos bem simples. De fato, o alto grau de liberdade combinado com seu comportamento randômico tornam essa tarefa muito difícil.

Embora seja complicado dar uma definição para turbulência que contemple todas as suas características, pode-se dizer que ela é dependente do tempo, tridimensional, rotacional, altamente difusiva e dissipativa, e um fenômeno que ocorre em elevados números de Reynolds (TENNEKES; LUMLEY, 1972; WILCOX, 1994; POPE, 2000). Esse conjunto de características torna a turbulência altamente não linear.

Outra característica marcante é a presença de um amplo espectro de energia - em escoamentos turbulentos existem estruturas com diferentes números de onda, e as interações 
entre essas estruturas com diferentes tamanhos característicos e frequências constituem um mecanismo sofisticado e complexo de transferência de energia. Neste mecanismo, os maiores vórtices retiram energia do escoamento e a transferem, sucessivamente, para outros vórtices de menor escala até que estes sejam destruídos por dissipação viscosa. Esse mecanismo de transferência de energia é conhecido como cascata de energia e foi descrito por (KOLMOGOV, 1941).

A Fig. 1 mostra as três regiões distintas no espectro de energia turbulento. A primeira região é denominada "região de produção", onde encontram-se os maiores vórtices e onde é produzida toda energia cinética turbulenta por cisalhamento. Na "região inercial", a energia cinética turbulenta é conservada: os vórtices não são afetados pela dissipação viscosa e nem pela geração de energia turbulenta. Segundo Kolmogorov, essa região do gráfico de espectro de energia possui inclinação de $-5 / 3$. Por fim, encontra-se a "região de dissipação", onde a energia cinética é convertida em energia interna por meio da dissipação viscosa.

Figura 1 - Espectro de energia cinética em um escoamento turbulento.

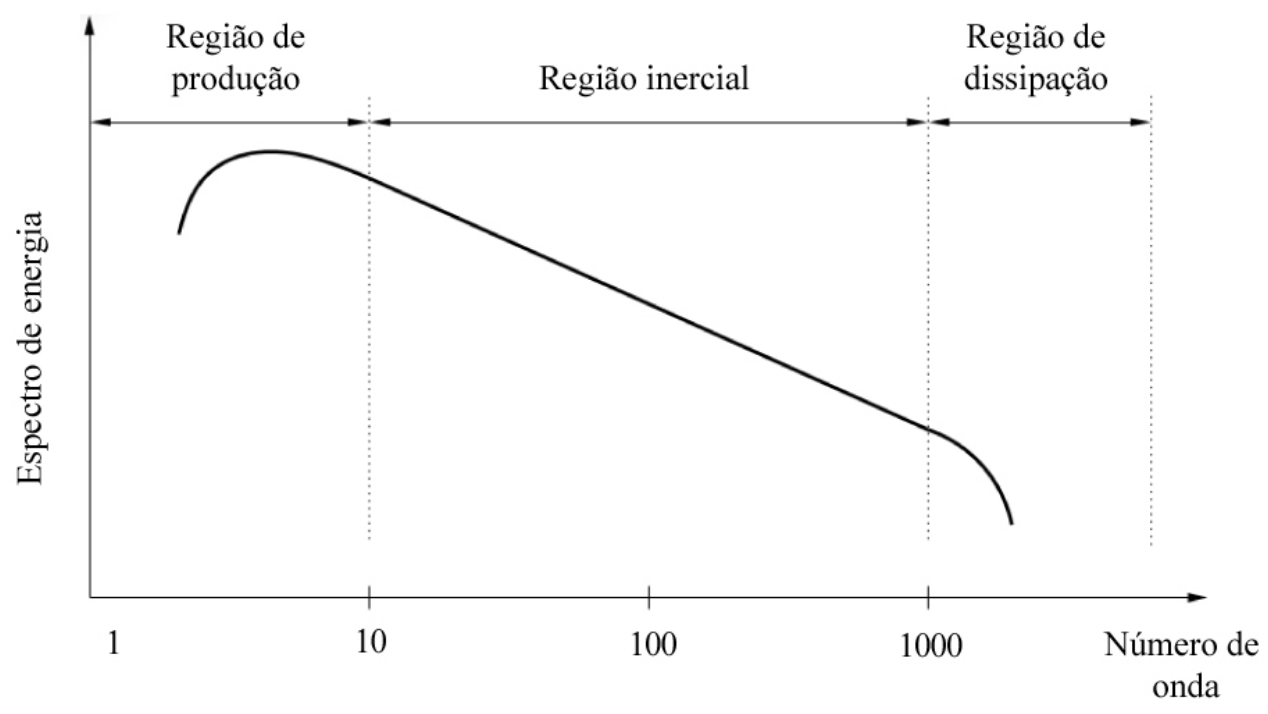

Fonte: Adaptada de Pronk (2012).

Os primeiros relatos sobre o fenômeno da turbulência se devem a Leonardo da Vinci no início do século 16. Constantemente preocupado com problemas clássicos da mecânica, da Vinci dedicou seus últimos anos de vida à mecânica dos fluidos. Deste modo, ao observar um escoamento ao redor de placas, desenhou com bastante fidelidade padrões turbulentos do escoamento (ver Fig. 2). Esse fenômeno foi então chamado por da Vinci de "turbolenza".

Desde então não houve grande progresso nessa área até o começo do século 19, quando as equações que regem o movimento dos fluidos foram introduzidas por Navier e Stokes. Segundo (SCHLICHTING, 1979), foi somente no final desse século que Osborne Reynolds estudou brilhantemente o processo de transição de um escoamento laminar para o regime turbulento através da injeção de um corante em um escoamento num tubo que tinha parede transparente 
Figura 2 - Figura de Leonardo da Vinci retratando a turbulência.

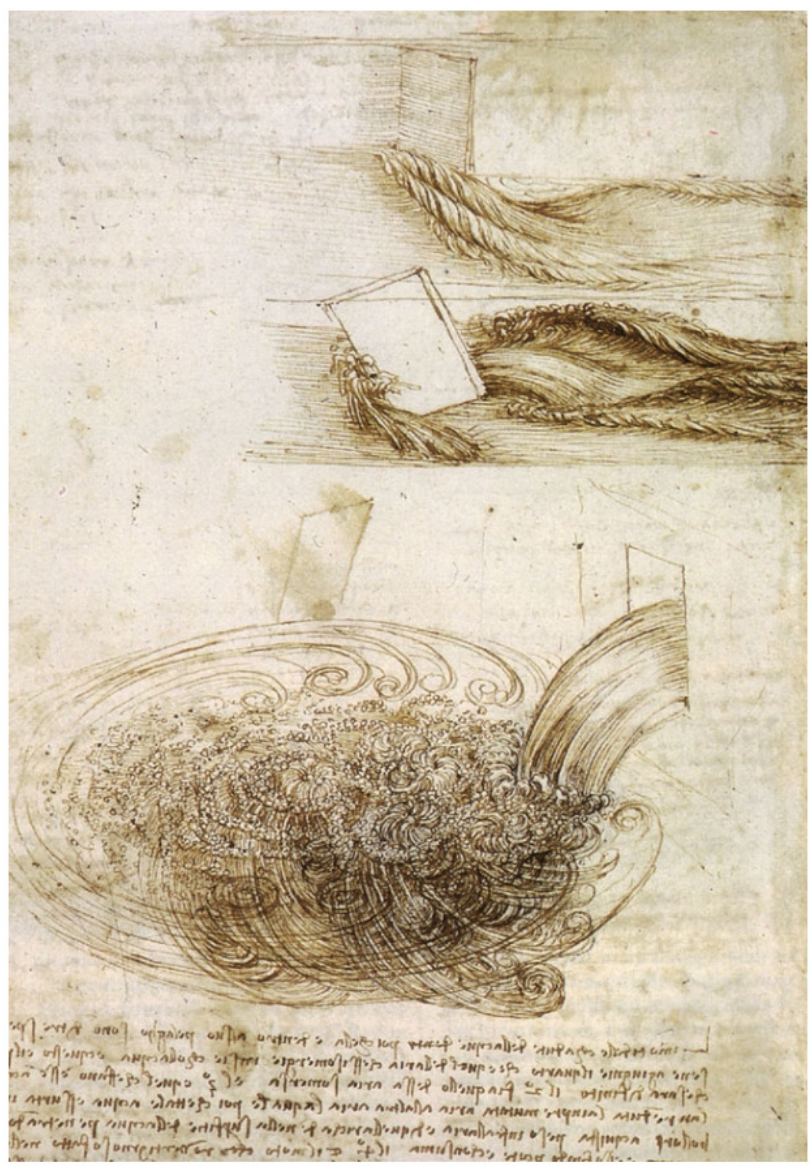

(ver Fig. 3). Tais observações levaram a identificação de um parâmetro adimensional chamado número de Reynolds ( $R e$ ), cujos valores acima de 2300 tornavam tal escoamento turbulento. Outra contribuição importante deixada por Reynolds foi a decomposição das variáveis do escoamento em partes médias e flutuantes através da introdução das tensões de Reynolds, o que deu origem às famosas Equações Médias de Reynolds.

O fechamento das Equações Médias de Reynolds foi proposto por Boussinesq (1877) via conceito de viscosidade turbulenta. Ele propôs que as tensões de Reynolds fossem proporcionais às taxas de deformação, mas com um coeficiente de proporcionalidade chamado viscosidade turbulenta.

Um grande feito que revolucionou e proporcionou a compreensão real do movimentos dos fluidos foi realizado em 1904 por Prandtl (TANI, 1977). Analisando um escoamento sobre um corpo sólido, Prandtl mostrou que o atrito faz com que o fluido, imediatamente adjacente à superfície, torne-se aderido à esta e que o efeito friccional é evidenciado apenas na camada limite - uma região fina e próxima da superfície, onde a viscosidade não poderia ser desprezada (SCHLICHTING, 1979). Fora da camada limite, o escoamento é essencialmente invíscido, na qual as equações de Euler e Bernoulli podem ser aplicadas. Antes da descoberta de Prandtl, os escoamentos eram basicamente potenciais, o que gerava clara contradição com a realidade. 
Figura 3 - Experimento de Osborne Reynolds em 1883.
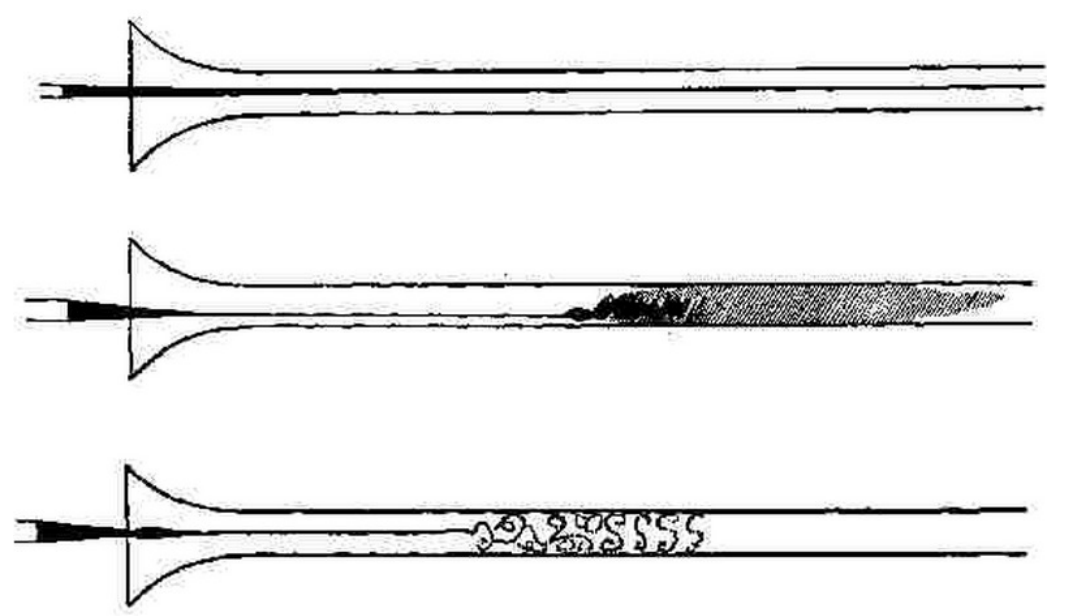

Fonte: Reynolds (1883).

O conceito de camada limite, desenvolvido originalmente para escoamentos laminares ao longo de contornos sólidos, foi posteriormente estendido para o caso turbulento e também para escoamentos com superfícies livres. Juntamente com estes avanços, a estabilidade do escoamento laminar foi estudada como possível causa para a origem da turbulência. De acordo com Schlichting (1979), o fenômeno da transição foi primeiramente estudado por Reynolds no final do século 19. Entretanto, a investigação teórica da transição foi iniciada por Prandtl em 1921, mas o sucesso veio somente em 1929 quando Tollmien calculou teoricamente o número de Reynolds crítico para a transição sobre uma placa plana de incidência zero.

Na década de 1930, a teoria estatística da turbulência foi tratada com maior rigor matemático por Taylor. Em Taylor (1935) foram apresentados métodos estatísticos envolvendo correlações, transformadas de Fourier e espectros para estudar a turbulência.

As décadas de 1950 e 1960 foram marcadas pelos trabalhos e evolução de técnicas experimentais para o estudo da turbulência, o que proporcionou que os modelos turbulentos fossem testados contra grandezas médias, mas também, com momentos de segunda e terceira ordem. Nas décadas seguintes, grandes esforços foram voltados ao desenvolvimento de ferramentas numéricas para a simulação da turbulência. Nesse sentido, houve crescimento pela procura por modelos matemáticos e métodos de simulação dos movimentos turbulentos (DEARDORFF, 1972; ORSZAG; PATTERSON, 1972; LAUNDER; SPALDING, 1974). É importante lembrar que juntamente com os avanços ocorridos no desenvolvimento de metodologias numéricas, o incessante crescimento na capacidade de processamento e armazenamento dos computadores também contribuiu para a compreensão mais detalhada do fenômeno da turbulência e sua melhor aplicação em casos práticos.

De acordo com Silveira Neto (1998), há muitas formas de se modelar e simular o fenômeno da turbulência, que variam desde correlações e diagramas empíricos até as modernas metodologias de simulação numérica. Como esse trabalho tem ênfase numérica, as principais 
metodologias utilizadas atualmente para simular numericamente a turbulência são abordadas na próxima seção.

\subsection{Principais técnicas de modelagem}

As equações de Navier-Stokes são equações diferenciais parciais que descrevem tanto o movimento de fluidos laminares quanto turbulentos. Contudo, mesmo depois de anos de pesquisa a solução dessas equações altamente não lineares ainda é um problema pendente na área de dinâmica dos fluidos, principalmente quando o número de Reynolds é elevado (TENNEKES; LUMLEY, 1972; WILCOX, 1994).

O progresso computacional combinado com o natural interesse da solução numérica dessas equações governantes proporcionou grande avanço no desenvolvimento de modelos matemáticos e ferramentas numéricas nas últimas décadas. Dessa forma, as técnicas de modelagem que mais se destacam na solução de escoamentos de fluidos são: DNS (Direct Numerical Simulation), RANS (Reynolds-Averaged Navier-Stokes) e LES (Large Eddy Simulation).

A metodologia DNS fornece a descrição completa da dinâmica do escoamento através da resolução das equações de Navier-Stokes e da continuidade sem a imposição de nenhum modelo de turbulência. Este fato então exige uma malha e um passo de tempo extremamente refinados, o que faz esta metodologia esbarrar em custos computacionais excessivos até mesmo para os mais poderosos computadores existentes (WILCOX, 1994; LESIEUR; MÉTAIS, 1996). Consequentemente, essa metodologia de simulação é restrita a escoamentos simples, tendo sua aplicação limitada para maioria dos casos de interesse prático, onde o número Reynolds é muito elevado (Silveira Neto, 1998, POPE, 2000; SILVESTRINI, 2000).

Foram restrições como estas que levaram os pesquisadores a direcionarem seus estudos para modelos de turbulência baseados na hipótese de decomposição de escalas (seja através de médias temporais ou de filtragens espaciais). Como visto da seção anterior, Reynolds, no final do século 19, iniciou uma reflexão sobre o assunto e propôs um processo de decomposição das equações governantes de tal forma a analisar a turbulência em termos médios e modelar as flutuações. Mais tarde, esse processo de decomposição deu origem a uma outra metodologia para a turbulência - a chamada LES.

A aplicação da média temporal nas equações de Navier-Stokes e continuidade faz com que as escalas da turbulência sejam representadas pela média temporal e pelas flutuações em torno dessa média (WILCOX, 1994, POPE, 2000). A decomposição de escalas dos termos advectivos leva à criação de um tensor adicional, denominado tensor de Reynolds, que deve ser modelado. A abordagem mais utilizada para o cálculo desse tensor é a hipótese de Boussinesq, que relaciona o tensor das tensões de Reynolds com o tensor da taxa de deformação, através da introdução de uma variável escalar de proporcionalidade - a chamada viscosidade turbulenta (WILCOX, 1994; SILVESTRINI, 2000). Essa metodologia é denominada RANS e sua grande 
vantagem é a utilização de malhas mais grossas que implicam em menor custo computacional. Por outro lado, essa modelagem não captura informações detalhadas do escoamento, uma vez que elas são perdidas pela aplicação da média temporal e modelagem total do espectro de energia.

Uma alternativa para a aplicação da média temporal é a metodologia LES, que emprega um processo de filtragem espacial. Aqui, as escalas da turbulência são separadas em dois grupos: o grupo de grandes escalas (ou escalas resolvidas) e o das pequenas escalas (ou escalas submalha) (WILCOX, 1994; LESIEUR; MÉTAIS, 1996; TENNEKES; LUMLEY, 1972; Silveira Neto, 1998). As grandes escalas são resolvidas diretamente, enquanto que as pequenas escalas são modeladas usando os chamados modelos submalha (SILVESTRINI, 2000). Segundo Lesieur e Métais (1996) e Tennekes e Lumley (1972), geralmente as informações mais relevantes estão contidas nas maiores escalas do escoamento - aquelas que controlam a difusão turbulenta da quantidade de movimento e de calor - o que justifica a ideia por trás dessa metodologia. Devido ao processo de separação das escalas, LES tornou-se uma alternativa com menor esforço computacional do que DNS e, então, pode ser aplicada na resolução de escoamentos com Reynolds mais elevados, justificando a sua popularidade nos últimos anos.

Com respeito às condições de entrada para simulações RANS, somente perfis médios para as velocidades e variáveis turbulentas devem ser impostos, levando à definição direta de condições de entrada. Por outro lado, quando se utiliza as metodologias DNS e LES, as condições de entrada são mais complexas, exigindo o uso de técnicas especiais para impor um perfil de velocidade transiente que represente o campo turbulento na entrada do domínio. Nesse contexto, a próxima seção apresenta uma revisão dos principais métodos para a geração artificial de condições de entrada turbulentas para simulações LES/DNS.

\subsection{Geração de condições de entrada turbulentas}

Um dos maiores desafios da abordagem numérica da turbulência é a prescrição de condições de contorno fisicamente consistentes (LUND; WU; SQUIRES, 1998; KEATING et al. 2004; SAGAUT, 2006). Sendo o escoamento na entrada instável e tridimensional, é necessária a especificação fiel de flutuações turbulentas de velocidade que representem bem o campo de turbulência nesta região. Além disso, a evolução espacial dos escoamentos turbulentos é altamente sensível às condições de entrada, o que reforça que todas as propriedades físicas do escoamento devem ser bem representadas pelas condições iniciais.

Uma dificuldade a mais envolve a resolução numérica de escoamentos em camada limite turbulenta em placa plana. De fato, as condições não homogêneas ao longo da direção longitudinal não permitem a aplicação de condições periódicas na direção principal do escoamento - há a necessidade da geração de um campo turbulento a todo passo de tempo computacional.

A abordagem mais natural para simular a evolução de uma camada limite turbulenta é impor flutuações de velocidade randômicas sobre o escoamento médio e, então, permitir a 
transição natural do escoamento (JARRIN et al., 2006). Entretanto, nenhum tipo de correlação espacial e/ou temporal é apresentada. Além disso, a turbulência gerada não fornece níveis de energia adequados sobre comprimentos de ondas corretos, o que conduz a um rápido amortecimento da turbulência e à volta do escoamento ao estado laminar (KLEIN; SADIKI; JANICKA, 2003; JARRIN et al., 2006; SAGAUT, 2006). Uma opção é inicializar a simulação a partir de um escoamento em repouso ou com uma solução RANS obtida previamente (SMIRNOV; SHI; CELIK, 2001). Infelizmente, um longo tempo de simulação é necessário para que o escoamento se desenvolva espacialmente e temporalmente, o que muitas vezes torna-se inviável.

A fim de evitar tais problemas, vários métodos têm sido desenvolvidos na área de modelagem de condições de entrada turbulentas. De acordo com Keating et al. (2004) e Pamies et al. (2009), os métodos desenvolvidos para este fim podem ser classificados em três categorias: Métodos de reciclagem (Recycling methods), Precursor databases methods e Métodos sintetizadores (Synthetic turbulence methods).

A ideia dos chamados métodos de reciclagem é estimar o perfil de entrada do domínio, baseando-se num plano a jusante do escoamento, o qual é corrigido e introduzido (rescaling) na entrada levando-se em conta leis de similaridade nessa região. As primeiras tentativas de simular uma camada limite em desenvolvimento usando este método foi publicada por Spalart (1988) mas, a ideia de rescaling foi proposta e investigada em placas planas por Lund, Wu e Squires (1998).

A segunda categoria de métodos para geração de condições de entrada turbulentas faz uso de simulações secundárias ou soluções pré-calculadas (precursor calculation) para fornecer informações para a simulação principal. Isto é feito através da simulação prévia de uma camada limite em equilíbrio em que condições de periodicidade podem ser assumidas. Então, uma sequência de planos perpendiculares à direção predominante do escoamento é armazenada para cada passo no tempo. Esses planos são então lidos como condição de entrada para uma nova simulação de um escoamento turbulento mais complexo. Essa metodologia possibilita um controle rigoroso sobre variáveis integrais da camada limite. Entretanto, este processo implica em um custo computacional alto pelo armazenamento de uma grande massa de dados, podendo em alguns casos, dependendo da resolução, inviabilizar o cálculo (KEATING et al., 2004; JARRIN et al., 2006).

Métodos que não usam nenhuma forma de reciclagem ou correção de um plano a jusante do escoamento são os métodos sintetizadores. Estes baseiam-se em procedimentos estocásticos que usam geradores de números randômicos para criar um sinal de velocidade similar àqueles encontrados em escoamentos turbulentos. De acordo com Jarrin et al. (2006), o principal objetivo dos métodos sintetizadores é reduzir a região de transição para que um menor domínio computacional possa ser utilizado.

Umas das vertentes dos métodos sintetizadores é a abordagem espectral, em que utiliza-se uma decomposição do sinal no espaço de Fourier. O princípio é construir flutuações de velocidade 
por meio da superimposição de funções no espaço de Fourier com amplitudes e fases randômicas. Kraichnan (1970) utilizou a decomposição de Fourier para gerar campo de turbulência sintético, isotrópico e homogêneo, para o estudo da difusão de um escalar passivo.

Le, Moin e Kim (1997) realizaram estudos de um escoamento na presença de um degrau com a geração de sinais randômicos e anisotrópicos. Aqui as flutuações resultantes correspondem ao tensor de Reynolds prescrito.

Smirnov, Shi e Celik (2001) introduziram algumas modificações ao método de Le, Moin e Kim (1997) de forma que fossem somente necessárias informações estatísticas para a obtenção de um campo de flutuações turbulento. Este baseia-se na decomposição de Fourier, onde seus coeficientes são calculados por meio de dados espectrais em diferentes regiões do escoamento, em tempos turbulentos locais e escalas de comprimento. O método de Smirnov é chamado de RFG (Random Flow Generation), e difere-se do método de Le, Moin e Kim (1997) por não utilizar transformadas de Fourier, sendo somente baseado em operações de escalonamento e transformação de coordenadas. Esse método foi incorporado com sucesso por Smirnov, Shi e Celik (2001) para apropriada representação das condições iniciais turbulentas na simulação de camada limite e na previsão da esteira de vórtices formada atrás de navios.

Tutar, Celik e Yavuz (2006) adotaram o método RFG em um modelo LES para simulação de um escoamento turbulento sobre um cilindro. Os resultados numéricos mostram que o método RFG melhora a resolução próximo à esteira de vórtices e, portanto, o cálculo dos parâmetros integrais.

Em Vedovoto (2011), três diferentes métodos para a geração artificial de condições de entrada turbulentas foram comparados: imposição de ruído brando sobre um perfil médio; o método de Klein, Sadiki e Janicka (2003), que é fundamentado na filtragem digital de sinais aleatórios; e o método RFG de Smirnov, Shi e Celik (2001). Vale a pena ressaltar que embora os dois últimos métodos citados sejam semelhantes, há duas diferenças cruciais entre eles. $\mathrm{O}$ método de Klein, Sadiki e Janicka (2003) não apresenta correlações temporais, somente são garantidas correlações espaciais. Além disso, este método não gera campos de velocidades não divergentes na entrada do domínio. Por outro lado, o método RFG de Smirnov, Shi e Celik (2001) garante essas três características mencionadas.

Neste sentido, o método RFG proposto por Smirnov, Shi e Celik (2001) foi escolhido para geração de pertubações próximas à entrada para o código LES desenvolvido nesta pesquisa. Maiores detalhes estão descritos na Seção 3.5 .

\subsection{Camada limite laminar e turbulenta}

A real compreensão do movimento de fluidos parietais é explicada pelo conceito de camada limite introduzido por Prandtl em 1904 (TANI, 1977). Observando um fluido escoando 
paralelamente a uma superfície sólida, Prandtl notou que as partículas do fluido que estão na vizinhança imediata de uma superfície sólida estão sujeitas à ação de forças de cisalhamento impostas pela sua desaceleração (condição de não deslizamento). A região em que a camada de fluido teve sua velocidade afetada pela superfície é chamada de camada limite - região fina e próxima da superfície onde a viscosidade não pode ser desprezada. Na região fora desta camada, o efeito da viscosidade é desprezível e o fluido pode ser tratado como não viscoso.

Para melhor visualização, considere a Fig. 4 onde a formação da camada limite sobre uma placa plana é ilustrada. O fluido se aproxima da placa com velocidade uniforme $U_{\infty}$. A velocidade do fluido na superfície é zero. As partículas do fluido que aderem à superfície exercem sobre as demais um efeito de frenagem que diminui, à medida que $x_{2}$ aumenta até atingir a região fora da camada limite, onde a velocidade do escoamento é uniforme.

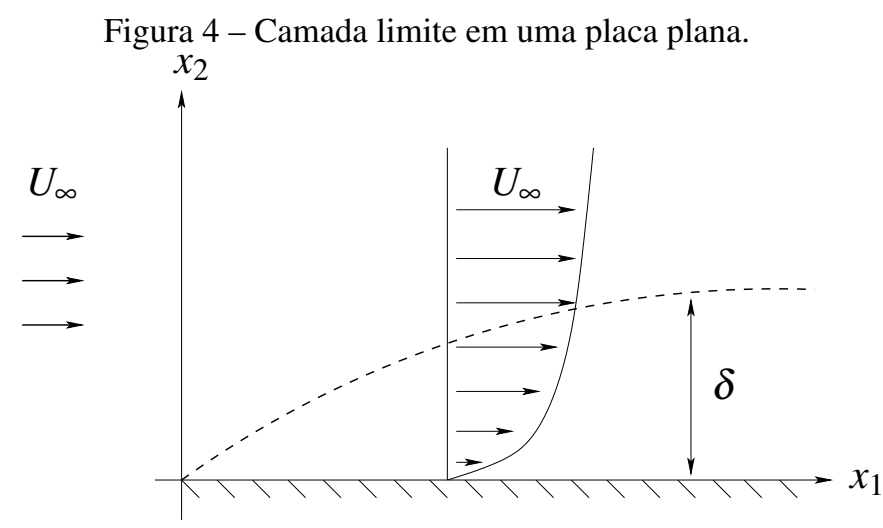

Fonte: Elaborada pelo autor.

De acordo com Schlichting (1979) é possível definir a espessura da camada limite $(\delta)$ como a distância a partir da parede onde a velocidade difere $1 \%$ da velocidade do escoamento livre $\left(U_{\infty}\right)$. Essa espessura cresce ao longo da placa na direção do escoamento e, evidentemente, cresce com o aumento da viscosidade. Outros parâmetros podem ser utilizados para caracterizar a camada limite: a espessura de deslocamento $\left(\delta^{*}\right)$, que indica a distância da parede pela qual as linhas de corrente são deslocadas devido à formação da camada limite:

$$
\delta^{*}=\int_{0}^{\delta}\left(1-\frac{u_{1}}{U_{\infty}}\right) \partial x_{2}
$$

a espessura de quantidade de movimento $(\theta)$, que representa a espessura da perda de quantidade de movimento do escoamento devido ao cisalhamento presente na parede:

$$
\theta=\int_{0}^{\delta} \frac{u_{1}}{U_{\infty}}\left(1-\frac{u_{1}}{U_{\infty}}\right) \partial x_{2}
$$

O coeficiente de atrito é calculado por

$$
C_{f}=\frac{\tau_{w}}{\frac{1}{2} \rho U_{\infty}^{2}}
$$


onde $\tau_{w}=\left.\frac{\partial u_{1}}{\partial x_{2}}\right|_{x_{2}=0}$ é a tensão de cisalhamento na parede. A razão entre a espessura de deslocamento e espessura de quantidade de movimento define o fator de forma (SCHLICHTING, 1979; WHITE, 2002):

$$
H=\frac{\delta^{*}}{\theta} .
$$

Se um valor aproximadamente constante de $H$ é atingido, a camada limite está em um estado de equilíbrio

Pode ser observado na prática que a camada limite pode ser tanto laminar ou como turbulenta. $\mathrm{O}$ escoamento em placa plana tem início com uma camada limite laminar, onde as partículas de fluido se movem de forma ordenada e paralela umas às outras. No entanto, a uma certa distância do bordo de ataque começam a surgir pertubações infinitesimais no escoamento e o processo de transição tem início (ver Fig. 5). Em escoamentos reais, as condições da superfície, pertubações da corrente livre, instabilidades e mudança de curvaturas das paredes são fatores que contribuem para antecipação do processo de transição.

Como pode ser notado na Fig. 5, a turbulência contida após a região de transição da camada limite diminui em direção à parede em tal extensão que começam a predominar os efeitos viscosos. Isto sugere que, mesmo na camada limite turbulenta, se desenvolve uma fina subcamada laminar, onde os efeitos viscosos predominam sobre os efeitos de inércia.

Figura 5 - Transição da camada limite em placa plana.

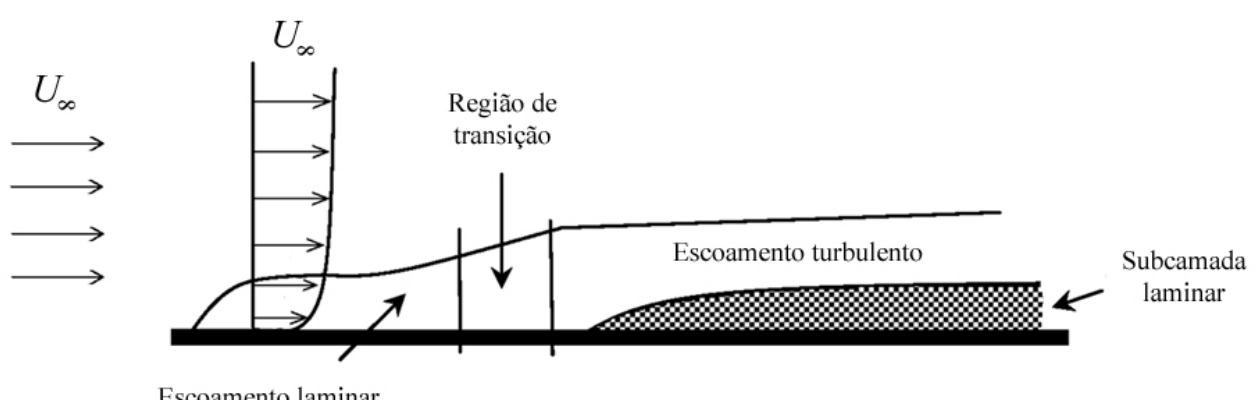

Fonte: Adaptada de Souza et al. (2011).

A Fig. 6 mostra o perfil de velocidade típico de uma camada limite turbulenta. De acordo com Tennekes e Lumley (1972), Schlichting (1979), Wilcox (1994), os escoamentos turbulentos podem ser divididos em duas regiões: a camada externa que é caracterizada pela ausência da turbulência, e a camada interna, onde o movimento aleatório se faz presente na camada limite turbulenta. Além disso, a camada interna é subdivida em três regiões:

- Subcamada laminar ou viscosa $\left(0<x_{2}^{+}<5\right)$ : os efeitos viscosos predominam sobre os efeitos inerciais, fazendo que haja a formação de fina camada de escoamento laminar. Nessa subcamada, o perfil de velocidade é linear e dado por:

$$
u_{1}^{+}=x_{2}^{+},
$$


Figura 6 - Estrutura camada limite turbulenta junto a uma parede sólida.

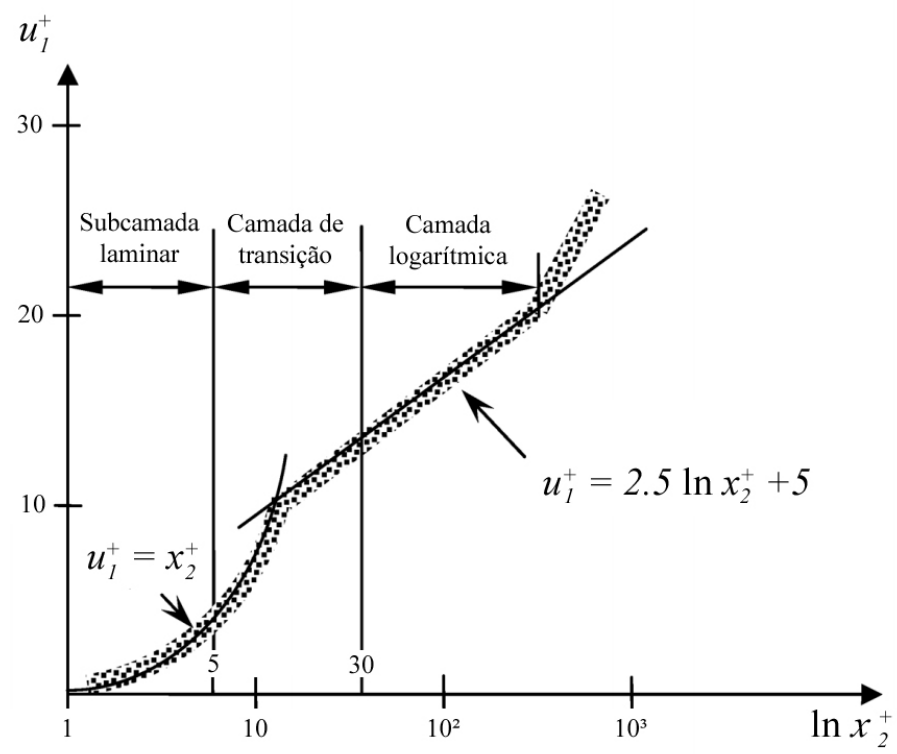

Fonte: Adaptada de Souza et al. (2011).

onde $x_{2}^{+}=\frac{x_{2} u_{\tau}}{v}$ é a menor distância adimensional à parede e $u_{1}^{+}=\frac{u_{1}}{u_{\tau}}$, onde $u_{\tau}=\sqrt{\frac{\tau_{w}}{\rho}}$ é a velocidade de cisalhamento. $v$ é a viscosidade cinemática.

- Camada de transição $\left(5<x_{2}^{+}<30\right)$ : os efeitos viscosos e inerciais são de igual importância.

- Camada logarítmica $\left(x_{2}^{+}>30\right)$ : essa região tem a predominância dos efeitos de inércia e então o escoamento é turbulento. Nessa região, a camada limite é descrita pela lei logarítmica:

$$
u_{1}^{+}=\frac{1}{\kappa} \ln x_{2}^{+}+B,
$$

onde $\kappa=0.41$ é a constante de von Kárman e $B=5-5.5$.

Detalhes extras sobre a derivação da lei logarítmica podem ser consultados em Pope (2000).

As expressões empíricas acima são conhecidas como "Leis de parede" e têm sido validadas pela comunidade científica ao longo dos anos. Elas também podem ser utilizadas como condição de contorno para modelar a dinâmica do movimento próximo à parede onde uma malha extremamente refinada é exigida para que uma predição confiável do problema seja possível.

$\mathrm{Na}$ literatura, existe uma variedade de trabalhos envolvendo camada limite turbulenta. Apesar de Spalart (1988) ser um dos artigos pioneiros em simulações DNS de camada limite em placa plana, onde alcançou-se $R e_{\theta}=300,670$ e 1400, ele ainda permanece muito utilizado para validação de códigos numéricos. Como trabalhos mais recentes bastante usados para validação, pode-se citar o estudo para camada limite em transição de Wu e Moin (2009) $\left(\operatorname{Re}_{\theta}=800\right.$ e 900) 
e os casos de turbulência totalmente desenvolvida de Simens et al. (2009) $\left(R e_{\theta}=1000,1550 \mathrm{e}\right.$ 1968) e Schlatter e Orlu (2010) $\left(R e_{\theta}=\right.$ entre 500 e 4300).

O próximo capítulo engloba as equações governantes LES na formulação vorticidadevelocidade que são utilizadas nesse trabalho. 


\section{3}

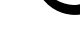

\section{FORMULAÇÃO MATEMÁTICA}

O modelo matemático que rege o estudo do movimento dos fluidos é composto pelas equações de Navier-Stokes e continuidade. Embora a metodologia RANS seja amplamente utilizada para o estudo de escoamentos a altos números de Reynolds, esta abordagem fornece apenas valores médios do escoamento. Por outro lado, a simulação DNS resolve todas as escalas do movimento, o que eleva exorbitantemente os custos da simulação. Uma abordagem intermediária às duas anteriores é a chamada LES, que através do processo de separação de escalas apresenta maior confiabilidade do que RANS e menor esforço computacional do que DNS.

Em vista disto, este capítulo concentra-se na fundamentação teórica e nas equações governantes para a simulação LES de escoamentos incompressíveis turbulentos. Ressalta-se que a formulação vorticidade-velocidade é utilizada neste trabalho como alternativa à formulação de variáveis primitivas. Ainda, a Seção 3.5 apresenta o método RFG (SMIRNOV; SHI; CELIK. 2001) que foi adotado no presente trabalho para modelar as pertubações turbulentas na simulação de escoamentos em camada limite.

\subsection{LES: uma breve introdução}

LES é uma metodologia de simulação que tem como princípio básico a separação das grandes e pequenas escalas da turbulência através de um processo de filtragem espacial (WILCOX, 1994; LESIEUR; MÉTAIS, 1996; SAGAUT, 2006). O processo de filtragem é aplicado às equações governantes primitivas, em que o comprimento característico do filtro, baseado na malha de discretização, é o que determina a frequência de corte (LESIEUR; MÉTAIS, 1996; PIOMELLI, 1999; MENEVEAU; KATZ, 2000; SAGAUT, 2006). As escalas que são de tamanho característico maior do que a frequência de corte, são chamadas de grandes escalas (resolvidas ou filtradas), enquanto as outras, são chamadas de pequenas escalas (submalha). 
Desta forma, as grandes escalas turbulentas são resolvidas diretamente das equações filtradas, enquanto que as menores estruturas, que são mais homogêneas e isotrópicas, são avaliadas através de um modelo apropriado (WILCOX, 1994; Silveira Neto, 1998; POPE, 2000).

Vale ressaltar que após o processo de separação de escalas e filtragem das equações há a introdução de um tensor adicional que conduz ao não fechamento das equações governantes filtradas. É aí que entra em jogo a chamada modelagem submalha. Deste modo, o tensor adicional é substituído por um modelo submalha, que exerce o papel de introduzir a influência das pequenas escalas sobre os campos filtrados (GERMANO et al., 1991; POPE, 2000).

Os primeiros trabalhos realizados envolvendo LES foram motivados por aplicações meteorológicas. Em 1963, utilizando as ideias da decomposição de Reynolds, Smagorinsky (1963) propôs essa nova metodologia de simulação e realizou as primeiras tentativas tridimensionais para simular o clima. Outros trabalhos como o de Lilly (1967) e Deardorff (1974) também seguem a mesma linha e tiveram grande importância para a divulgação dessa nova técnica de simulação. Nos últimos anos, juntamente com o aperfeiçoamento dos computadores e das técnicas de simulação, LES tornou-se umas das mais usadas e promissoras metodologias de simulação para a solução de escoamentos turbulentos.

\subsection{Filtragem das equações}

Considerando escoamentos de fluidos incompressíveis e newtonianos, as equações governantes de Navier-Stokes e continuidade, escritas na forma dimensional, são dadas da seguinte forma:

$$
\begin{aligned}
\frac{\partial u_{i}}{\partial t}+\frac{\partial\left(u_{i} u_{j}\right)}{\partial x_{j}} & =-\frac{1}{\rho_{0}} \frac{\partial P}{\partial x_{i}}+\frac{\partial}{\partial x_{j}}\left[v\left(\frac{\partial u_{i}}{\partial x_{j}}+\frac{\partial u_{j}}{\partial x_{i}}\right)\right], \quad i=1,2,3 \\
\frac{\partial u_{i}}{\partial x_{i}} & =0
\end{aligned}
$$

onde o campo de velocidade $\mathbf{u}=\left(u_{1}, u_{2}, u_{3}\right)$, expresso em coordenadas cartesianas $\mathbf{x}=\left(x_{1}, x_{2}, x_{3}\right)$, é a solução do sistema. $P$ é a pressão estática, $\rho_{0}$ é a densidade e $v$ é viscosidade cinemática (constante).

A fim de separar o cálculo das escalas filtradas (resolvidas) das escalas que serão modeladas, um processo de filtragem é aplicado às equações que governam o movimento (Eqs. (3.1) e (3.2)). Para isso, as variáveis instantâneas (escalar ou vetorial) presentes nessas equações são separadas em duas partes:

$$
f(\mathbf{x}, t)=\bar{f}(\mathbf{x}, t)+f^{\prime}(\mathbf{x}, t)
$$

em que $\bar{f}(\mathbf{x}, t)$ representa as componentes de grandes escalas (ou filtradas) e $f^{\prime}(\mathbf{x}, t)$ corresponde as componentes de pequenas escalas (ou submalha). 
A parte filtrada é definida como

$$
\bar{f}(\mathbf{x}, t)=\int_{D} f\left(\mathbf{x}^{\prime}, t\right) G\left(\mathbf{x}-\mathbf{x}^{\prime}\right) d \mathbf{x}^{\prime},
$$

onde $G$ é a função filtro determinada da forma:

$$
G(\mathbf{x}, t)=\left\{\begin{array}{lll}
\frac{1}{\Delta^{3}}, & \text { se } & |\mathbf{x}| \leq \Delta \\
0, & \text { se } & |\mathbf{x}|>\Delta
\end{array}\right.
$$

onde $\Delta=\sqrt[3]{V}$ é o tamanho característico do filtro, sendo o volume do elemento de malha dado por $V$. Outros filtros também podem ser usados, como indicado por (LESIEUR; MÉTAIS, 1996), (POPE, 2000) e (SAGAUT, 2006).

É importante ressaltar que nesta pesquisa a filtragem é implícita, ou seja, o processo de filtragem é implicitamente realizado baseado no fato de que o atual processo de discretização das equações de transporte é, intrinsecamente, um processo de filtragem no espaço e no tempo.

Aplicando-se o operador filtro nas equações (3.1) e (3.2), obtém-se as expressões:

$$
\begin{aligned}
\frac{\partial \bar{u}_{i}}{\partial t}+\frac{\partial\left(\overline{u_{i} u_{j}}\right)}{\partial x_{j}} & =-\frac{1}{\rho_{0}} \frac{\partial \bar{P}}{\partial x_{i}}+\frac{\partial}{\partial x_{j}}\left[v\left(\frac{\partial \bar{u}_{i}}{\partial x_{j}}+\frac{\partial \bar{u}_{j}}{\partial x_{i}}\right)\right], \\
\frac{\partial \bar{u}_{i}}{\partial x_{i}} & =0 .
\end{aligned}
$$

Observa-se que (3.6) é uma equação de transporte para $\bar{u}_{i}$. No entanto, há o aparecimento de um produto filtrado de variáveis desconhecidas no termo não linear das equações, o que impede a resolução direta do sistema formado por (3.6) e 3.7).

Para resolver esse problema, define-se o tensor de Reynolds submalha da forma

$$
\tau_{i j}=\bar{u}_{i} \bar{u}_{j}-\overline{u_{i} u_{j}}
$$

e, substituindo-o em (3.6), a equação de Navier-Stokes após o processo de filtragem torna-se

$$
\frac{\partial \bar{u}_{i}}{\partial t}+\frac{\partial\left(\bar{u}_{i} \bar{u}_{j}\right)}{\partial x_{j}}=-\frac{1}{\rho_{0}} \frac{\partial \bar{P}}{\partial x_{i}}+\frac{\partial}{\partial x_{j}}\left[v\left(\frac{\partial \bar{u}_{i}}{\partial x_{j}}+\frac{\partial \bar{u}_{j}}{\partial x_{i}}\right)+\tau_{i j}\right] \text {. }
$$

Nota-se que após o processo de filtragem surge um novo termo $\left(\tau_{i j}\right)$ nas equações governantes filtradas, resultando em um sistema com mais incógnitas do que equações. Isso conduz ao conhecido problema do fechamento da turbulência. Em vista disso, Boussinesq, em 1877, introduziu o conceito de viscosidade turbulenta, assumindo modelar o tensor de Reynolds submalha $\tau_{i j}$ como

$$
\tau_{i j}=+2 v_{t} \bar{S}_{i j}+\frac{1}{3} \tau_{k k} \delta_{i j}
$$

em que $v_{t}$ é viscosidade turbulenta que pode ser calculada via diferentes modelos e $\delta_{i j}$ é o delta de Kronecker $\left(\delta_{i j}=1\right.$, se $i=j ; \delta_{i j}=0$, se $\left.i \neq j\right)$. $\bar{S}_{i j}$ é o tensor de deformação filtrado, dado da forma

$$
\bar{S}_{i j}=\frac{1}{2}\left(\frac{\partial \bar{u}_{i}}{\partial x_{j}}+\frac{\partial \bar{u}_{j}}{\partial x_{i}}\right) .
$$


Ressalta-se que enquanto a viscosidade cinemática $v$ é uma propriedade do fluido, a viscosidade turbulenta $v_{t}$ é uma propriedade do escoamento e depende do tempo e do espaço.

Agora, substituindo 3.10 em 3.9) e depois de alguma álgebra, chega-se em:

$$
\frac{\partial \bar{u}_{i}}{\partial t}+\frac{\partial\left(\bar{u}_{j} \bar{u}_{i}\right)}{\partial x_{j}}=-\frac{1}{\rho_{0}} \frac{\partial \bar{P}_{m o d}}{\partial x_{i}}+2 \frac{\partial}{\partial x_{j}}\left[\left(v+v_{t}\right) \bar{S}_{i j}\right],
$$

onde é introduzida a pressão modificada $\bar{P}_{\text {mod }}=\bar{P}-\frac{1}{3} \rho_{0} \tau_{k k}$.

Adimensionalizando as equações (3.12) e (3.7), as equações filtradas de Navier-Stokes e continuidade são reescritas na forma final por:

$$
\begin{aligned}
\frac{\partial \bar{u}_{i}^{*}}{\partial t^{*}}+\frac{\partial\left(\bar{u}_{j}^{*} \bar{u}_{i}^{*}\right)}{\partial x_{j}^{*}} & =-\frac{\partial \bar{P}_{m o d}^{*}}{\partial x_{i}^{*}}+\frac{1}{R e} \nabla^{2} \bar{u}_{i}^{*}+\bar{f}_{i}^{*}, \\
\frac{\partial \bar{u}_{i}^{*}}{\partial x_{i}^{*}} & =0
\end{aligned}
$$

com

$$
\bar{f}_{i}^{*}=v_{t}^{*} \nabla^{2} \bar{u}_{i}^{*}
$$

O operador Laplaciano é definido por

$$
\nabla^{2}=\frac{\partial}{\partial x_{j}}\left(\frac{\partial}{\partial x_{j}}\right)
$$

Tomando as variáveis adimensionais representadas pelo sobrescrito $(*)$, as adimensionalizações adotadas são:

$$
\begin{gathered}
t=\frac{t^{*} L}{U_{\infty}} ; \quad x_{j}=x_{j}^{*} L ; \quad u_{j}=u_{j}^{*} U_{\infty} ; \quad P=\rho_{0} U_{\infty}^{2} P_{m o d}^{*} ; \quad v_{t}=L U_{\infty} v_{t}^{*} \\
\tau_{k k}=\frac{v U_{\infty}}{L} \tau_{k k}^{*} ; \quad P_{\text {mod }}^{*}=P^{*}-\frac{1}{3 R e} \tau_{k k}^{*} .
\end{gathered}
$$

O número de Reynolds é definido como $R e=\frac{U_{\infty} L}{v}$, onde $L$ é o comprimento característico e $U_{\infty}$ a velocidade de referência.

A questão que surge agora é como deve ser modelada $v_{t}$ de forma a estimar melhor os efeitos das pequenas escalas na solução filtrada final. O procedimento para calcular essa variável denomina-se modelagem submalha e é abordado a seguir.

Salienta-se que a partir desse ponto do texto, os símbolos $(*)$ das equações filtradas adimensionais (3.13) e (3.14) são omitidos para simplificar a notação.

\subsection{Modelagem submalha}

A modelagem submalha consiste em modelos matemáticos usados para descrever $v_{t}$. Tais modelos introduzem nas equações filtradas o efeito das pequenas escalas turbulentas, as quais são retidas pelo processo de filtragem (LESIEUR; MÉTAIS, 1996; SAGAUT, 2006). 
Como é bem conhecido em mecânica dos fluidos, é de crucial importância descrever o comportamento das pequenas escalas próximas as superfícies rígidas. Isso implica que os modelos submalha além de modelar adequadamente o processo de transferência de energia devem, também, fornecer a distribuição correta da viscosidade turbulenta na direção normal a parede.

\subsubsection{Modelo de Smagorinsky}

Este modelo submalha foi proposto pelo meteorologista Smagorinsky, em 1963, para simulação das grandes escalas de escoamentos atmosféricos. Smagorinsky (1963) assumiu como princípio básico a hipótese de equilíbrio local para as pequenas escalas, ou seja, que a produção e a dissipação de tensões turbulentas são equivalentes nas escalas submalha (LESIEUR; MÉTAIS, 1996; PIOMELLI, 1999; SAGAUT, 2006). A viscosidade turbulenta é então calculada da forma

$$
v_{t}=\left(C_{s} \Delta\right)^{2}|\bar{S}|
$$

onde $C_{s}$ é a constante de Smagorinsky e a magnitude do tensor de deformação é dada como

$$
|\bar{S}|=\sqrt{2 \bar{S}_{i j} \bar{S}_{i j}}
$$

Apesar da crescente busca por modelos de turbulência mais sofisticados, o modelo de Smagorinsky vem sendo aplicado nas mais diversas situações (LESIEUR; MÉTAIS, 1996; RODI et al., 1997). No entanto, a constante $C_{s}$ pode e deve ser ajustada de escoamento para escoamento (GERMANO et al., 1991; LILLY, 1992; WILCOX, 1994; LESIEUR; MÉTAIS, 1996: SILVESTRINI, 2000). Lilly (1967) determinou analiticamente $C_{s}=0.18$ para turbulência homogênea e isotrópica, entretanto, um valor adequado para situações particulares é difícil de ser encontrado.

Outra deficiência diz respeito ao valor $v_{t}$ na parede, que deve ser nulo, o que não acontece nesse modelo. Assim sendo, $v_{t}$ é comumente multiplicada por uma função de amortecimento de forma a diminuir seu valor à medida que se aproxima da parede. Apesar disso, os altos gradientes de velocidade ainda levam à produção excessiva de viscosidade turbulenta nas fronteiras sólidas desde que este modelo depende do tensor deformação (LESIEUR; MÉTAIS, 1996; RODI et al., 1997). Segundo Germano et al. (1991) e Lesieur e Métais (1996), o modelo submalha de Smagorinsky não permite simular a transição de uma camada limite sobre uma placa plana onde, em um escoamento inicialmente laminar, uma perturbação é introduzida: o escoamento permanece laminar, devido à geração de viscosidade excessiva pelo modelo.

Outra possibilidade para modelagem submalha é o conhecido modelo dinâmico desenvolvido por Germano et al. (1991) e Lilly (1992), onde o parâmetro $C_{s}$ torna-se variável no espaço e no tempo, ajustando-se dinamicamente ao escoamento e à geometria. Uma das grandes vantagens desse modelo é na modelagem de escoamentos parietais onde a viscosidade turbulenta 
tende automaticamente a zero nas paredes, o que torna o uso de funções de amortecimento não mais necessário.

Mais recentemente, o modelo WALE proposto por Nicoud e Ducros (1999), além de respeitar o correto comportamento da viscosidade próximo às paredes e não exigir o uso de funções de amortecimento, também não faz uso de nenhum procedimento dinâmico. Por esse motivo, esse modelo submalha foi adotado nessa pesquisa. Mais detalhes são dados a seguir.

\subsubsection{Modelo WALE}

O modelo submalha WALE (Wall-Adapting Local Eddy-viscosity) de Nicoud e Ducros (1999) foi desenvolvido para fornecer o correto perfil de viscosidade turbulenta $\left(v_{t}=O\left(x_{2}^{3}\right)\right)$ próximo as fronteiras sólidas. Isto é possível devido à definição de viscosidade turbulenta que é baseada não apenas no tensor deformação, mas também no tensor gradiente de velocidade filtrado.

Neste modelo, a viscosidade turbulenta $v_{t}$ é calculada por

$$
v_{t}=\left(C_{\mathrm{W}} \Delta_{c}\right)^{2} \frac{\left(S_{i j}^{d} S_{i j}^{d}\right)^{3 / 2}}{\left(\bar{S}_{i j} \bar{S}_{i j}\right)^{5 / 2}+\left(S_{i j}^{d} S_{i j}^{d}\right)^{5 / 4}},
$$

em que $C_{\mathrm{W}}$ é a constante do modelo WALE e

$$
\begin{gathered}
S_{i j}^{d}=\frac{1}{2}\left(\bar{g}_{i j}^{2}+\bar{g}_{j i}^{2}\right)-\frac{1}{3} \delta_{i j} \bar{g}_{k k}^{2}, \\
\bar{g}_{i j}=\frac{\partial \bar{u}_{i}}{\partial x_{j}} .
\end{gathered}
$$

Apesar de fazer uso de uma constante, este modelo retorna valor zero de viscosidade turbulenta em escoamentos cisalhantes e pode ser usado corretamente para simulações em que regiões de relaminarização ou transição estão presentes.

\subsection{Formulação vorticidade-velocidade}

Neste trabalho, a formulação vorticidade-velocidade é usada como alternativa à formulação de variáveis primitivas para que o termo da pressão seja eliminado das equações governantes. Assumindo a vorticidade do escoamento como

$$
\bar{\omega}=-\nabla \times \overline{\mathbf{u}},
$$

os componentes do vetor vorticidade tornam-se

$$
\bar{\omega}_{i}=-\varepsilon_{i j k} \frac{\partial \bar{u}_{k}}{\partial x_{j}}, \quad i, j, k=1,2,3
$$


onde $\varepsilon_{i j k}$ é o tensor permutação $\left(\varepsilon_{i j k}=1\right.$, se $(i, j, k)$ são diferentes e constituem uma permutação par de $(1,2,3) ; \varepsilon_{i j k}=-1$, se $(i, j, k)$ são diferentes e constituem uma permutação ímpar de $(1,2,3) ; \varepsilon_{i j k}=0$, se dois ou mais índices são iguais).

Assim, as equações de Navier-Stokes dadas em (3.13) podem ser reescritas na formulação vorticidade-velocidade como

$$
\frac{\partial \bar{\omega}_{i}}{\partial t}+\varepsilon_{i j k} \frac{\partial \bar{a}_{k}}{\partial x_{j}}=\frac{1}{R e} \nabla^{2} \bar{\omega}_{i}+\varepsilon_{i j k} \frac{\partial \bar{f}_{i}}{\partial x_{j}}, \quad i, j, k=1,2,3
$$

onde $\bar{a}_{i}=-\varepsilon_{i j k} \bar{u}_{j} \bar{\omega}_{k}$ são os termos não lineares e $\bar{f}_{i}$ é dada pela expressão 3.15. Os termos $\bar{f}_{i}$ incluem os efeitos da modelagem submalha. Destaca-se aqui que os termos não lineares são escritos na forma dada acima para reduzir o custo computacional associado às transformadas de Fourier utilizadas no método numérico espectral adotado na direção $x_{3}$. Mais detalhes são discutidos no próximo capítulo.

Considerando a equação de continuidade filtrada (Eq. (3.14)) e a definição de vorticidade (Eq. (3.24)), as equações de Poisson para as velocidades nas direções 1, 2 e 3 são como segue:

$$
\begin{gathered}
\frac{\partial^{2} \bar{u}_{1}}{\partial x_{1}^{2}}+\frac{\partial^{2} \bar{u}_{1}}{\partial x_{3}^{2}}=-\frac{\partial \bar{\omega}_{2}}{\partial x_{3}}-\frac{\partial^{2} \bar{u}_{2}}{\partial x_{1} \partial x_{2}}, \\
\frac{\partial^{2} \bar{u}_{2}}{\partial x_{1}^{2}}+\frac{\partial^{2} \bar{u}_{2}}{\partial x_{2}^{2}}+\frac{\partial^{2} \bar{u}_{2}}{\partial x_{3}^{2}}=-\frac{\partial \bar{\omega}_{3}}{\partial x_{1}}+\frac{\partial \bar{\omega}_{1}}{\partial x_{3}}, \\
\frac{\partial^{2} \bar{u}_{3}}{\partial x_{1}^{2}}+\frac{\partial^{2} \bar{u}_{3}}{\partial x_{3}^{2}}=\frac{\partial \bar{\omega}_{2}}{\partial x_{1}}-\frac{\partial^{2} \bar{u}_{2}}{\partial x_{2} \partial x_{3}} .
\end{gathered}
$$

Em suma, a formulação vorticidade-velocidade baseia-se na solução numérica da equação de transporte da vorticidade dada por (3.26), juntamente com as equações de Poisson (3.27), (3.28) e 3.29). Além disso, nesse trabalho, assume-se periodicidade do escoamento na direção $x_{3}$ e, então, um método pseudo-espectral foi adotado nesta direção para a solução numérica. Mais detalhes desta metodologia estão descritos no próximo capítulo.

\subsection{Condição de entrada turbulenta - método RFG}

A simulação de escoamentos turbulentos é fortemente influenciada pelas condições de entrada. Como visto na Seção 2.3, uma breve revisão sobre modelagem de condições de entrada turbulentas foi apresentada. Entretanto, devido às características e os bons resultados apontados na literatura (SMIRNOV; SHI; CELIK, 2001; TUTAR; CELIK; YAVUZ, 2006; VEDOVOTO, 2011), o método RFG foi escolhido nesse estudo para a prescrição de perturbações turbulentas. 
O método RFG de Smirnov, Shi e Celik (2001), foi desenvolvido baseado no trabalho de Kraichnan (1970), podendo ser usado para prescrever condições iniciais/entrada para escoamentos turbulentos não homogêneos e anisotrópicos.

Em suma, esse método tem por ideia básica uma geração randômica de escoamento que envolve operações de transformação ortogonais e de escalonamento aplicadas ao campo de escoamento contínuo por meio de superposição de funções harmônicas. O procedimento consiste dos seguintes passos:

Passo 1: Dado um tensor anisotrópico de correlação de velocidades

$$
r_{i j} \equiv \overline{\tilde{u}_{i} \tilde{u}_{j}}
$$

encontrar um tensor de transformação $a_{i j}$ que diagonalize $\left.r_{i j}\right]^{1}$.

$$
\begin{gathered}
a_{m i} a_{n j} r_{i j}=\delta_{m n} c_{(n)}^{2}, \\
a_{i k} a_{k j}=\delta_{i j} .
\end{gathered}
$$

Os coeficientes $c_{i}$ fazem o papel das flutuações de velocidades $u_{i}^{\prime}$ no novo sistema de coordenadas produzido pela transformação do tensor $a_{i j}$.

Passo 2: Gerar um campo de escoamento transiente tridimensional $\left\{v_{i}\left(x_{j}, t\right)\right\}_{i, j=1, \ldots 3}$ usando o método de (KRAICHNAN, 1970) modificado:

$$
\begin{gathered}
v_{i}\left(x_{j}, t\right)=\sqrt{\frac{2}{N}} \sum_{n=1}^{N}\left[p_{i}^{n} \cos \left(\tilde{k}_{j}^{n} \tilde{x}_{j}+\omega_{n} \tilde{t}\right)+q_{i}^{n} \sin \left(\tilde{k}_{j}^{n} \tilde{x}_{j}+\omega_{n} \tilde{t}\right)\right], \\
\tilde{x}_{j}=\frac{x_{j}}{l}, \quad \tilde{t}=\frac{t}{\tau}, \quad c=\frac{l}{\tau}, \quad \tilde{k}_{j}^{n}=k_{j}^{n} \frac{c}{c_{(j)}}, \\
p_{i}^{n}=\varepsilon_{i, j, m} \zeta_{j}^{n} k_{m}^{n} \quad q_{i}^{n}=\varepsilon_{i, j, m} \xi_{j}^{n} k_{m}^{n}, \\
\zeta_{i}^{n}, \xi_{i}^{n}, \omega_{n} \in N(0,1), \quad k_{i}^{n} \in N(0,1 / 2),
\end{gathered}
$$

onde $L, \tau$ são as escalas de comprimento e tempo da turbulência. $\varepsilon_{i, j, k}$ é o tensor permutação usado nas operações de produto vetorial e $N(M, \sigma)$ é a distribuição normal com média $M$ e desvio padrão $\sigma . k_{j}^{n}$ e $\omega_{n}$ representam uma amostragem de $n$ vetores números de onda e frequências do espectro de turbulência modelado, que é expresso por

$$
E(k)=16\left(\frac{2}{\pi}\right)^{1 / 2} k^{4} \exp \left(-2 k^{2}\right) .
$$

1 De acordo com Smirnov, Shi e Celik (2001), subíndices repetidos implicam somatório e parêntesis em volta de subíndices não permitem somatórios. 
Passo 3: Aplicar uma transformação ortogonal e escalar ao campo de escoamento $v_{i}$ para obter um novo campo $u_{i}$ :

$$
\begin{gathered}
w_{i}=c_{(i)} v_{(i)}, \\
u_{i}=a_{i k} w_{k} .
\end{gathered}
$$

Este procedimento utiliza como parâmetros de entrada o tensor $r_{i j}$ e as informações das escalas de comprimento e de tempo da turbulência. O resultado do último passo é um campo de escoamento dependente do tempo $u_{i}\left(x_{j}, t\right)$ com funções de correlação $u_{i} u_{j}$ iguais a $r_{i j}$ e escalas de comprimento e tempo turbulentos iguais a $L$ e $\tau$, respectivamente.

Nesse trabalho, a rotina computacional para a implementação do método RFG foi desenvolvida originalmente por Smirnov (2004) e após modificações foi incorporada no código numérico desenvolvido neste estudo.

\subsection{Domínio de integração}

A Fig. 7 mostra o domínio computacional onde as equações 3.26) e (3.27)-(3.29) são resolvidas. $\mathrm{O}$ escoamento principal está alinhado com a coordenada $x_{1}$ e a origem do sistema de coordenadas encontra-se em $x_{1}=0$. A direção normal à placa é definida por $x_{2}$, com o valor $x_{2}=0$ na superfície da placa. A direção transversal é definida por $x_{3}$, onde o escoamento é periódico, com o domínio estendendo-se de $x_{3}=0$ até $x_{3}=\lambda_{x_{3}}$, onde $\lambda_{x_{3}}$ é o comprimento de onda transversal. Em $x_{1}^{\prime}$ são inseridas as flutuações de velocidade para a geração do escoamento turbulento: adota-se a solução da equação de Blasius adicionada às flutuações de velocidade geradas pelo método RFG. Além disso, os pontos $x_{1}=0$ e $x_{1}^{\prime}$, e, $x_{1}^{\prime \prime}$ e $x_{1}^{\prime \prime \prime}$ determinam regiões de amortecimento prevenindo problemas numéricos (ver Seção 4.5).

\subsection{Condições de contorno}

Com relação as condições de contorno adotadas, pode-se dizer:

- No contorno rígido, adota-se a condição de não deslizamento e impermeabilidade, resultando em $\bar{u}_{i}=0$, para $i=1,2,3$.

- Na região de entrada adota-se uma condição de contorno do tipo Dirichlet para $\bar{u}_{2}$ e $\bar{\omega}_{3}$. Estes valores são obtidos através da resolução da equação de Blasius (SCHLICHTING, 1979), que produz um perfil inicial da camada limite 2D. Feito isso, a velocidade $\bar{u}_{1}$ é calculada através da definição da vorticidade em $x_{3}$ (Eq. (3.24)), que pode ser rescrita como:

$$
\frac{\partial \bar{u}_{1}}{\partial x_{2}}=\frac{\partial \bar{u}_{2}}{\partial x_{1}}+\bar{\omega}_{3}
$$




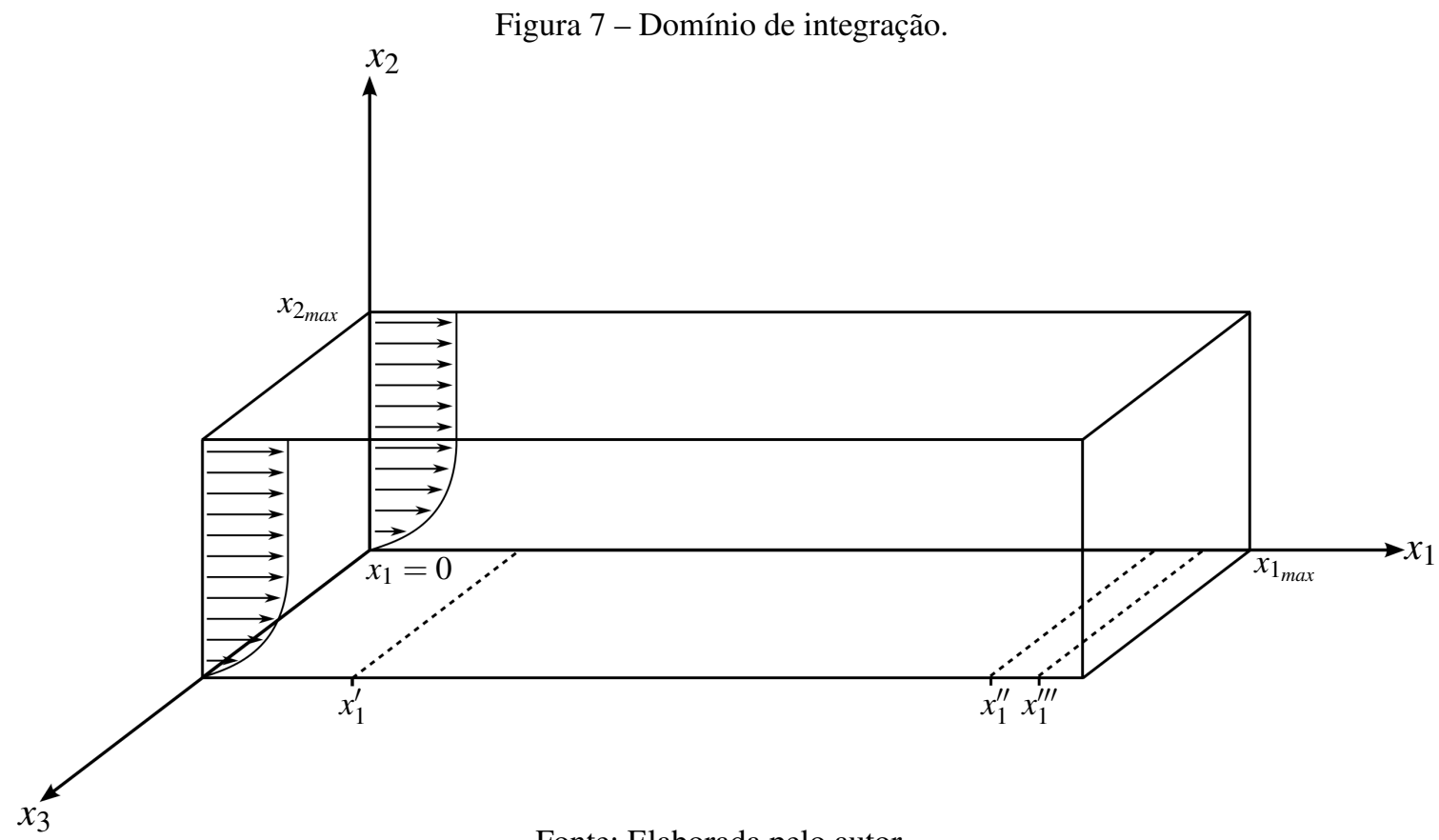

Fonte: Elaborada pelo autor.

Salienta-se que apenas o perfil de camada limite 2D é considerado pois no presente estudo o escoamento é periódico na direção $x_{3}$.

- No contorno superior, em $x_{2}=x_{2_{\max }}$, assume-se que as perturbações da velocidade decaem exponencialmente com o afastamento da parede. Admitindo-se que o valor de $x_{2_{\max }}$ seja suficientemente grande, os componentes de vorticidades são nulos $\left(\bar{\omega}_{i}=0\right.$, para $\left.i=1,2,3\right)$.

- Para os contornos na direção transversal, em $x_{3}=0$ e $x_{3}=\lambda_{x_{3}}$, aplicam-se condições de periodicidade. Então, para todas as variáveis e suas derivadas, são adotadas as condições

$$
\begin{aligned}
f\left(x_{1}, x_{2}, 0, t\right) & =f\left(x_{1}, x_{2}, \lambda_{x_{3}}, t\right), \\
\left.\frac{\partial^{n} f}{\partial x_{3}^{n}}\right|_{x_{1}, x_{2}, 0, t} & =\left.\frac{\partial^{n} f}{\partial x_{3}^{n}}\right|_{x_{1}, x_{2}, \lambda_{x_{3}}, t},
\end{aligned}
$$

onde $n \in \mathbb{N}^{*}$.

- Após a entrada e próximo à saída do domínio, uma região de relaminarização foi adotada, região onde todas as perturbações são dissipadas. Em vista disso, pode-se considerar a condição no contorno de saída como

$$
\frac{\partial^{2} f}{\partial x_{1}^{2}}=0,
$$

em que $f$ pode ser as velocidades ou as vorticidades em todas as direções.

- Em um ponto não muito distante da entrada $\left(x_{1}^{\prime}\right)$, as flutuações de velocidade são adicionadas à solução da equação de Blasius pra introdução de condições turbulentas:

$$
\bar{u}_{i}(\mathbf{x}, t)=U_{i}(\mathbf{x})+u_{i}^{\prime}(\mathbf{x}, t)
$$


onde $U_{i}$ e $u_{i}^{\prime}$ são a solução de Blasius e as flutuações vindas do método RGF, respectivamente.

O próximo capítulo apresenta a metodologia numérica utilizada no trabalho. 

A escolha do método numérico é um fator determinante para a qualidade dos resultados. Como o fenômeno físico em estudo apresenta uma grande variedade de escalas de tempo e comprimento, o código computacional deve ter características que minimizem as perdas de informação inerentes à discretização numérica. Além disso, o uso de aproximações mais precisas é recomendada para LES em virtude da interferência de erros de discretização nos termos do modelo submalha.

Dessa forma, o código numérico utilizado neste trabalho adota a formulação vorticidadevelocidade e um método espectral na direção transversal $\left(x_{3}\right)$ do escoamento. O método escolhido para a evolução temporal é o método de Runge-Kutta de $4^{a}$ ordem de precisão e, para a discretização espacial nas direções longitudinal $\left(x_{1}\right)$ e normal $\left(x_{2}\right)$, optou-se por diferenças finitas compactas de alta ordem. Com isso, obtém-se alta ordem tanto no tempo quanto no espaço.

Para solução da equação de Poisson é utilizado um método multigrid do tipo FAS (Full Approximation Scheme). Além disso, o código é paralelizado por meio da decomposição do domínio na direção $x_{1}$ - direção em que há um maior número de pontos. Ainda, objetivando uma redução do custo computacional e melhor resolução próximo aos contornos rígidos, utilizou-se uma técnica de estiramento de malha (stretching) na direção $x_{2}$ do escoamento, sendo esta representada por uma progressão geométrica de razão constante.

Nesse sentido, este capítulo dedica-se ao metodologia numérica empregada para a solução das equações governantes (3.26) e 3.27), (3.28) e (3.29).

\subsection{Método espectral}

Neste trabalho assume-se periodicidade na direção transversal do escoamento. Nesse sentido, um método espectral foi adotado na direção $x_{3}$, utilizando-se para tal as transformadas de Fourier. A introdução destas transformadas torna menos complicada a solução numérica e, ao 
mesmo tempo, preserva alta ordem de precisão no cálculo das derivadas.

Levando em conta as condições de periodicidade, todas as variáveis adimensionais podem ser expandidas em séries de Fourier com $K$ modos da forma:

$$
g\left(x_{1}, x_{2}, x_{3}, t\right)=\sum_{k=0}^{K} G_{k}\left(x_{1}, x_{2}, t\right) e^{-i \beta_{k} x_{3}},
$$

onde $g$ denota uma variável genérica no espaço físico e $i=\sqrt{-1}$ representa a unidade imaginária. $\beta_{k}$ é o número de onda na direção transversal que é definido como:

$$
\beta_{k}=\frac{2 \pi k}{\lambda_{3}}
$$

$\operatorname{com} \lambda_{3}$ sendo o comprimento de onda do modo de Fourier fundamental na direção transversal. As variáveis do espaço de Fourier são denotadas genericamente por letras maiúsculas $G$.

Substituindo as transformadas de Fourier 4.1 no sistema de equações formada por (3.26) e 3.27), 3.28) e (3.29), este pode ser reescrito, para $k$ modos de Fourier, da seguinte forma:

$$
\begin{aligned}
& \frac{\partial \bar{\Omega}_{1_{k}}}{\partial t}+\frac{\partial \bar{A}_{3_{k}}}{\partial x_{2}}+i \beta_{k} \bar{A}_{2_{k}}=\frac{1}{\operatorname{Re}} \nabla_{k}^{2} \bar{\Omega}_{1_{k}}-i \beta_{k} \bar{F}_{2_{k}}-\frac{\partial \bar{F}_{3_{k}}}{\partial x_{2}}, \\
& \frac{\partial \bar{\Omega}_{2_{k}}}{\partial t}-i \beta_{k} \bar{A}_{1_{k}}-\frac{\partial \bar{A}_{3_{k}}}{\partial x_{1}}=\frac{1}{R e} \nabla_{k}^{2} \bar{\Omega}_{2_{k}}+\frac{\partial \bar{F}_{3_{k}}}{\partial x}+i \beta_{k} \bar{F}_{1_{k}}, \\
& \frac{\partial \bar{\Omega}_{3_{k}}}{\partial t}+\frac{\partial \bar{A}_{2_{k}}}{\partial x_{1}}-\frac{\partial \bar{A}_{1_{k}}}{\partial x_{2}}=\frac{1}{R e} \nabla_{k}^{2} \bar{\Omega}_{3_{k}}+\frac{\partial \bar{F}_{1_{k}}}{\partial x_{2}}-\frac{\partial \bar{F}_{2_{k}}}{\partial x_{1}}, \\
& \frac{\partial^{2} \bar{U}_{1_{k}}}{\partial x_{2}^{2}}-\beta_{k}^{2} \bar{U}_{1_{k}}=i \beta_{k} \bar{\Omega}_{2_{k}}-\frac{\partial^{2} \bar{U}_{2_{k}}}{\partial x_{1} \partial x_{2}} \\
& \frac{\partial^{2} \bar{U}_{2_{k}}}{\partial x_{1}^{2}}+\frac{\partial^{2} \bar{U}_{2_{k}}}{\partial x_{2}^{2}}-\beta_{k}^{2} \bar{U}_{2_{k}}=-\frac{\partial \bar{\Omega}_{3_{k}}}{\partial x_{1}}-i \beta_{k} \bar{\Omega}_{1_{k}}, \\
& \frac{\partial^{2} \bar{U}_{3_{k}}}{\partial x_{2}^{2}}-\beta_{k}^{2} \bar{U}_{3_{k}}=\frac{\partial \bar{\Omega}_{2_{k}}}{\partial x_{1}}+i \beta_{k} \frac{\partial \bar{U}_{2_{k}}}{\partial x_{2}},
\end{aligned}
$$

onde

$$
\nabla_{k}^{2}=\left(\frac{\partial^{2}}{\partial x_{1}^{2}}+\frac{\partial^{2}}{\partial x_{2}^{2}}-\beta_{k}^{2}\right) .
$$

Todas as operações necessárias para a resolução dessas equações são realizadas no espaço de Fourier com exceção do cálculo dos produtos não lineares $\bar{A}_{i_{k}}$ e dos termos $\bar{F}_{i_{k}}$. Esse termos são calculados por um procedimento pseudo-espectral usando a regra do $2 / 3$. Para tanto, os componentes de velocidade e de vorticidade no espaço de Fourier devem ser transformados para o espaço físico e, em seguida, calculam-se então os produtos não lineares $\bar{a}_{i}$ e os termos $\bar{f}_{i}$ neste espaço. Feito isso, esses termos são transformados de volta para o espaço de Fourier e continuam-se os cálculos. 


\subsection{Decomposição do domínio}

A solução numérica de EDPs (Equações Diferenciais Parciais) implica na discretização do domínio através da criação de uma malha de pontos, onde estas equações vão ser computacionalmente calculadas. Geralmente, a quantidade de pontos necessária para se alcançar resultados de qualidade é elevada, exigindo memória e alta velocidade de processamento por parte dos computadores. Por esse motivo, a utilização de computadores em paralelo para a simulação numérica das mais diversas situações vem crescendo rapidamente ao longo dos anos.

Nesse trabalho, há a utilização de malhas refinadas, o que justifica a paralelização do código computacional utilizado nessa pesquisa. Esta paralelização é feita através da decomposição do domínio na direção $x_{1}$, direção com maior número de pontos. Para tanto, a malha precisa ser decomposta em subdomínios de modo que os cálculos associados a cada subdomínio sejam realizados em um dos processadores alocados de um cluster de computadores.

Na Fig. 8 está ilustrado a divisão do domínio como se fossem utilizados 4 processadores para simulação numérica de cada modo de Fourier K. A biblioteca MPI (Message-Passing Interface) é usada para a paralelização do código.

Figura 8 - Decomposição do domínio.

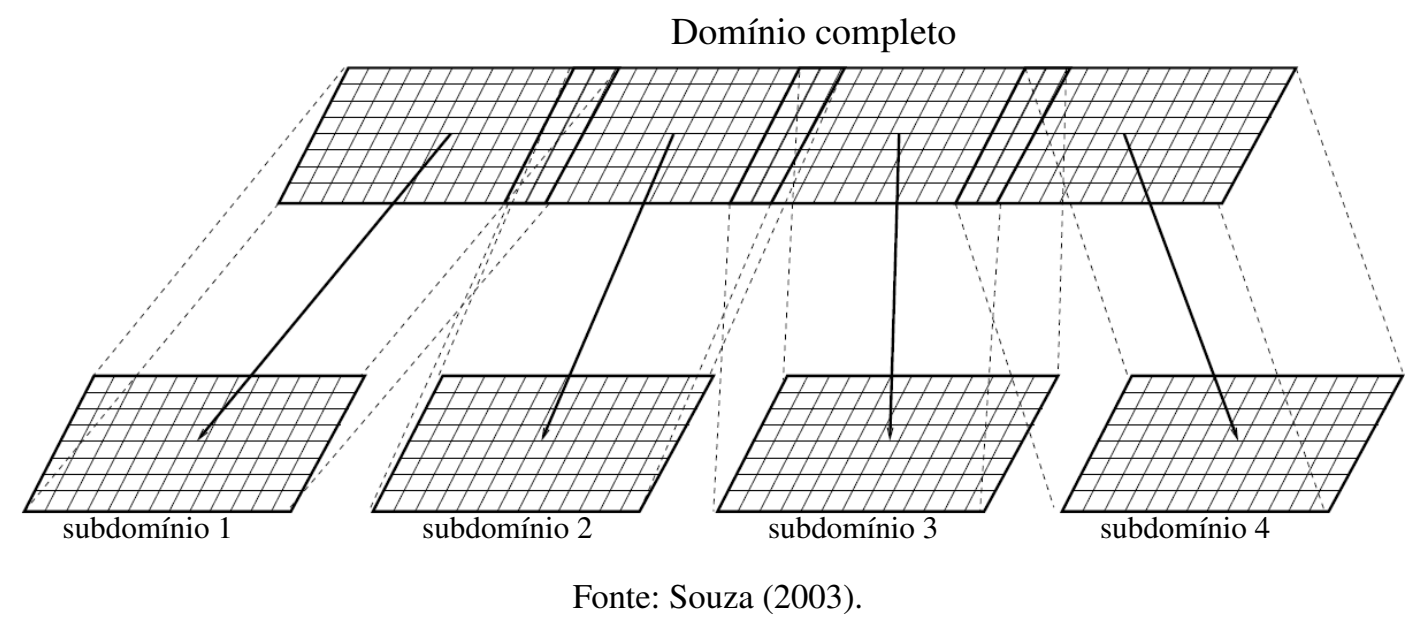

O número de pontos presentes na região de sobreposição dos subdomínios depende do número de níveis utilizado pelo método multigrid para a resolução da equação de Poisson. Quanto maior o número de níveis, maior o número de pontos usados na sobreposição (mais detalhes em Rogenski (2011)).

\subsection{Discretização do domínio}

O domínio de integração onde as equações (4.3)-(4.8) são resolvidas numericamente está esquematizado na Fig. 7 . 
A discretização do domínio é realizada pelo método de diferenças compactas e o integrador temporal adotado é o método de Runge-Kutta de $4^{\underline{a}}$ ordem de precisão. A solução da equação de Poisson para a velocidade $U_{2}$ (Eq. (4.7p) é calculada por meio de um método multigrid paralelizado tipo FAS. Neste trabalho, considerou-se a variação do espaçamento entre os pontos computacionais na direção normal como uma progressão geométrica de razão constante st $f$.

\subsubsection{Derivadas temporais}

Para o avanço no tempo utilizou-se o método de Runge-Kutta de $4^{a}{ }^{a}$ ordem de precisão clássico (FERZIGER; PERIC, 1997). As vantagens desse método foram confirmadas por Souza (2005), onde o autor testou a influência de diversos integradores temporais de alta ordem em simulações de escoamentos perturbados.

Para avançar a solução no tempo, são efetuados os passos:

$$
\begin{aligned}
q_{1} & =q^{(n)}+\frac{\Delta_{t}}{2} g_{0}, \\
q_{2} & =q^{(n)}+\frac{\Delta_{t}}{2} g_{1}, \\
q_{3} & =q^{(n)}+\Delta_{t} g_{2}, \\
q^{(n+1)} & =q^{(n)}+\frac{\Delta_{t}}{6}\left(g_{0}+2 g_{1}+2 g_{2}+g_{3}\right),
\end{aligned}
$$

em que $q_{i}$ são os valores intermediários da vorticidade, $q^{(n)}$ presenta a vorticidade no passo de tempo $n$ e $g_{i}$ é o lado direito da equação de transporte de vorticidade quando isola-se a derivada temporal do lado esquerdo. $\Delta_{t}$ é o passo no tempo.

\subsubsection{Derivadas espaciais}

A aplicação de aproximações compactas vem aumentando atualmente na área de CFD. De forma geral, há muitas contribuições científicas relacionadas a utilização de aproximações de altas ordens como, por exemplo, (WRAY; HUSSAINI, 1994; LELE, 1992; KLOKER, 1998; SOUZA; MENDONÇA; MEDEIROS, 2005, BOERSMA, 2011). De acordo com estes trabalhos, a escolha de métodos desse tipo é justificada por combinarem eficiência computacional, custo computacional razoável, redução do erro e alta precisão nas soluções numéricas.

Dessa forma, nesse trabalho de doutorado, para o cálculo das derivadas espaciais nas direções $x_{1}$ e $x_{2}$ são adotadas diferenças compactas de alta ordem. Salienta-se que como há a variação dos espaçamentos entre os pontos discretos do domínio na direção normal $\left(x_{2}\right)$ devido ao stretching, isso implica na variação dos coeficientes das aproximações para as derivadas. A dedução desses coeficientes leva em conta as ideias propostas por (LELE, 1992; SOUZA; MENDONÇA; MEDEIROS, 2005; LINNICK; FASEL, 2005) e é apresentada abaixo. 
Vale ressaltar que as aproximações abaixo são válidas tanto na direção $x_{1}$ quanto em $x_{2}$. Entretanto, na direção $x_{1}$, o valor de $s t f$ deve ser igual a 1 pois não aplica-se estiramento de malha. st $f$ é o fator de stretching.

\section{Aproximação da primeira derivada}

A Fig. 9 ilustra o espaçamento da malha centrada no ponto $i$ genérico. $\mathrm{O}$ espaçamento entre os pontos computacionais é então obtido através de uma progressão geométrica de razão constante (stf).

Figura 9 - Stretching na vizinhança de um ponto $i$ da malha.

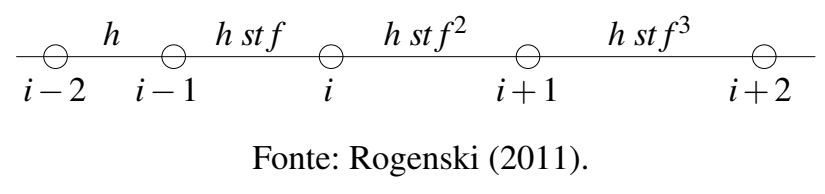

Para exemplificar o procedimento para o desenvolvimento de um esquema compacto, considera-se aproximar a primeira derivada de uma função genérica $f$ nos pontos centrais do domínio pela expressão

$$
\alpha_{i-1} f_{i-1}^{\prime}+\alpha_{i} f_{i}^{\prime}+\alpha_{i+1} f_{i+1}^{\prime}=a_{i-2} f_{i-2}+a_{i-1} f_{i-1}+a_{i} f_{i}+a_{i-1} f_{i-1}+a_{i+2} f_{i+2},
$$

em que os coeficientes $\alpha_{i-1}, \alpha_{i}, \alpha_{i+1}, a_{i-2}, a_{i-1}, a_{i}, a_{i+1}$ e $a_{i+2}$, que agora variam de acordo com o st $f$, devem ser determinados.

As relações entre esses coeficientes são encontradas expandindo cada termo $\left(f_{i-1}^{\prime}, f_{i}^{\prime}\right.$, $f_{i+1}^{\prime}, f_{i-2}, f_{i-1}, f_{i}, f_{i-1}$ e $\left.f_{i+2}\right)$ da equação (4.14) em série de Taylor centradas em $i$. Para tanto, adota-se $h_{1^{-}}=h s t f$ como a distância entre os pontos $i-1$ e $i$ e $h_{2^{-}}=h(1+s t f)$ como a distância entre $i-2$ e $i$. Similarmente, $h_{1^{+}}=h s t f^{2}$ e $h_{2^{+}}=h s t f^{2}(1+s t f)$ representam a distância dos pontos $i+1$ e $i+2$ com relação ao ponto $i$, respectivamente. Assim, um sistema linear que tem como solução o conjunto dos coeficientes procurados é gerado:

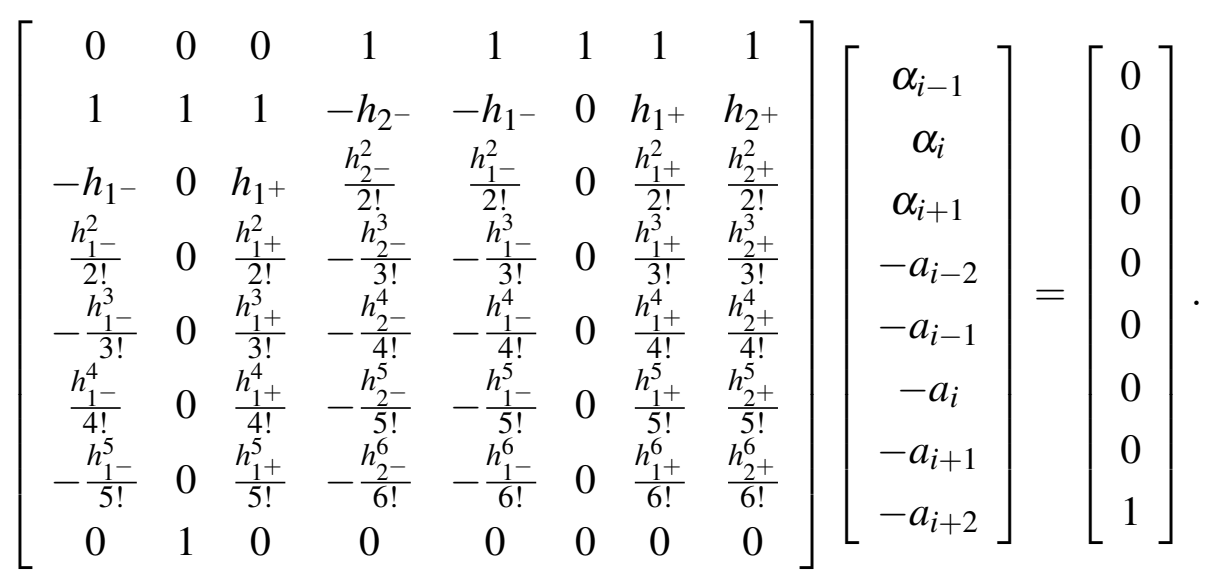


Para encontrar o conjunto de constantes que compõem a aproximação compacta (4.14), o sistema acima é resolvido pelo método LU. Como em (SOUZA, 2003), as moléculas computacionais adotadas para os pontos próximos ao contorno são:

- Primeiro ponto:

$$
\begin{aligned}
\alpha_{1}^{(f p)} f_{1}^{\prime}+\alpha_{2}^{(f p)} f_{2}^{\prime} & = \\
a_{1}^{(f p)} f_{1} & +a_{2}^{(f p)} f_{2}+a_{3}^{(f p)} f_{3}+a_{4}^{(f p)} f_{4}+a_{5}^{(f p)} f_{5} .
\end{aligned}
$$

- Segundo ponto:

$$
\begin{aligned}
\alpha_{1}^{(s p)} f_{1}^{\prime}+\alpha_{2}^{(s p)} & f_{2}^{\prime}+\alpha_{3}^{(s p)} f_{3}^{\prime}= \\
& a_{1}^{(s p)} f_{1}+a_{2}^{(s p)} f_{2}+a_{3}^{(s p)} f_{3}+a_{4}^{(s p)} f_{4}+a_{5}^{(s p)} f_{5}+a_{6}^{(s p)} f_{6}
\end{aligned}
$$

- Penúltimo ponto:

$$
\begin{aligned}
& \alpha_{1}^{(p p)} f_{N}^{\prime}+\alpha_{2}^{(p p)} f_{N-1}^{\prime}+\alpha_{3}^{(p p)} f_{N-2}^{\prime}= \\
& \quad a_{1}^{(p p)} f_{N}+a_{2}^{(p p)} f_{N-1}+a_{3}^{(p p)} f_{N-2}+a_{4}^{(p p)} f_{N-3}+a_{5}^{(p p)} f_{N-4}+a_{6}^{(p p)} f_{N-5}
\end{aligned}
$$

- Último ponto:

$$
\begin{aligned}
& \alpha_{1}^{(l p)} f_{N}^{\prime}+\alpha_{2}^{(l p)} f_{N-1}^{\prime}= \\
& a_{1}^{(l p)} f_{N}+a_{2}^{(l p)} f_{N-1}+a_{3}^{(l p)} f_{N-2}+a_{4}^{(l p)} f_{N-3}+a_{5}^{(l p)} f_{N-4} .
\end{aligned}
$$

A determinação dos coeficientes que aparecem em (4.16)-(4.19) é realizada de forma análoga à apresentada acima. Por fim, para calcular as primeiras derivadas em todos os pontos computacionais, há a necessidade da solução do conjunto de equações dadas por (4.14) e (4.16)(4.19), o que conduz ao um sistema tridiagonal. O algoritmo de Thomas foi implementado para a solução deste sistema.

\section{Aproximação da segunda derivada}

O desenvolvimento de aproximações compactas para a segunda derivada é obtido de maneira análoga ao realizado para a primeira derivada. As moléculas computacionais propostas são:

- Primeiro ponto:

$$
\begin{aligned}
\beta_{1}^{(f p)} f_{1}^{\prime \prime}+ & \beta_{2}^{(f p)} f_{2}^{\prime \prime}= \\
& b_{1}^{(f p)} f_{1}+b_{2}^{(f p)} f_{2}+b_{3}^{(f p)} f_{3}+b_{4}^{(f p)} f_{4}+b_{5}^{(f p)} f_{5}+b_{6}^{(f p)} f_{6} .
\end{aligned}
$$


- Segundo ponto:

$$
\begin{aligned}
\beta_{1}^{(s p)} f_{1}^{\prime \prime}+ & \beta_{2}^{(s p)} f_{2}^{\prime \prime}+\beta_{3}^{(s p)} f_{3}^{\prime \prime}= \\
& b_{1}^{(s p)} f_{1}+b_{2}^{(s p)} f_{2}+b_{3}^{(s p)} f_{3}+b_{4}^{(s p)} f_{4}+b_{5}^{(s p)} f_{5}+b_{6}^{(s p)} f_{6}+b_{7}^{(s p)} f_{7} .
\end{aligned}
$$

- Pontos centrais:

$$
\begin{aligned}
\beta_{i-1} f_{i-1}^{\prime \prime}+ & \beta_{i} f_{i}^{\prime \prime}+\beta_{i+1} f_{i+1}^{\prime \prime}= \\
b_{i-2} f_{i-2}+b_{i-1} f_{i-1} & +b_{i} f_{i}+b_{i-1} f_{i-1}+b_{i+2} f_{i+2}
\end{aligned}
$$

- Penúltimo ponto:

$$
\begin{aligned}
& \beta_{1}^{(p p)} f_{N}^{\prime \prime}+\beta_{2}^{(p p)} f_{N-1}^{\prime \prime}+\beta_{3}^{(p p)} f_{N-2}^{\prime \prime}= \\
& b_{1}^{(p p)} f_{N}+b_{2}^{(p p)} f_{N-1}+b_{3}^{(p p)} f_{N-2}+b_{4}^{(p p)} f_{N-3}+ \\
& b_{5}^{(p p)} f_{N-4}+b_{6}^{(p p)} f_{N-5}+b_{7}^{(p p)} f_{N-6} .
\end{aligned}
$$

- Último ponto:

$$
\begin{aligned}
\beta_{1}^{(l p)} & f_{N}^{\prime \prime}+\beta_{2}^{(l p)} f_{N-1}^{\prime \prime}= \\
& b_{1}^{(l p)} f_{N}+b_{2}^{(l p)} f_{N-1}+b_{3}^{(l p)} f_{N-2}+b_{4}^{(l p)} f_{N-3}+b_{5}^{(l p)} f_{N-4}+b_{6}^{(l p)} f_{N-5} .
\end{aligned}
$$

Após encontrar os coeficientes de (4.20)-(4.24), pode-se calcular a segunda derivada em todos os pontos computacionais por meio das aproximações obtidas. Semelhantemente, isto resulta em um sistema linear tridiagonal, que neste trabalho é resolvido pelo algoritmo de Thomas. Mais detalhes do desenvolvimento dessas aproximações pode ser encontradas em (ROGENSKI, 2011).

\subsubsection{Discretização da equação de Poisson}

A resolução da equação de Poisson (4.7) requer discretização da segunda derivada nas direções paralela $\left(x_{1}\right)$ e normal $\left(x_{2}\right)$ ao escoamento. Contudo, ao se adotar o stretching na direção $x_{2}$, as aproximações compactas para as derivadas devem ser generalizadas, como feito para as primeira e segunda derivadas. A diferença é a inclusão de informações de condições de contorno e o uso da equação da continuidade.

As moléculas computacionais adotadas são:

- Segundo ponto:

$$
\gamma_{1}^{(s p)} f_{b_{1}}^{\prime}+\gamma_{2}^{(s p)} f_{b_{2}}^{\prime \prime}+\gamma_{3}^{(s p)} f_{b_{3}}^{\prime \prime}=c_{1}^{(s p)} f_{b_{1}}+c_{2}^{(s p)} f_{b_{2}}+c_{3}^{(s p)} f_{b_{3}}+c_{4}^{(s p)} f_{b_{4}}
$$

onde, aqui, o símbolo ' representa derivação da função $U_{2}$ na direção normal. 
Ainda, a condição de não deslizamento para as velocidades $U_{1}$ e $U_{3}$ e o uso da equação da continuidade implicam

$$
\frac{\partial U_{2_{k}}}{\partial x_{2}}=0
$$

- Pontos centrais: utiliza-se a mesma aproximação dada pela equação 4.22).

- Penúltimo ponto:

$$
\gamma_{1}^{(p p)} f_{b_{N-1}}^{\prime \prime}=c_{1}^{(p p)} f_{b_{N}}+c_{2}^{(p p)} f_{b_{N-1}}+c_{3}^{(p p)} f_{b_{N-2}} .
$$

- Último ponto:

$$
\gamma_{1}^{(l p)} f_{b_{N}}^{\prime}+\gamma_{2}^{(l p)} f_{b_{N}}^{\prime \prime}=c_{1}^{(l p)} f_{b_{N}}+c_{2}^{(l p)} f_{b_{N-1}}+c_{3}^{(l p)} f_{b_{N-2}}
$$

Na direção onde não há stretching as aproximações são iguais àquelas utilizadas por (SOUZA, 2003). O emprego dessas aproximações leva a um sistema pentadiagonal para cada linha $j$ do domínio, que é então resolvido pelo método LU.

\subsection{O método multigrid e a equação de Poisson}

Neste trabalho, o método multigrid foi aplicado para a solução numérica da equação de Poisson (4.7). A ideia básica por trás desse método é a utilização de diversas malhas onde os cálculos são efetuados passando de uma malha mais fina para uma malha mais grossa e vice-versa, com o objetivo da eliminação das altas frequências de erro. A sua principal vantagem é a alta taxa de convergência (ZHANG, 1996; SPITALERI, 2000). Uma análise da performance de métodos multigrid para a solução da equação de Poisson para escoamentos incompressíveis pode ser encontradas em (ROGENSKI, 2011).

O algoritmo usado neste trabalho é o esquema de aproximação total FAS (Full Approximation Scheme) (STUBEN; TROTTENBERG, 1981). Optou-se ainda pela utilização de um ciclo de integração $\mathrm{V}$, composto por 4 níveis de malha, com razão de engrossamento igual a 2 . O número de ciclos $\mathrm{V}$ necessários para a solução da equação depende do valor do resíduo na malha mais fina. Se o valor obtido em todos os subdomínios for menor do que um valor de referência pré-estabelecido, finaliza-se o algoritmo.

Com respeito a paralelização do método multigrid, em que adotou-se a divisão do domínio apenas na direção $x_{1}$ (Fig. 8), é indispensável uma atenção especial na comunicação entre os valores da função entre os subdomínios: o número de níveis de engrossamento que se utiliza no método multigrid, associado ao tamanho da molécula computacional, é que define o número de pontos de interseção. O passo a passo e as considerações mais importantes do algoritmo computacional para a resolução da equação de Poisson são mostrados em (ROGENSKI, 2011) e, por isso, são omitidas aqui. 


\subsection{Relaminarização do escoamento}

No presente trabalho, adotam-se duas regiões de relaminarização do escoamento, uma localizada próxima à entrada do domínio (entre $x_{1}=0$ e $x_{1}^{\prime}$ ) e, a outra, próxima ao contorno de saída (entre $x_{1}^{\prime \prime}$ e $x_{1}^{\prime \prime \prime}$ ) (ver Seção 3.6.

Em simulações numéricas, os resultados podem sofrer influência dos efeitos não físicos associados à reflexão de perturbações que são transportadas para um dado contorno. Com a finalidade de evitar possíveis alterações, utiliza-se a técnica de relaminarização, onde as oscilações são forçadas a decair gradativamente para zero no final da malha horizontal. Para tanto, na região de relaminarização da saída do domínio, deve-se impor que os valores das perturbações dos componentes de vorticidade decaiam até zero de acordo com:

$$
\hat{\Omega}_{k}(x, y, t)=f_{r}(x) \Omega_{k}(x, y, t), \quad x_{1}^{\prime \prime} \leq x_{1} \leq x_{1}^{\prime \prime \prime}
$$

em que $\hat{\Omega}_{k}(x, y, t)$ é o valor do componente da perturbação da vorticidade depois de ser relaminarizada e $\Omega_{k}(x, y, t)$ é o valor da vorticidade depois de cada passo do Runge-Kutta. $f_{r}$ é uma função rampa estabelecida por Meitz (1996):

$$
f_{r}(x)=f_{r}(\varepsilon)=\left(1-\varepsilon^{50}\right)^{4} e^{-\varepsilon^{4} / 10},
$$

onde $\varepsilon=\frac{i-i_{1}^{\prime \prime}}{x_{1}^{\prime \prime \prime}-i_{1}^{\prime \prime}}$, para todo $i_{1}^{\prime \prime} \leq i_{1} \leq i_{1}^{\prime \prime \prime} . i_{1}^{\prime \prime}$ e $i_{1}^{\prime \prime \prime}$ correspondem respectivamente às posições $x_{1}^{\prime \prime} \mathrm{e}$ $x_{1}^{\prime \prime \prime}$ na direção $x_{1}$ do escoamento.

Para a região de relaminarização da entrada do domínio (entre $x_{1}=0$ e $x_{1}^{\prime}$ ) a função rampa adotada é:

$$
f_{r}(x)=f_{r}(\varepsilon)=6 \varepsilon^{5}-15 \varepsilon^{4}+10 \varepsilon^{3},
$$

em que $\varepsilon=\frac{i-1}{i_{1}^{\prime}-1}$, para todo $1 \leq i_{1} \leq i_{1}^{\prime}$. 1 e $i_{1}^{\prime}$ correspondem respectivamente as posições $x_{1}=0$ e $x_{1}^{\prime}$ na direção $x_{1}$ do escoamento.

Essa técnica é a aplicada a cada passo do integrador temporal.

\subsection{Filtragem espacial}

A utilização de aproximações de alta ordem centradas pode introduzir perturbações não físicas de alta frequência nas soluções no decorrer das simulações. Para não contaminar os resultados, geralmente aplica-se uma filtragem espacial que leva à atenuação das altas frequências.

Neste trabalho, um filtro numérico tridiagonal é aplicado sempre ao final de cada passo do método Runge-Kutta. Para tanto, os componentes de vorticidade são recalculados por meio da aproximação compacta dada por (LELE, 1992):

- $\operatorname{para} i=1$ :

$$
\hat{\Omega}_{i}=\frac{15}{16} \Omega_{i}+\frac{4}{16} \Omega_{i+1}-\frac{6}{16} \Omega_{i+2}+\frac{4}{16} \Omega_{i+3}-\frac{15}{16} \Omega_{i+4} .
$$


- $\operatorname{para} i=2$ :

$$
\hat{\Omega}_{i}=\frac{1}{16} \Omega_{i-1}+\frac{12}{16} \Omega_{i}+\frac{6}{16} \Omega_{i+1}-\frac{4}{16} \Omega_{i+2}+\frac{1}{16} \Omega_{i+3} .
$$

- para $i=3$ :

$$
\hat{\Omega}_{i}=-\frac{1}{16} \Omega_{i-2}+\frac{4}{16} \Omega_{i-1}+\frac{10}{16} \Omega_{i}-\frac{4}{16} \Omega_{i+1}-\frac{1}{16} \Omega_{i+2} .
$$

- $i=4, \ldots, N x_{1}-3$ :

$$
\begin{aligned}
\alpha \hat{\Omega}_{i-1}+\hat{\Omega}_{i-1} & +\alpha \hat{\Omega}_{i+1}= \\
a_{f} \Omega_{i}+b_{f}\left(\Omega_{i-1}+\Omega_{i+1}\right)+c_{f}\left(\Omega_{i-2}\right. & \left.+\Omega_{i+2}\right)+d_{f}\left(\Omega_{i-3}+\Omega_{i+3}\right),
\end{aligned}
$$

em que

$$
\begin{gathered}
a_{f}=\frac{1}{16}\left(11+10 \alpha_{f}\right), \quad b_{f}=\frac{1}{32}\left(15+34 \alpha_{f}\right), \quad c_{f}=\frac{1}{16}\left(-3+6 \alpha_{f}\right), \\
d_{f}=\frac{1}{32}\left(1-2 \alpha_{f}\right) \quad \text { e } \quad \alpha_{f}=0.48 .
\end{gathered}
$$

$N x_{1}$ é o número máximo de pontos na direção longitudinal.

- para $i=N x_{1}-2, N x_{1}-1$ e $N x_{1}$ são as mesmas utilizadas nos 3 primeiros itens.

O filtro é aplicado somente aos componentes de vorticidade na direção longitudinal.

\subsection{Verificação do código}

Uma questão que deve ser levada em conta em estudos numéricos é a credibilidade do código computacional adotado para as simulações.

A Verificação é um processo matemático que checa se o código computacional está livre de erros de programação e se não há inconsistências no algoritmo lógico implementado (ROACHE, 1998). Esse procedimento investiga a ordem de precisão das equações discretizadas para uma posterior comparação com a ordem formal do esquema numérico (ROACHE, 1998; SALARI; KNUPP, 2000). Vale ressaltar, que essa metodologia não está preocupada se o modelo matemático utilizado apresenta qualquer relação com o problema físico.

O Método das Soluções Manufaturadas (MMS - Method of Manufactured Solutions) é o método mais eficiente para verificação de códigos e tem sido amplamente utilizado na comunidade científica (ROACHE, 1998; SALARI; KNUPP, 2000; ECA et al., 2007). Em suma, esse método consiste em fabricar uma "função solução" - a manufatura - que é assumida para satisfazer as equações governantes de interesse. O objetivo é resolver um problema similar, no qual a solução exata está disponível.

Nesse sentido, o código DNS 3D que é base desse trabalho, foi verificado em Petri et al. (2015) através do método MMS. Os autores realizaram simulações com dois conjuntos de malha, 
com stretching e sem stretching, onde foram calculados normas de erro (para os componentes de velocidade e vorticidade) e ordens de convergência.

Nos dois conjuntos de malha, o decaimento do erro é evidente mas, como esperado, a malha com stretching apresentou erro maior. Além disso, é possível perceber que o stretching diminui a ordem de convergência, ficando esta entre 1.93 e 3.83 para malhas sem stretching e, entre 1.47 e 3.18, para malhas com stretching. Aproximações de alta ordem compactas são usadas para o cálculo das derivadas espaciais, no entanto, para a equação de Poisson adota-se $2^{a} a$ ordem de precisão no contorno superior. Isso leva a redução da ordem formal do método mas não influencia nos resultados das simulações, uma vez que a região de interesse concentra-se região próxima ao contorno sólido. Dessa forma, o código 3D usado nesse trabalho foi considerado verificado.

O próximo capítulo engloba os resultados numéricos obtidos nesse trabalho para simulações de camadas limite turbulentas sobre placa plana. 



\section{CAMADA LIMITE TURBULENTA EM PLACA PLANA}

Esse capítulo é dedicado à validação do presente código LES para simulação de escoamentos turbulentos. Nesse contexto, a capacidade do código LES de alta ordem, que combina o modelo submalha WALE e o método de geração de flutuações turbulentas RFG, é investigada através de simulações de escoamentos em camada limite turbulenta em placa plana.

Para caracterizar a qualidade das simulações é feita uma comparação dos resultados numéricos com dados da literatura para os perfis de velocidade média, componentes do tensor de Reynolds e espectro de energia. Além disso, investiga-se também o comportamento dos parâmetros integrais como o fator de forma $(H)$ e o coeficiente de atrito $\left(C_{f}\right)$ - tais parâmetros são bons indicadores da qualidade da camada limite. Os testes numéricos realizados abrangem uma faixa de $\operatorname{Re}_{\theta}$ entre 900 até 1300 . $\operatorname{Re}_{\theta}$ é calculado com base na espessura de quantidade de movimento e na velocidade do escoamento livre.

Ressalta-se que os resultados numéricos são obtidos através de um processo de média temporal, denotado por $\langle$. $\rangle$. Esse processo tem início após o monitoramento temporal das variáveis, que é realizado por sondas em diversos pontos no domínio, e tem como objetivo indicar o momento em que o escoamento sofre a mínima influência das condições de entrada. A turbulência totalmente desenvolvida é estabelecida quando a camada limite atinge um estado de equilíbrio onde a produção e dissipação de energia cinética turbulenta estão balanceadas. No estado totalmente desenvolvido, a solução média já não mostra mudanças substanciais no tempo.

Os perfis da velocidade média e das flutuações são computados da seguinte forma:

$$
u_{1}^{+}=\frac{<\overline{u_{1}}>}{u_{\tau}},
$$




$$
\begin{gathered}
u_{1}^{\prime} u_{1}^{\prime+}=\frac{\sqrt{<\overline{u_{1}^{\prime} u_{1}^{\prime}}>}}{u_{\tau}}, \quad u_{2}^{\prime} u_{2}^{\prime+}=\frac{\sqrt{<\overline{u_{2}^{\prime} u_{2}^{\prime}}>}}{u_{\tau}}, \\
u_{3}^{\prime} u_{3}^{\prime+}=\frac{\sqrt{<\overline{u_{3}^{\prime} u_{3}^{\prime}}>}}{u_{\tau}}, \quad u_{1}^{\prime} u_{2}^{\prime+}=\frac{\sqrt{<\overline{u_{1}^{\prime} u_{2}^{\prime}}>}}{u_{\tau}^{2}} .
\end{gathered}
$$

Como solução de referência são considerados os dados DNS de Spalart (1988) $\left(R e_{\theta}=\right.$ $1410)$ e Schlatter e Orlu (2010) $\left(R e_{\theta}=1000,1410\right)$ e, também, os resultados das simulações LES de Lund, Wu e Squires (1998) $\left(R e_{\theta}=1530\right)$ e Schlatter et al. (2009) $\left(R e_{\theta}=1000,1410\right)$. Ainda, o perfil de velocidade média descrito pela teoria clássica de camada limite turbulenta (ver Seção 2.4) (linhas sólidas na cor preta) é adotado como mais um indicador da qualidade dos resultados.

Em todas as simulações numéricas realizadas nesse trabalho, o campo de flutuações criado pelo método RFG (ver Eq. (3.33) ) é gerado com amostra espectral de 1000 vetores de onda $(N=1000)$. De acordo com Vedovoto et al. (2015), a escolha do número de modos influencia tanto no custo computacional da simulação quanto na precisão dos resultados. Entretanto, os autores mostraram que para $N$ maior que 1000 não há melhorias significativas na reprodução do tensor de Reynolds e nem na representatividade do espectro de energia.

A extensão do domínio computacional na direção normal é pelo menos duas vezes maior que a maior espessura da camada limite em desenvolvimento. $O$ transporte de energia das escalas resolvidas para as escalas submalha é feito pelo modelo WALE.

\subsection{Influência da modelagem submalha}

Como mencionado na Seção 3.3, o modelo submalha WALE foi implementado no código LES desenvolvido nesse trabalho para introduzir os efeitos das escalas submalhas na solução filtrada final. Esse modelo contém uma constante $C_{\mathrm{W}}$ que deve assumir valores diferentes dependendo da natureza do escoamento. Em Nicoud e Ducros (1999) essa constante foi calibrada numericamente como 0.5 mas valores entre 0.1 e 0.6 podem ser encontrados na literatura $(\overline{\mathrm{KU}}-$ BAN et al., 2012). Assim sendo, essa seção investiga a sensitividade dos resultados numéricos em relação ao coeficiente $C_{\mathrm{W}}$ para que nas próximas simulações numéricas apenas um valor ótimo para essa constante seja adotado.

Para tanto, três simulações numéricas foram realizadas, onde os dados computacionais de entrada diferem somente nos valores adotados para a constante $C_{\mathrm{W}}: 0,0.325$ e 0.5 . Nota-se claramente, a partir da equação que descreve a modelo WALE (ver Seção 3.3), que nenhum modelo submalha é usado quando $C_{\mathrm{W}}=0$. Consequentemente, também pode ser avaliada a influência da modelagem da turbulência (onde $C_{\mathrm{W}}$ é não nulo) nas simulações realizadas. 
Os dados computacionais em comum são: o domínio é discretizado usando 537 e 335 pontos nas direções longitudinal e normal, respectivamente. Na direção transversal, adotase 11 modos de Fourier e 32 pontos no espaço físico. $\Delta_{x_{1}}=5 \times 10^{-3}$. O valor inicial do espaçamento na direção normal é $\Delta_{x_{2}}=1 \times 10^{-4}$, sendo fixado stretching de $1 \% . \Delta_{t}=10^{-4}$. Para a geração das flutuações turbulentas por meio do método RGF, considera-se o número de modos de Fourier igual a 1000 e o tempo característico da turbulência de $\tau=10^{-4}$. Os valores para a velocidade de referência, viscosidade cinemática e tamanho característico da placa são $U_{\infty}=26 \mathrm{~m} / \mathrm{s}, v=1.55 \times 10^{-5} \mathrm{~m}^{2} / \mathrm{s}$ e $L=0.1 \mathrm{~m}$, respectivamente.

As Figs. 10 e 11 mostram, respectivamente, os perfis de velocidade média e os componentes do tensor de Reynolds correspondentes a posição longitudinal onde $R e_{\theta}=1006$, permitindo a comparação dos resultados numéricos para os três valores adotados para $C_{\mathrm{W}} \operatorname{com}$ dados DNS e LES da literatura.

Para o perfil de velocidade média normalizado por $u_{\tau}$ (Fig. 10) observa-se que na subcamada viscosa $\left(x_{2}^{+}<5\right)$ todos os resultados concordam muito bem com o perfil linear esperado. Para $C_{\mathrm{W}}=0$ (sem modelagem submalha), o perfil de $u_{1}^{+}$é reproduzido com precisão até $x_{2}^{+} \approx 100$ mas uma subestimação considerável dos resultados para valores maiores de $x_{2}^{+}$é observada. Isso sugere que o esquema numérico implementado é bastante não dissipativo e a introdução de uma viscosidade adicional, que é fornecida pelo modelo submalha, é necessária para obtenção de bons resultados. Vale ressaltar que esse perfil se afasta das soluções de referência com o avanço temporal da simulação. Nos resultados obtidos para $C_{\mathrm{W}}$ iguais a 0.325 e 0.5 podese observar uma pequena superestimação do perfil na região logarítmica $\left(30<x_{2}^{+}<60\right)$ mas, ainda assim, são considerados em boa concordância com a literatura. De acordo com Lund, Wu e Squires (1998), essa é uma característica comumente encontrada em simulações que utilizam diferenças finitas em malhas relativamente grossas, podendo ser notado em seus resultados (ver Fig. 10). As simulações de camada limite em transição de Rai e Moin (1993) e os dados numéricos de um canal turbulento de Lund e Kaltenbach (1995) também apresentam essa discrepância nos resultados.

Com relação as flutuações de velocidade, idealmente, os valores mais altos são encontrados próximos à parede onde grandes gradientes de velocidade garantem alta produção de energia. Por outro lado, bem perto da parede o escoamento e suas flutuações de velocidade estão sujeitos à condição de não deslizamento, o que leva a diminuição drástica das tensões turbulentas nesta região. Longe da parede, as flutuações de velocidade tendem assintoticamente a zero indicando que a turbulência se torna mais isotrópica. Isso pode ser constatado na Fig. 11, onde as flutuações (Figs. 11 (a), (b), (c)) e o tensor de Reynolds (Fig. 11 (d)) para $\operatorname{Re}_{\theta}=1006$ são apresentadas.

Nota-se claramente que as simulações apresentam superestimação do pico máximo dos perfis de $u_{1}^{\prime} u_{1}^{\prime+}$ (Fig, 11 (a)) e $u_{3}^{\prime} u_{3}^{\prime+}$ (Fig 11 (c)). Essa discrepância é mais perceptível na região onde acontecem as grandes flutuações e, certamente, isso é causada pelo refinamento insuficiente da malha computacional adotada. Pode-se notar bem claramente que os resultados onde não há 
Figura 10 - Comparação da velocidade média $u_{1}^{+}$em função de $x_{2}^{+}$(escala log) onde $R e_{\theta}=1006$ para $C_{\mathrm{W}}=$ $0,0.325$ e 0.5 .

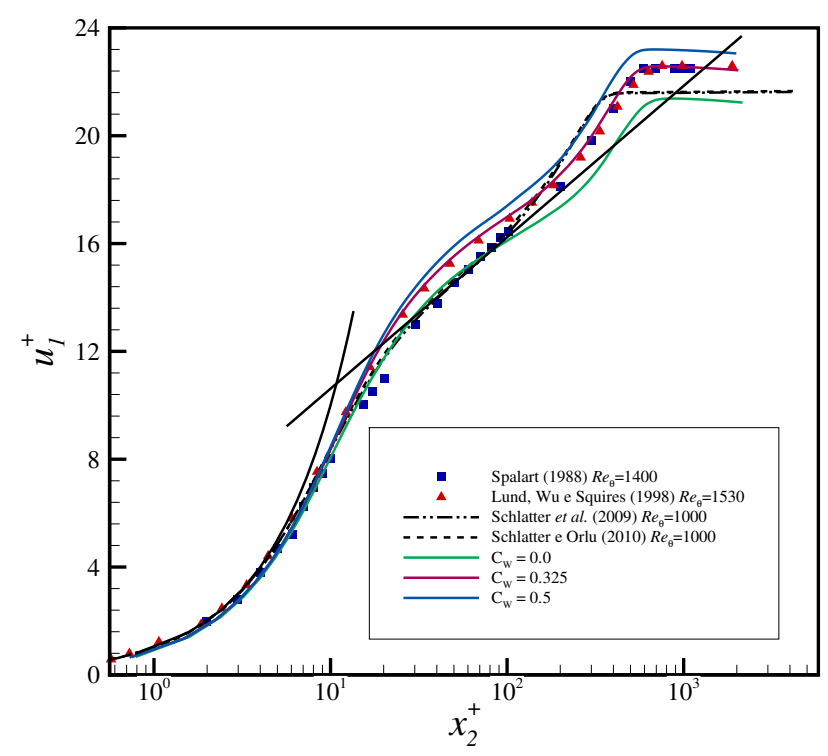

Fonte: Elaborada pelo autor.

modelagem submalha $\left(C_{\mathrm{W}}=0\right)$ apresenta um acúmulo de energia, que confirma que o esquema numérico implementado é bastante não dissipativo, que é uma características desejada para códigos numéricos para simulação de escoamentos. Os resultados melhoram gradativamente com o aumento dos valores de $C_{\mathrm{W}}$.

Em geral, nota-se que o modelo WALE fornece a distribuição correta da viscosidade turbulenta na direção normal a parede $-v_{t}$ assume naturalmente valor zero na vizinhança da placa placa sem a necessidade de um procedimento dinâmico ou de funções de amortecimento. $C_{\mathrm{W}}=$ 0.5 produziu a quantidade mais adequada de dissipação, sendo que isso é notado principalmente nos resultados para os componentes do tensor de Reynolds. Dessa maneira, nas próximas simulações assume-se o valor 0.5 para a constante $C_{\mathrm{W}}$ presente no modelo submalha WALE. Ainda, buscando alcançar melhoria nos resultados e mostrar a dependência de malha do método numérico, a próxima seção investiga o efeito do refinamento de malha em simulações de camada limite turbulenta.

\subsection{Estudo de convergência de malha}

Esta seção investiga o impacto da resolução espacial para as simulações LES de escoamentos turbulentos em placa plana realizadas nesse trabalho. 
Figura 11 - Comparação dos componentes do tensor de Reynolds em função de $\frac{x_{2}}{\delta}$ onde $R e_{\theta}=1006$ para $C_{\mathrm{W}}=$ $0,0.325$ e 0.5 . $\delta$ é a espessura da camada limite local.

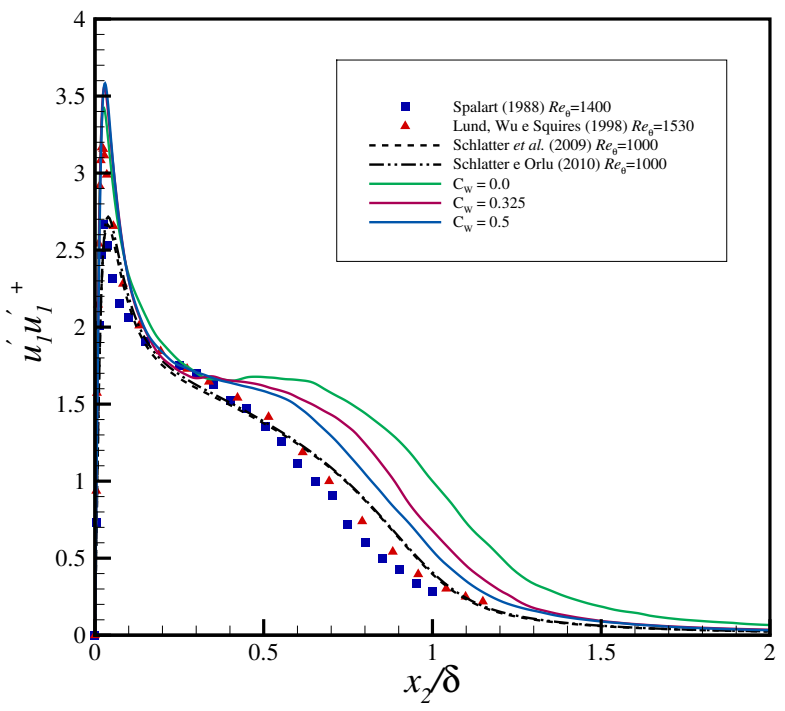

(a)

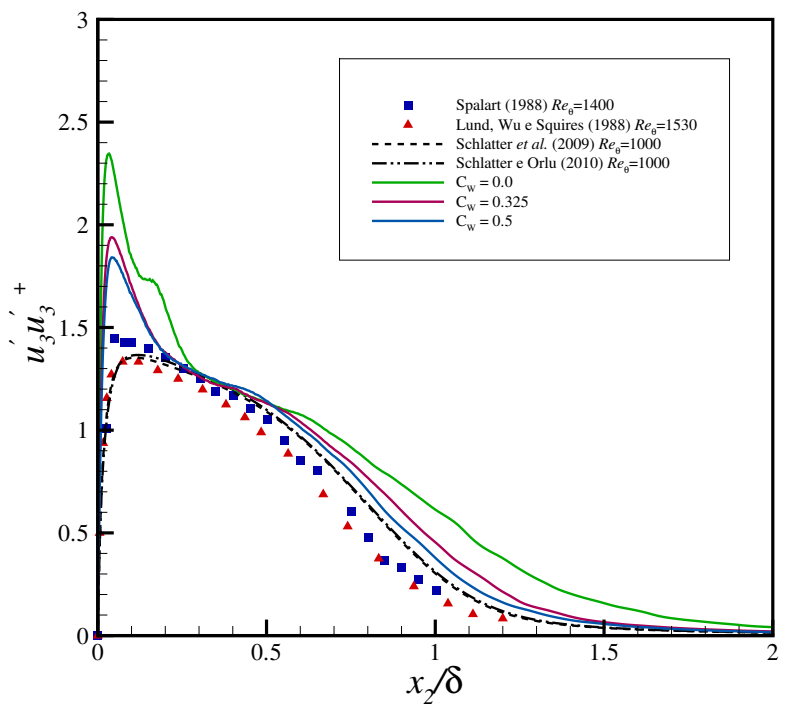

(c)

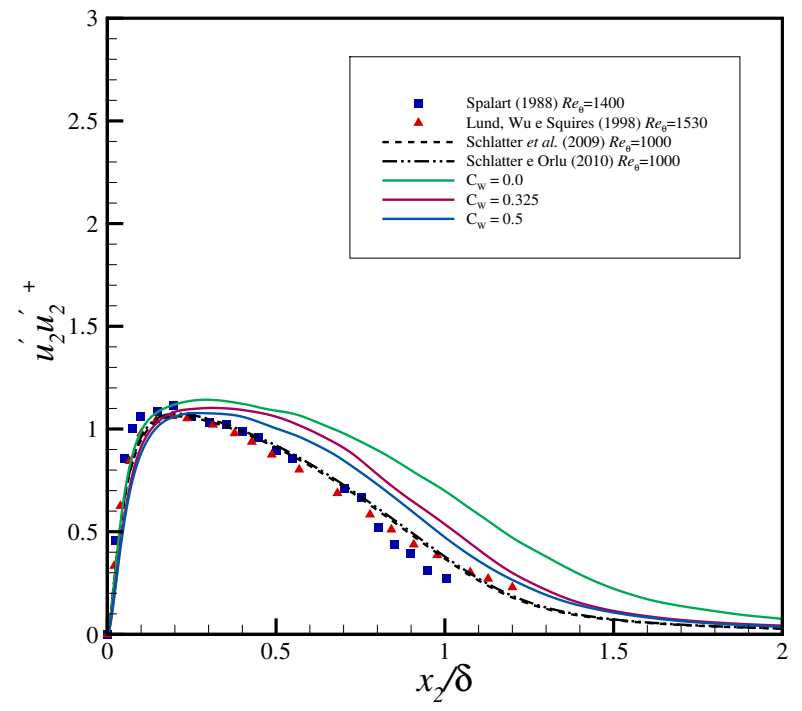

(b)

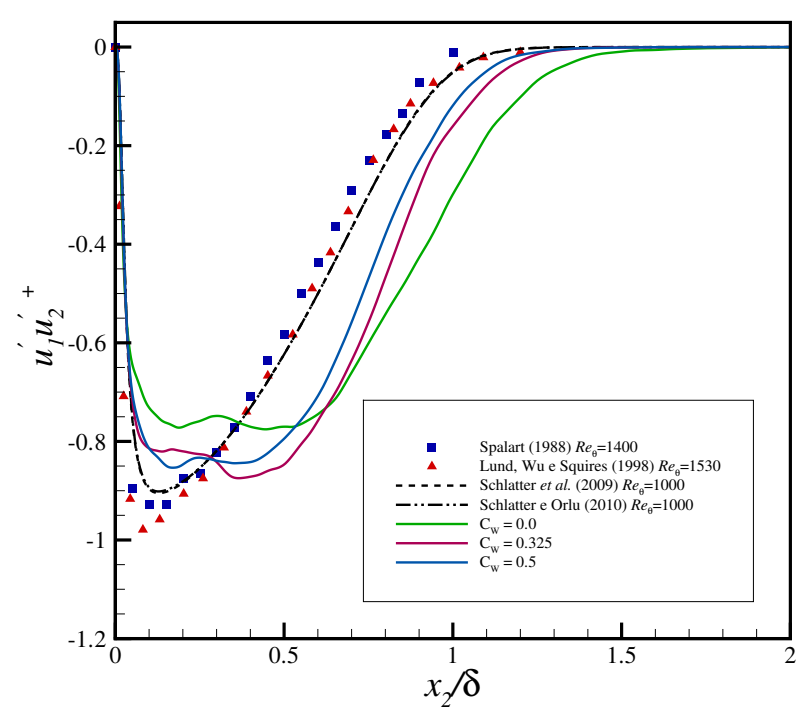

(d)

Fonte: Elaborada pelo autor. 


\subsubsection{Resolução transversal}

Como explicitado na Seção 4.1, aproveitando da condição de periodicidade transversal, esse estudo adota um método espectral para a resolução das equações governantes nessa direção. Como a turbulência é um fenômeno que apresenta enorme quantidade de escalas, talvez o número de modos de Fourier tenha importância relevante na precisão nos resultados numéricos.

Dessa forma, a qualidade dos resultados é testada através do refinamento da resolução na direção transversal, ou seja, com o aumento do número de modos de Fourier $(K)$ adotados no método espectral. Para tanto, duas simulações de camada limite em placa plana são realizadas onde considera-se dois valores distintos para o número total de modos Fourier - $K=11$ e $K=21$, onde os respectivos pontos no espaço físico são 32 e 64 . Adota-se $C_{w}=0.5$ como constante do modelo submalha WALE. Os domínios computacionais são igualmente discretizados usando 2875 e 385 pontos na direção longitudinal $\left(x_{1}\right)$ e normal $\left(x_{2}\right)$ do escoamento, respectivamente. $\mathrm{Na}$ direção $x_{1}$, a malha é uniforme com espaçamento $\Delta_{x_{1}}=1 \times 10^{-3}$. Já na na direção $x_{2}$, a malha é estirada com espaçamento inicial de $\Delta_{x_{2}}=1 \times 10^{-4}$ e stretching de $0.7 \%$. Considera-se um passo de tempo de $\Delta_{t}=5 \times 10^{-5}$. A velocidade de referência, a viscosidade e o tamanho característico da placa são $U_{\infty}=26 \mathrm{~m} / \mathrm{s}, v=1.55 \times 10^{-5} \mathrm{~m}^{2} / \mathrm{s}$ e $L=0.1 \mathrm{~m}$, respectivamente. Esta combinação de parâmetros garante uma faixa de $\operatorname{Re}_{\theta}$ entre 400 e 1200 não muito próximo da entrada e nem da saída do domínio computacional. Para a geração de condições iniciais turbulentas, além de $N=1000$ considera-se o tempo característico da turbulência $\tau=10^{-4}$ como parâmetro de entrada para o método RGF.

A Fig. 12 mostra o perfil de velocidade média normalizado pela velocidade de cisalhamento local obtido para $R e_{\theta} \approx 1000$ juntamente com os dados DNS de Spalart (1988) e Schlatter e Orlu (2010), e, as simulações LES de Lund, Wu e Squires (1998) e de Schlatter et al. (2009). As discrepâncias para $K=11$ são evidentes aqui. Isso confirma que 11 modos de Fourier não são suficientes para resolver com precisão a turbulência gerada - há dissipação excessiva do perfil da velocidade a não ser na região onde o escoamento é predominantemente laminar $\left(x_{2}^{+}<5\right)$. Em contrapartida, a simulação com $K=21$ reproduziu com melhor fidelidade a média da velocidade $u_{1}$, apenas mostrando pequena superpredição na região logarítmica $\left(x_{2}^{+}>30\right)$. Vale ressaltar, que essa discrepância vem diminuindo com a evolução da simulação numérica.

As tensões de Reynolds obtidas para $R e_{\theta}=1000$ são comparados com as simulações DNS e LES adotados como referência na Fig. 13.

Como pode ser visto na Fig. 13, as simulações com $K=21$ recuperam com precisão as flutuações junto a parede, diferentemente do que pode ser observado para $K=11$, onde um deslocamento do perfil nessa região é constatado. Além disso, ambas as simulações apresentam superestimação do pico máximo dos perfis de $u_{1}^{\prime} u_{1}^{\prime+}$ (Fig.13 (a)) e $u_{3}^{\prime} u_{3}^{\prime+}$ (Fig.13 (c)). Provavelmente, a malha utilizada não é ainda suficientemente refinada para capturar o fenômeno com total fidelidade, e isso se torna mais perceptível na região onde acontecem as grandes flutuações. 
Figura 12 - Velocidade média $u_{1}^{+}$em função de $x_{2}^{+}$(escala $\log$ ) onde $R e_{\theta} \approx 1000$ para diferentes resoluções na direção transversal.

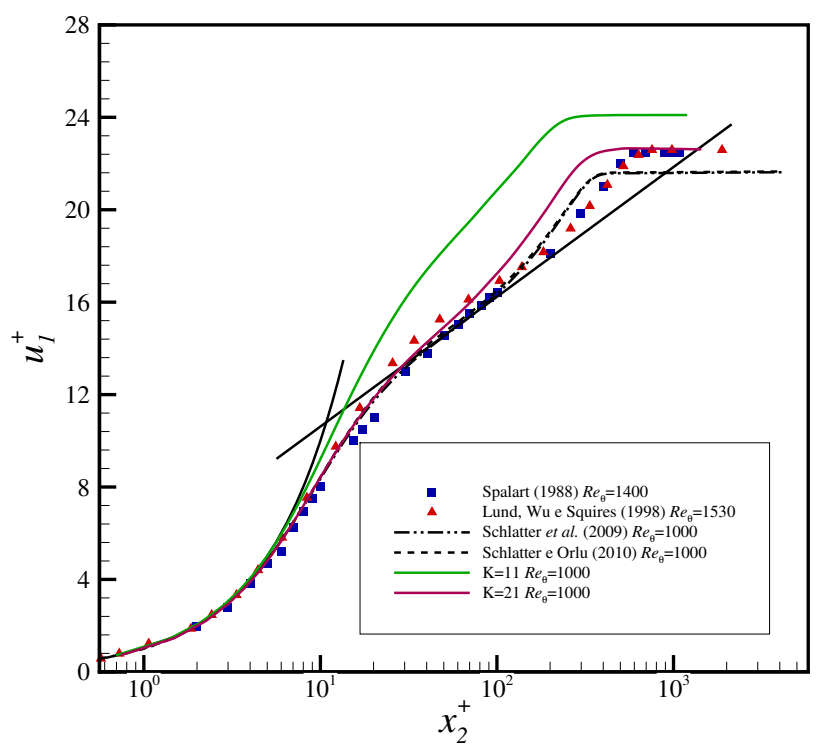

Fonte: Elaborada pelo autor.

Entretanto, é bastante claro que os melhores resultados são obtidos para a simulação com maior resolução na direção transversal.

As flutuações da componente de velocidade normal à parede $u_{2}^{\prime} u_{2}^{\prime+}$ (Fig.13 (b)) para $K=21$ mostram boa concordância com as soluções de referência especialmente com os dados de Spalart (1988).

\subsubsection{Resolução longitudinal e normal}

Para esse teste três malhas diferentes são consideradas:

- Malha 1: $\Delta_{x_{1}}=5 \times 10^{-3}$ e $\Delta_{x_{2}}=5 \times 10^{-4}$ (grossa).

- Malha 2: $\Delta_{x_{1}}=2.5 \times 10^{-3}$ e $\Delta_{x_{2}}=2.5 \times 10^{-4}$ (intermediária).

- Malha 3: $\Delta_{x_{1}}=1 \times 10^{-3}$ e $\Delta_{x_{2}}=1 \times 10^{-4}$ (fina).

Devido as deficiências encontradas nos resultados da Subseção 5.2.1 para $K=11$, todas as simulações assumem 21 modos de Fourier e 64 pontos no espaço físico na direção transversal. $C_{\mathrm{W}}=0.5$.

A quantidade de pontos computacionais nas direções $x_{1}$ e $x_{2}$ para as malhas 1,2 e 3 são, respectivamente, $837 \times 225,1129 \times 313,2825 \times 385$. Em todas as simulações, o estiramento 
Figura 13 - Componentes do tensor de Reynolds em função de $\frac{x_{2}}{\delta}$ para $R e_{\theta}=1000$ e diferentes resoluções na direção transversal. $\delta$ é a espessura da camada limite local.

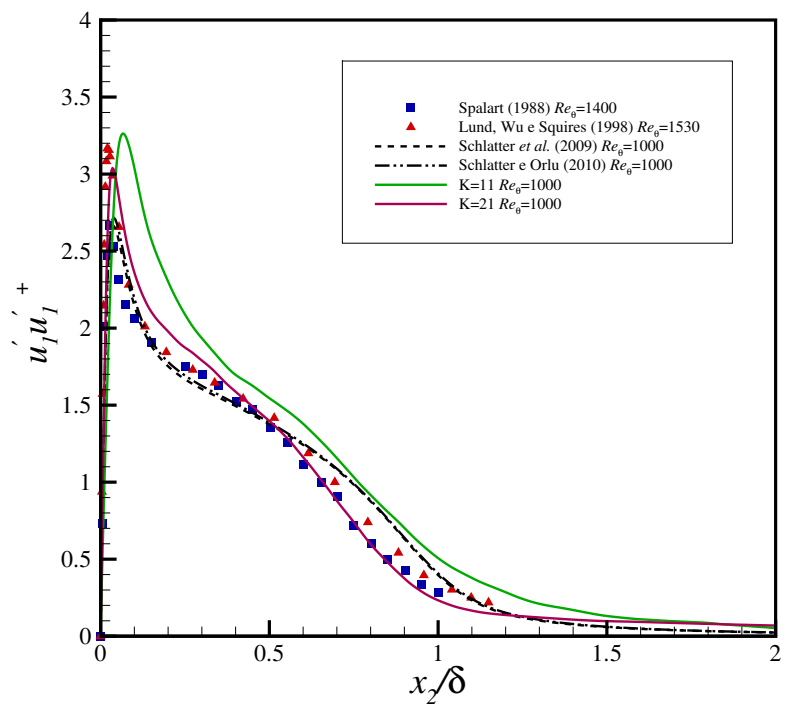

(a)

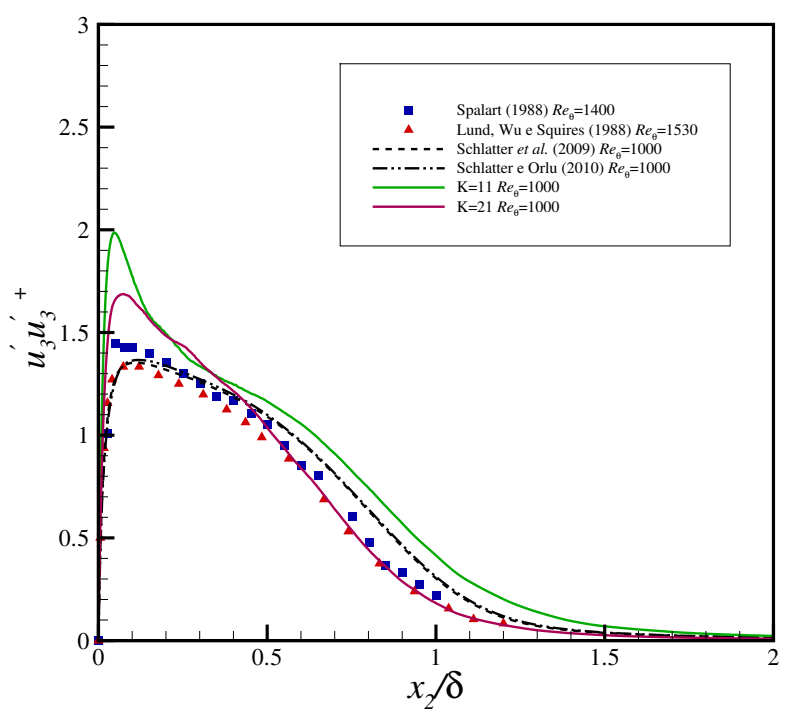

(c)

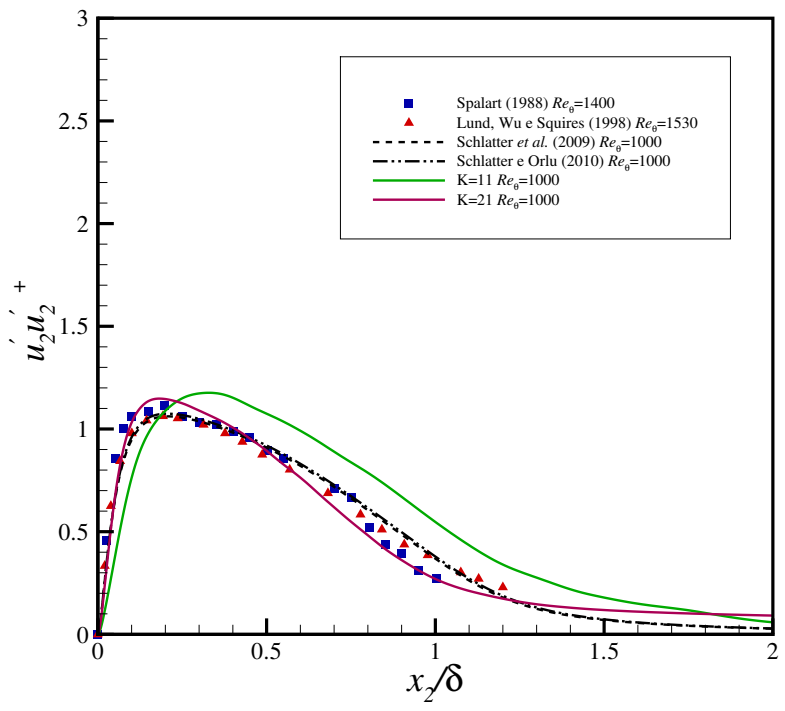

(b)

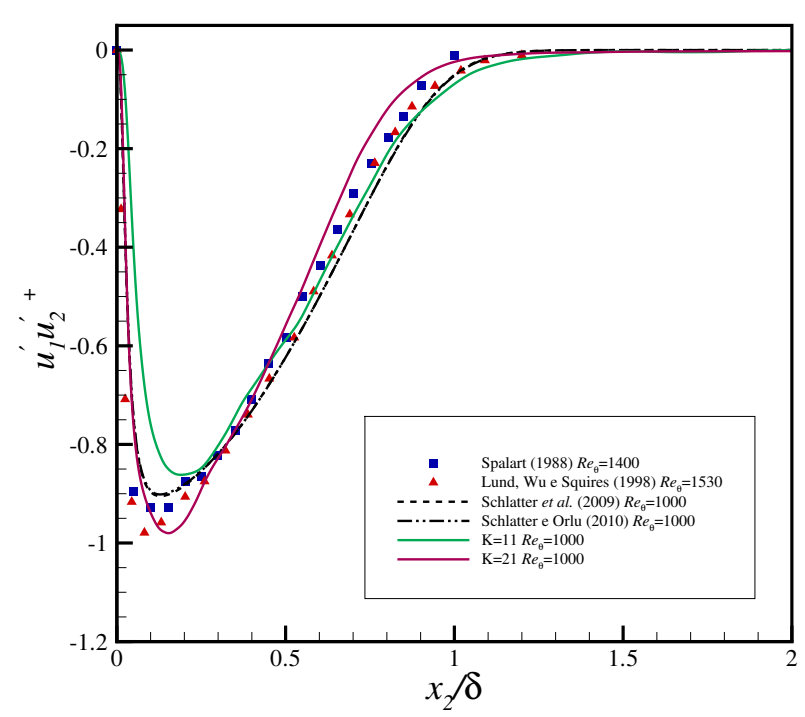

(d)

Fonte: Elaborada pelo autor. 
na direção direção normal é de $0.7 \%$ e passo temporal de $\Delta_{t}=10^{-5}$. Os parâmetros físicos comprimento de referência, velocidade do escoamento livre e viscosidade cinemática são os mesmos adotados nos testes acima $\left(L=0.1 \mathrm{~m}, U_{\infty}=26 \mathrm{~m} / \mathrm{s}\right.$ e $\left.v 1.55 \times 10^{-5} \mathrm{~m}^{2} / \mathrm{s}\right)$.

A Fig. 14 (a) ilustra a comparação do perfis de velocidade média para as 3 malhas adotadas. Uma ampliação da região próxima à parede é mostrada na Fig. 14.(b). $\mathrm{O} \operatorname{Re}_{\theta}$ alcançado é aproximadamente 1300 .

Observa-se que para as Malhas 1 (grossa), 2 (intermediária) e 3 (fina) os pontos iniciais na direção normal localizam-se em $x_{2}^{+} \simeq 4.3, x_{2}^{+} \simeq 2$ e $x_{2}^{+} \simeq 0.7$, respectivamente. É evidente a melhora significativa dos resultados numéricos com o refinamento da malha. De fato, o cálculo preciso dos gradientes de velocidade próximo a parede é somente possível se uma resolução computacional suficientemente fina é usada para capturar estruturas fortemente anisotrópicas presentes nessa região. De acordo com a literatura (PIOMELLI; BALARAS, 2002, SAGAUT, 2006), para representar adequadamente tais estruturas em simulações LES, o primeiro ponto de malha na direção normal deve ser localizado em $x_{2}^{+}<1$.

Figura 14 - Velocidade média $u_{1}^{+}$em função de $x_{2}^{+}$(escala $\log$ ) onde $R e_{\theta} \approx 1300$ para 3 diferentes malhas computacionais.

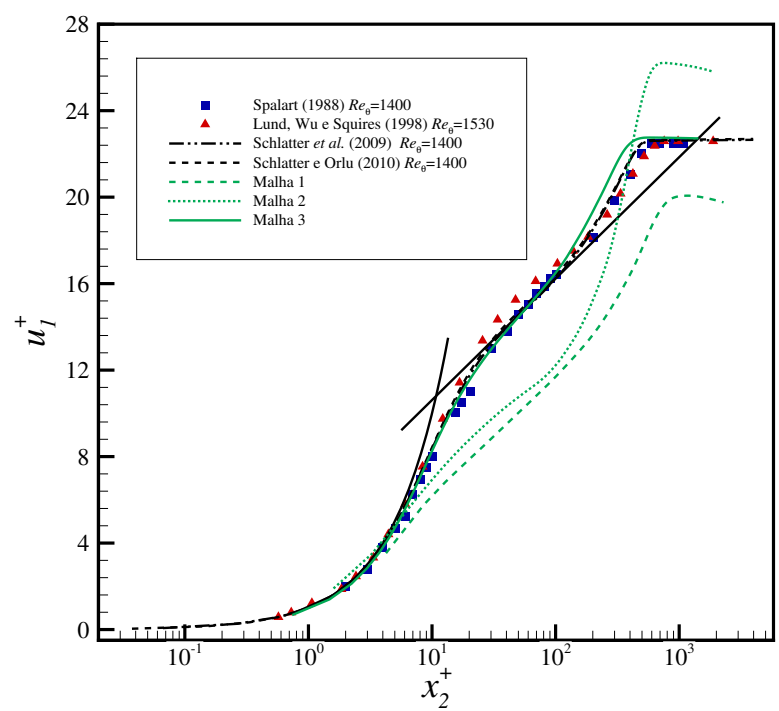

(a)

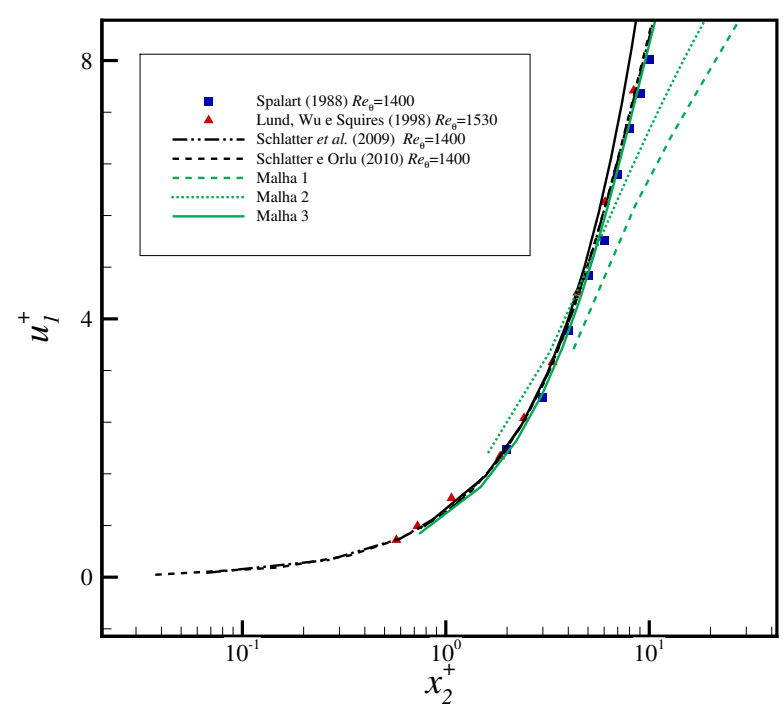

(b)

Fonte: Elaborada pelo autor.

Com o engrossamento da malha, a solução filtrada final é mais afetada pela modelagem submalha. Para investigar se o modelo submalha é o responsável pela má qualidade dos resultados para as Malhas 1 e 2 mostrados na Fig. 14 (onde $C_{\mathrm{W}}=0.5$ ), a Fig. 15 apresenta um comparação dos perfis de velocidade média para vários valores da constante do modelo WALE: $C_{\mathrm{W}}=0$, 0.104, 0.325 e 0.5. As Figs. 15 (a) e (b) apresentam os resultados para a Malha 1 (grossa) e 
Malha 2 (intermediária), respectivamente. Constata-se claramente que a modelagem submalha não é a responsável pela falta de precisão observada nos resultados sob investigação - não há diferença significativa entre os perfis de velocidade para diferentes valores de $C_{\mathrm{W}}$ para as duas malhas adotadas, inclusive onde não há modelagem submalha $\left(C_{\mathrm{W}}=0\right)$. Isso certamente ocorre devido ao cálculo inadequado da velocidade na parede que é decorrente da resolução computacional considerada. Além disso, a qualidade dos resultados também é prejudicada pela adimensionalização utilizada para a obtenção dos perfis mostrados.

Figura 15 - Comparação dos perfis de velocidade média $u_{1}^{+}$em função de $x_{2}^{+}$(escala log) para diferentes valores da constante $C_{\mathrm{W}}$ do modelo submalha WALE.

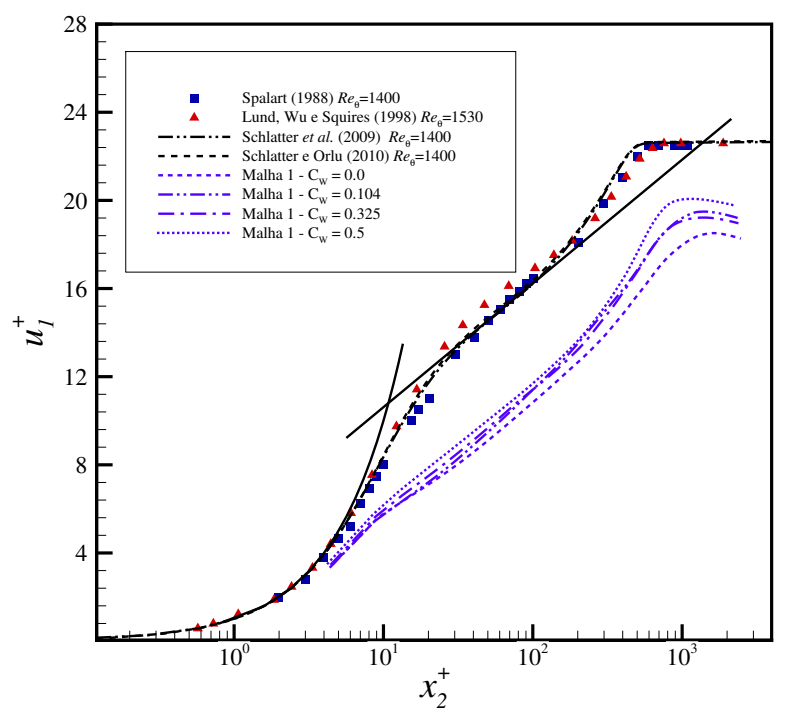

(a) Malha 1

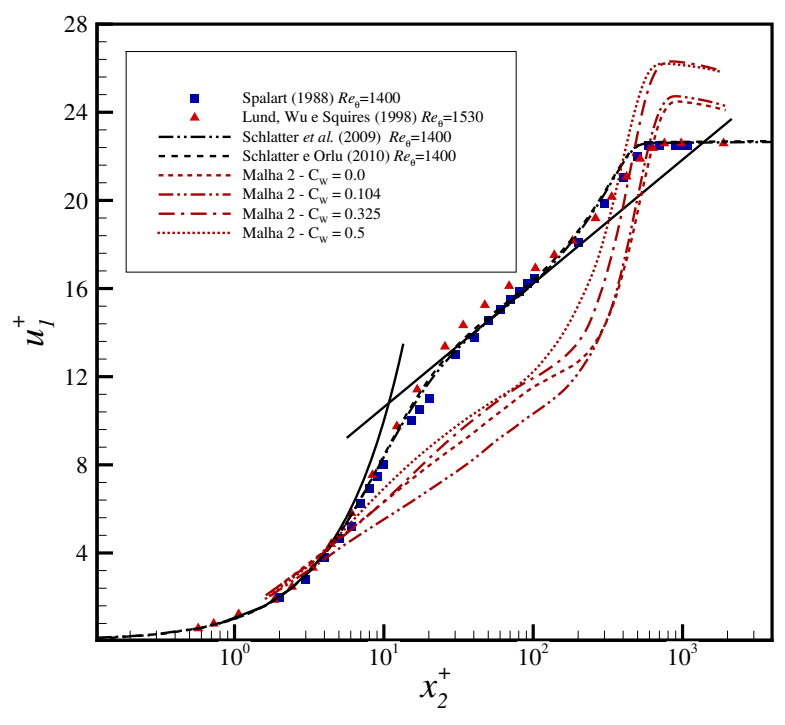

(b) Malha 2

Fonte: Elaborada pelo autor.

\subsection{Influência das condições iniciais}

Após a melhora significativa na qualidade dos resultados com o refinamento da resolução computacional é interessante investigar qual o impacto da variação do parâmetro de entrada $\tau$ na reprodução das condições iniciais turbulentas pelo método RFG. Para tanto, considera-se a resolução da Malha 3 (fina) em virtude da maior precisão alcançada nos testes anteriores.

\subsubsection{O parâmetro $\tau$}

A escala de tempo da turbulência, $\tau$, é um parâmetro de entrada que deve ser fornecido para o algoritmo RFG para geração das condições inciais turbulentas utilizado nesse trabalho. De acordo com Huang, Li e Wu (2010), esse parâmetro pode ser estimado através de dados 
experimentais, o que é uma tarefa bem difícil. Dessa forma, na presente subseção, vários valores de $\tau$ são avaliados para a geração adequada de pertubações para simulações de camada limite em placa plana dessa pesquisa. Vale destacar, que nenhuma simulação de escoamento foi realizada, apenas foram geradas consecutivas pertubações de velocidade pelo algoritmo RFG.

O isocontorno do campo de flutuações e o monitoramento temporal da pertubação $u_{1}^{\prime}$ em um ponto fixo do domínio, obtidos com diferentes valores de $\tau$, são mostrados nas Figs. 16 e 17. Cinco valores para a escala de tempo da turbulência são adotados: $\tau=10^{-2}, \tau=10^{-3}$, $\tau=10^{-4}, \tau=10^{-5}$ e $\tau=10^{-6}$. Para a visualização da variação temporal da pertubação na direção longitudinal são considerados 30000 iterações. Observa-se que a variação de $\tau$ altera o comprimento e a frequência das flutuações de velocidade geradas randomicamente pelo método RFG. Quanto maior o $\tau$, maiores as escalas de tempo e comprimento do sinal gerado. Entretanto, nota-se claramente a redução do tamanho dos vórtices e o aumento da frequência da pertubação de velocidade com a diminuição de $\tau$.

\subsubsection{A influência do parâmetro $\tau$}

Essa seção investiga o impacto causado por diferentes valores de $\tau$, que conduzem a geração de flutuações de velocidade com escalas de tempo e comprimento diferentes, na metodologia numérica proposta para a simulação de camada limite em placa plana que estão sendo realizadas nessa pesquisa.

Para tanto, foram adotados quatro valores de escala de tempo da turbulência para o método RFG: $\tau=10^{-3}, \tau=10^{-4}, \tau=10^{-5}$ e $\tau=10^{-6}$. Os parâmetros físicos são os mesmos utilizados nas seções anteriores. Em ambas as simulações, a malha computacional contém $2745 \times 385$ pontos nas direções longitudinal e normal, respectivamente, sendo considerados 21 modos de Fourier e 64 pontos no espaço físico na direção transversal. Os espaçamentos são $\Delta_{x_{1}}=1 \times 10^{-3}$ e $\Delta_{x_{2}}=1 \times 10^{-4}$ (inicial). Essa resolução computacional foi a mesma adotada para o teste com Malha 3 (mais refinada) realizado na Seção 5.2.2. Como nos outros testes, a malha na direção $x_{2}$ tem um stretching de $0.7 \%$. $\Delta_{t}=5 \times 10^{-5}$.

Os testes numéricos realizados para $\tau=10^{-3}$ e $\tau=10^{-6}$ não são mostrados aqui. De fato, a introdução das pertubações resultaram na não convergência do código numérico para $\tau=10^{-3}$ em virtude das grandes escalas de comprimento do sinal. Para $\tau=10^{-6}$, o escoamento permaneceu laminar devido ao tamanho insuficientemente das flutuações geradas.

A Fig. 18 apresenta os resultados numéricos para a velocidade média em duas posições longitudinais diferentes, mais especificante para valores de $R e_{\theta}=900$ (Fig. 18 (a)) e $R e_{\theta}=$ 1200 (Fig. 18 (b)). Para $R e_{\theta}=900$, as simulações usando tanto $\tau=10^{-4}$ quanto $\tau=10^{-5}$ produzem bons resultados quando comparados com as soluções de referência, apenas mostrando uma pequena superestimação da região exterior da camada limite. Em contraste, para uma posição mais a jusante do domínio $\left(R e_{\theta}=1200\right)$ (ver Fig. 18 (b)), os resultados para $\tau=10^{-5}$ 
Figura 16 - Isocontorno do campo inicial e monitoramento temporal da pertubação $u_{1}^{\prime}$ gerada pelo método RFG para diferentes valores de $\tau$.
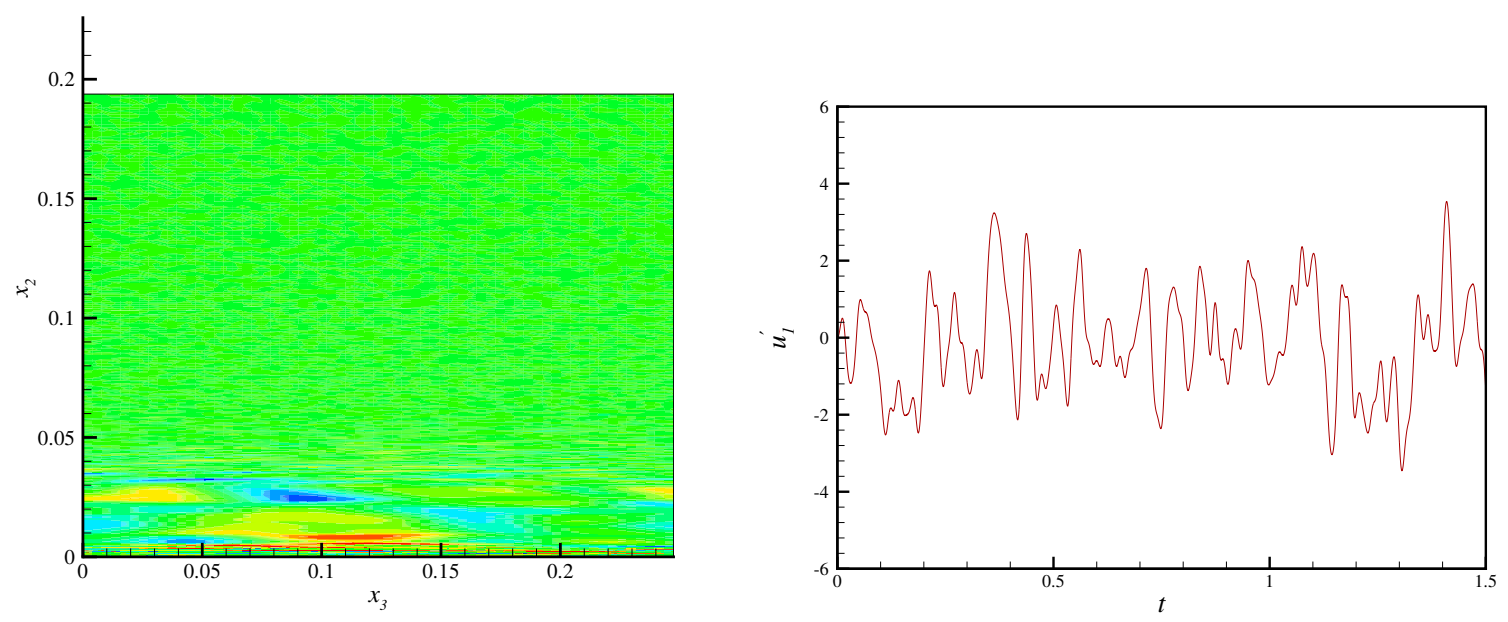

(a) $\tau=10^{-2}$
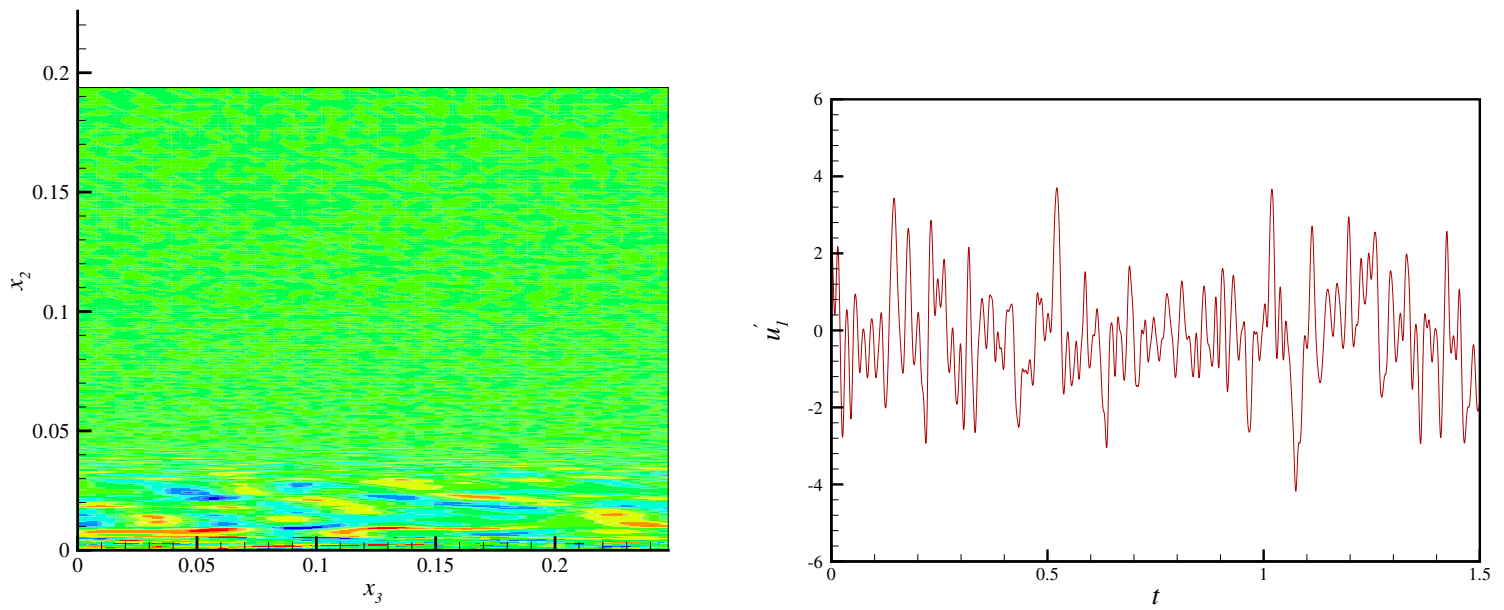

(b) $\tau=10^{-3}$
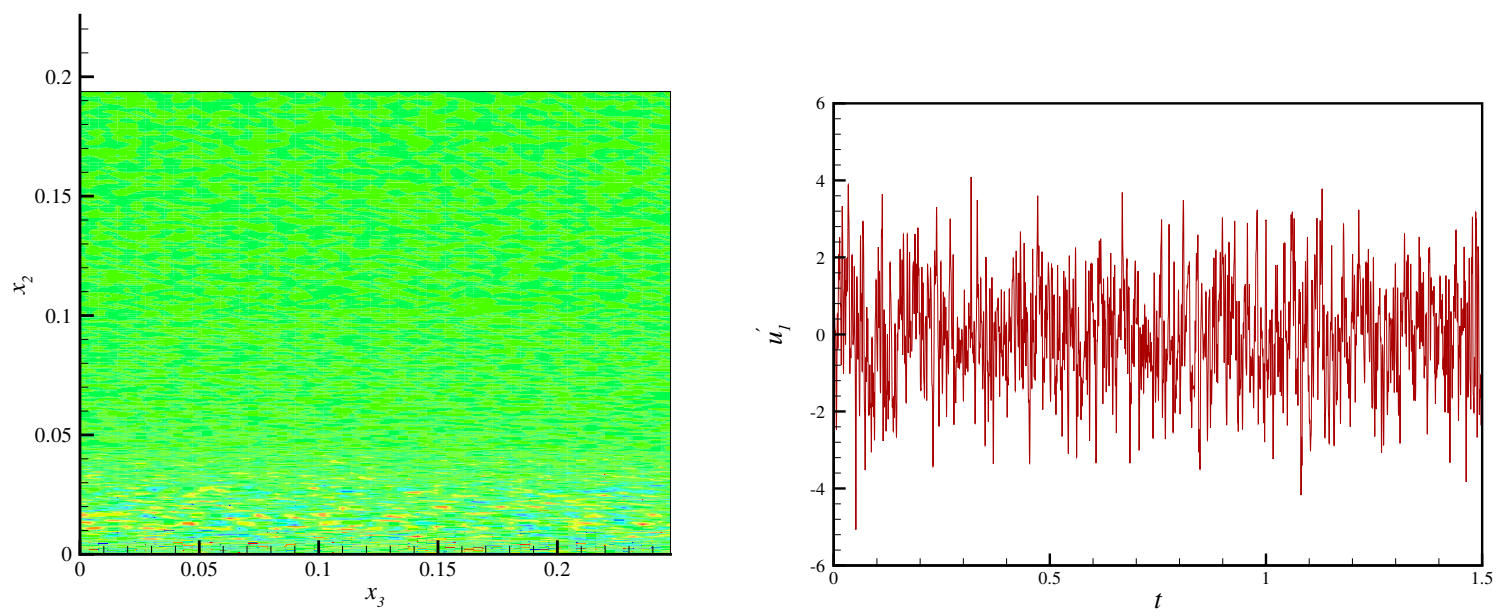

(c) $\tau=10^{-4}$

Fonte: Elaborada pelo autor. 
Figura 17 - Continuação: Isocontorno do campo inicial e monitoramento temporal da pertubação $u_{1}^{\prime}$ gerada pelo método RFG para diferentes valores de $\tau$.
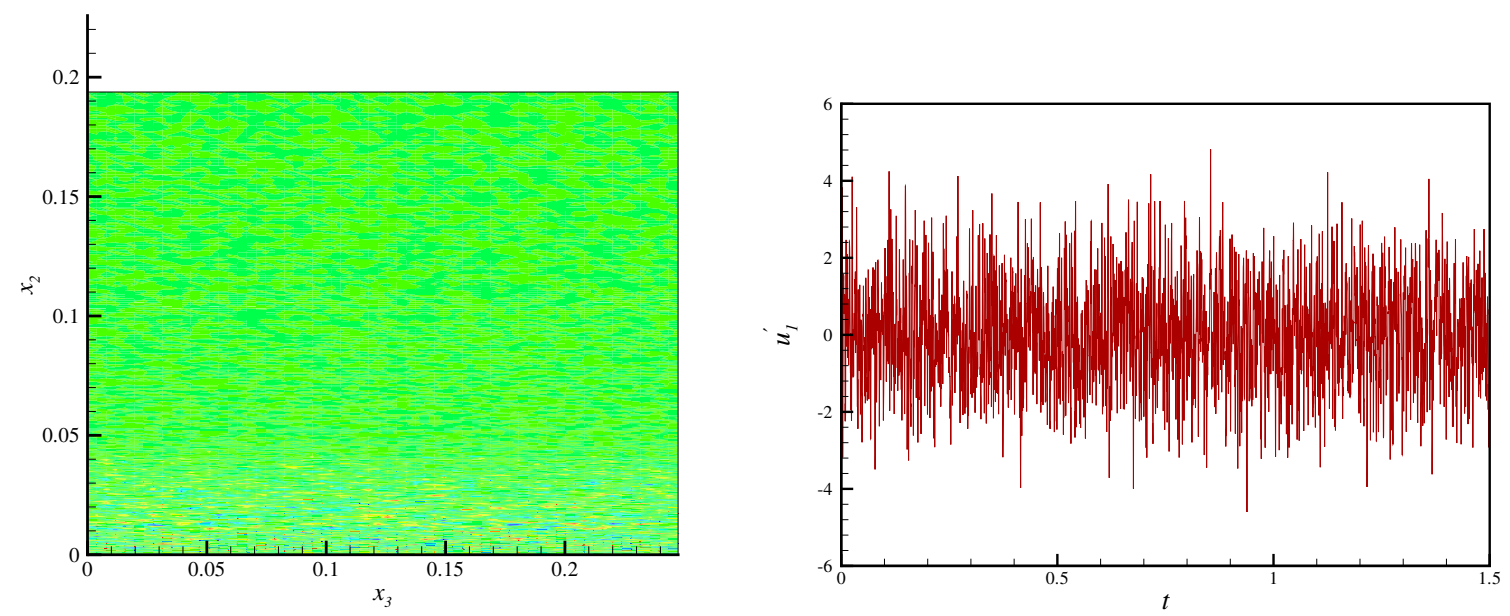

(d) $\tau=10^{-5}$
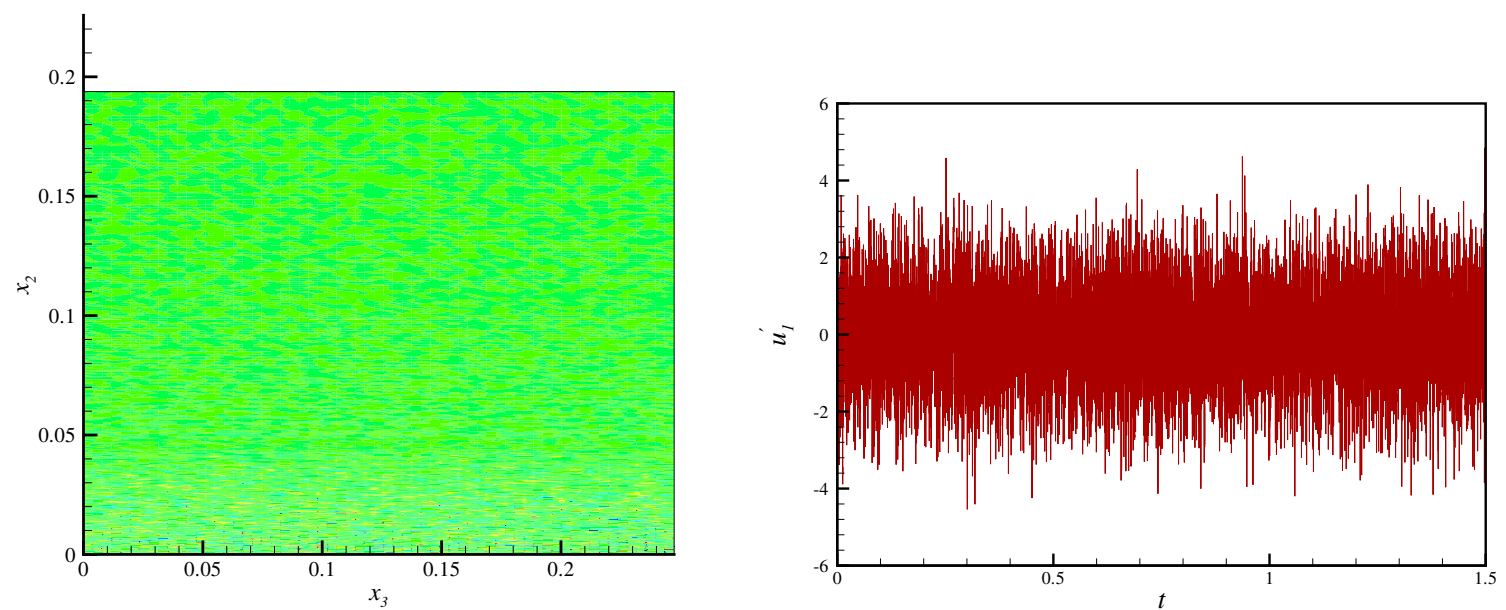

(e) $\tau=10^{-6}$

Fonte: Elaborada pelo autor. 
demonstram que o esquema numérico captura com bastante fidelidade o perfil de velocidade média, enquanto que a simulação usando $\tau=10^{-4}$ mostra uma grande sobrestimação do perfil.

A provável causa dessa discrepância é que a turbulência criada pela introdução das flutuações de velocidade com $\tau=10^{-4}$, onde a escala de comprimento é mais elevada, requer mais tempo para tornar-se totalmente desenvolvida em uma posição mais afastada da região de introdução de pertubações. Para ambas as simulações, o processo de média temporal $(<.>)$ levou em conta 90000 iterações no mesmo intervalo de tempo. Contudo, o perfil de velocidade média para $\tau=10^{-4}$ mostrou uma convergência muito mais lenta quando comparado aos dados obtidos para $\tau=10^{-5}$.

Figura 18 - Velocidade média $u_{1}^{+}$em função de $x_{2}^{+}$(log scale) para duas posições longitudinais $-R e_{\theta}=900 \mathrm{e}$ $\operatorname{Re}_{\theta}=1200$

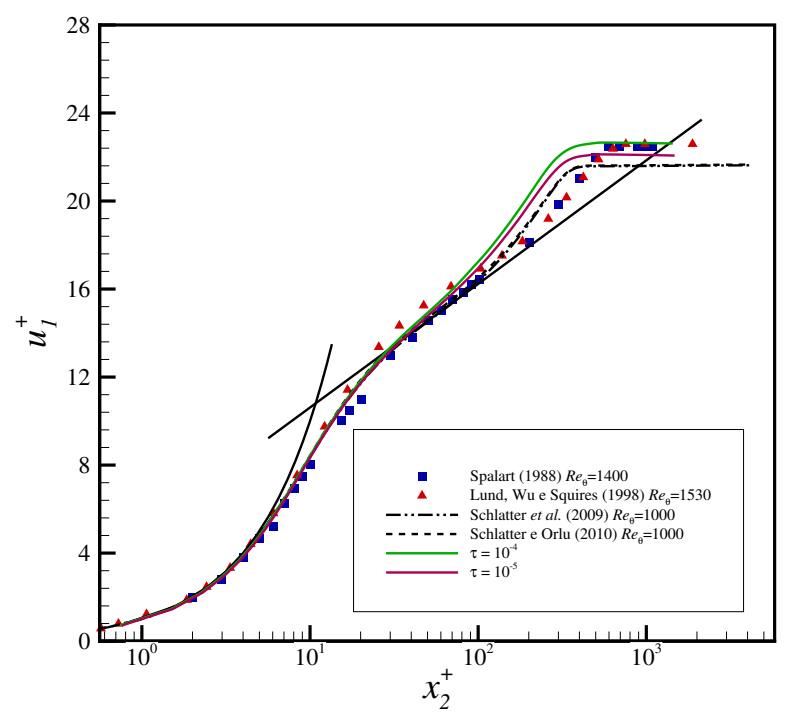

(a) $R e_{\theta}=900$

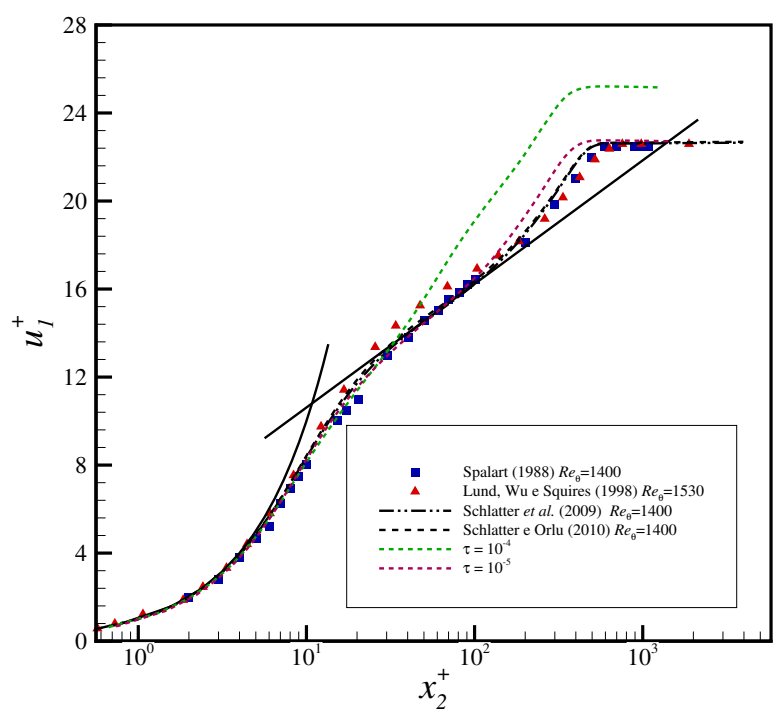

(b) $R e_{\theta}=1200$

Fonte: Elaborada pelo autor.

As estatísticas da camada limite em estudo extraídas em duas posições $x_{1}$ do domínio $\left(R e_{\theta}=900\right.$ e $\left.R e_{\theta}=1200\right)$ são apresentadas em detalhes nas Figs. 19, 20, 21 e 22, Para a posição mais a montante $\left(R e_{\theta}=900\right)$ há pouca diferença entre os perfis de $u_{1}^{\prime} u_{1}^{\prime+}, u_{2}^{\prime} u_{2}^{\prime+}$ e $u_{3}^{\prime} u_{3}^{\prime+}$ para os dois valores de $\tau$ considerados. Para o tensor de Reynolds $u_{1}^{\prime} u_{2}^{\prime+}$ um maior nível de turbulência é constatado para $\tau=10^{-4}$ (Fig. 22 (b)).

Para as estatísticas calculadas na segunda posição em $x_{1}\left(R e_{\theta}=1200\right)$ uma grande discrepância em comparação as soluções de referência é vista no perfil de $u_{1}^{\prime} u_{1}^{\prime+}$ para $\tau=10^{-4}$. Isto indica que a simulação está levando um tempo computacional maior para convergir para o estado totalmente turbulento. Quando adota-se $\tau=10^{-5}$, as flutuações $u_{2}^{\prime} u_{2}^{\prime+}$ (Fig. 20 (b)) e $u_{1}^{\prime} u_{2}^{\prime+}$ (Fig. 22 (b)) são muito bem reproduzidas, alcançando alta concordância com os dados 
DNS de Spalart (1988) e Schlatter e Orlu (2010). Além disso, também pode-se notar uma pequena superestimação do pico máximo para as flutuação $u_{1}^{\prime} u_{1}^{\prime+}$ (Fig. 19] e $u_{3}^{\prime} u_{3}^{\prime+}$ (Fig. 21). Como explicado anteriormente, essa disparidade perto da parede está associada a insuficiente resolução da malha próxima à parede que foi adotada para os cálculos.

Figura 19 - Componente $u_{1}^{\prime} u_{1}^{\prime+}$ do tensor de Reynolds em função de $\frac{x_{2}}{\delta}$ para duas posições longitudinais $-\operatorname{Re}_{\theta}=900$ e $R e_{\theta}=1200$. $\delta$ é a espessura da camada limite local.

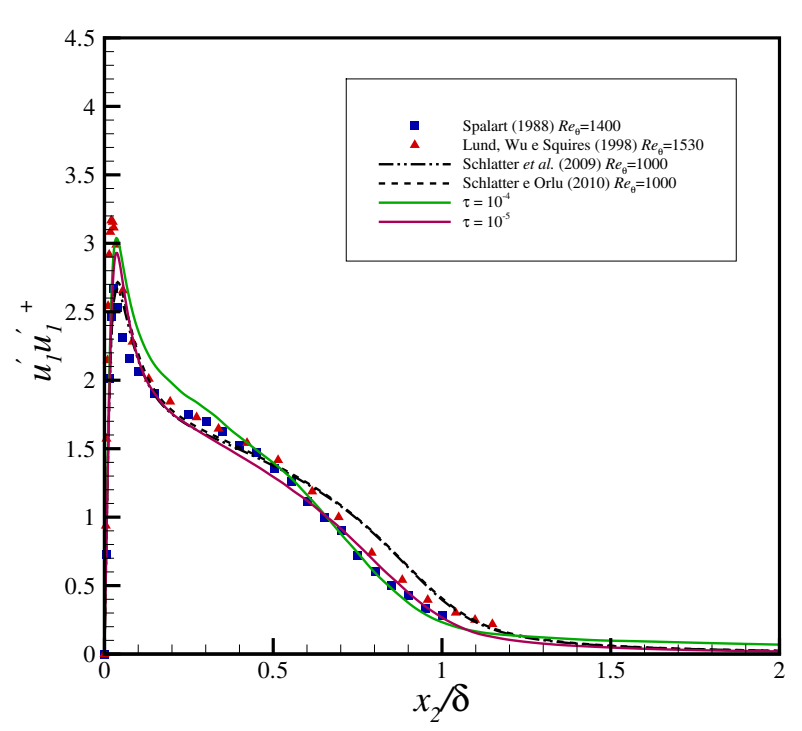

(a) $R e_{\theta}=900$

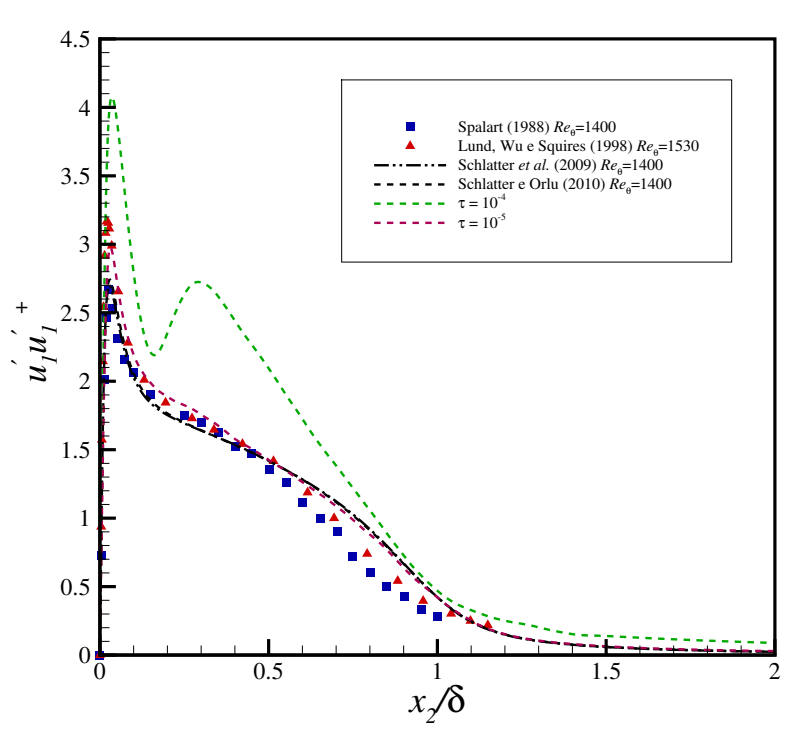

(b) $R e_{\theta}=1200$

Fonte: Elaborada pelo autor.

Uma das características mais importantes e que deve ver investigada em metodologia de simulação LES é a capacidade do modelo submalha adotado em produzir a distribuição correta do espectro de energia. De acordo com Kolmogorov, existe uma faixa nesse complexo mecanismo de transferência de energia em que o espectro de energia tem decaimento $-5 / 3$.

As Figs. 23 e 24 mostram o espectro de energia em função da frequência $(f)$ nas duas posições $x_{1}$ para cada umas das simulações, com $\tau=10^{-4}$ e $\tau=10^{-5}$, respectivamente. Para o cálculo da densidade espectral, os sinais de velocidade foram gravados em posições préselecionadas dentro da camada limite turbulenta. Para ambas as simulações foram considerados aproximadamente 90000 amostras temporais da velocidade $u_{1}$. Em todos os casos pode-se observar a existência da região subintervalo inercial que segue a lei de $-5 / 3$ de Kolmogorov. 
Figura 20 - Componente $u_{2}^{\prime} u_{2}^{\prime+}$ do tensor de Reynolds em função de $\frac{x_{2}}{\delta}$ para duas posições longitudinais $-R e_{\theta}=900$ e $\operatorname{Re}_{\theta}=1200$. $\delta$ é a espessura da camada limite local.

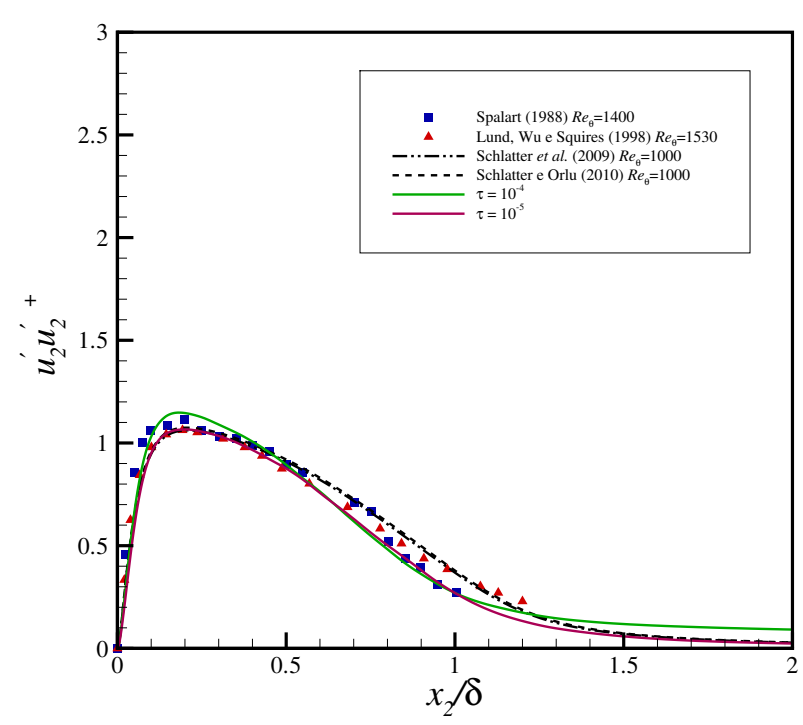

(a) $R e_{\theta}=900$

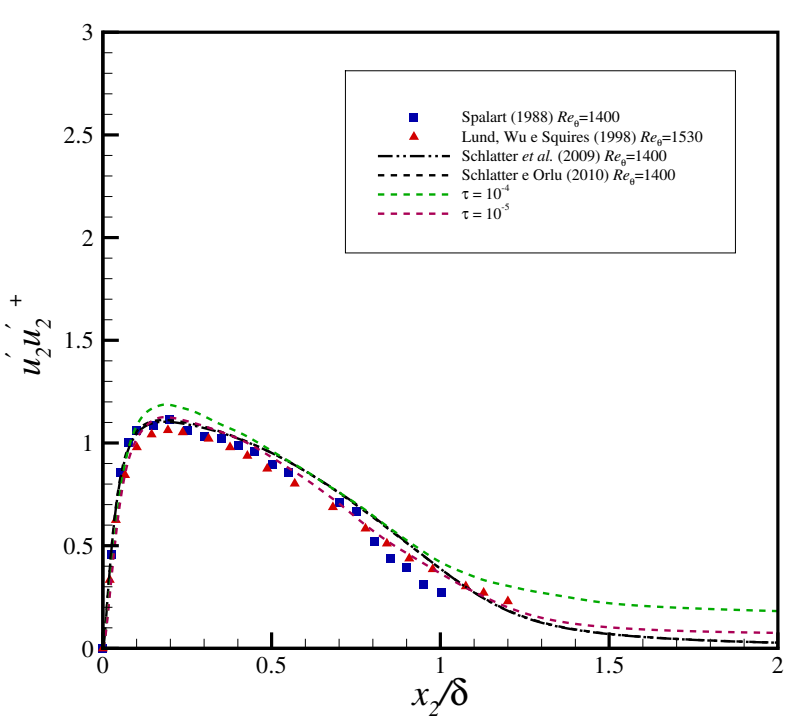

(b) $R e_{\theta}=1200$

Fonte: Elaborada pelo autor.

Figura 21 - Componente $u_{3}^{\prime} u_{3}^{\prime+}$ do tensor de Reynolds em função de $\frac{x_{2}}{\delta}$ para duas posições longitudinais $-R e_{\theta}=900$ e $R e_{\theta}=1200$. $\delta$ é a espessura da camada limite local.

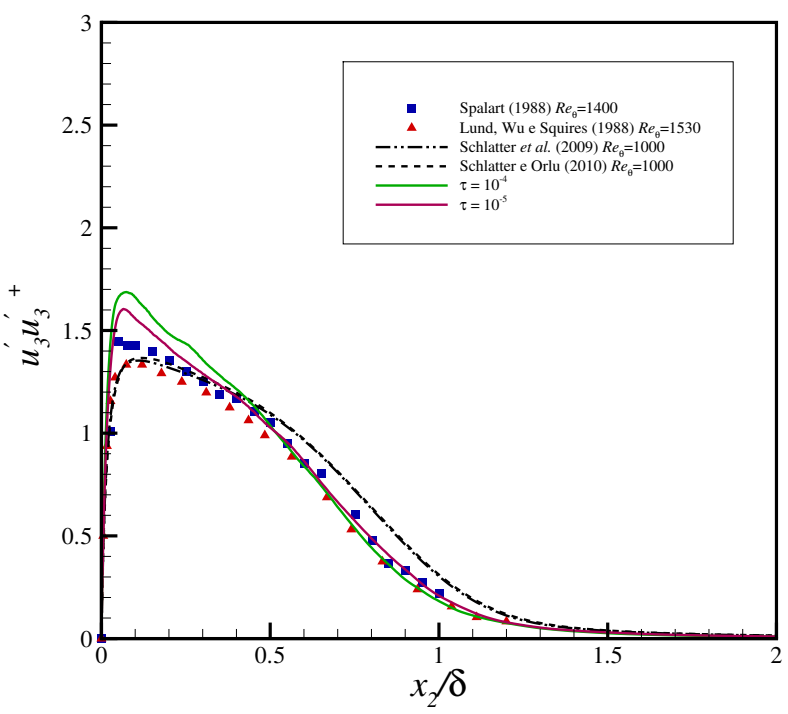

(a) $R e_{\theta}=900$

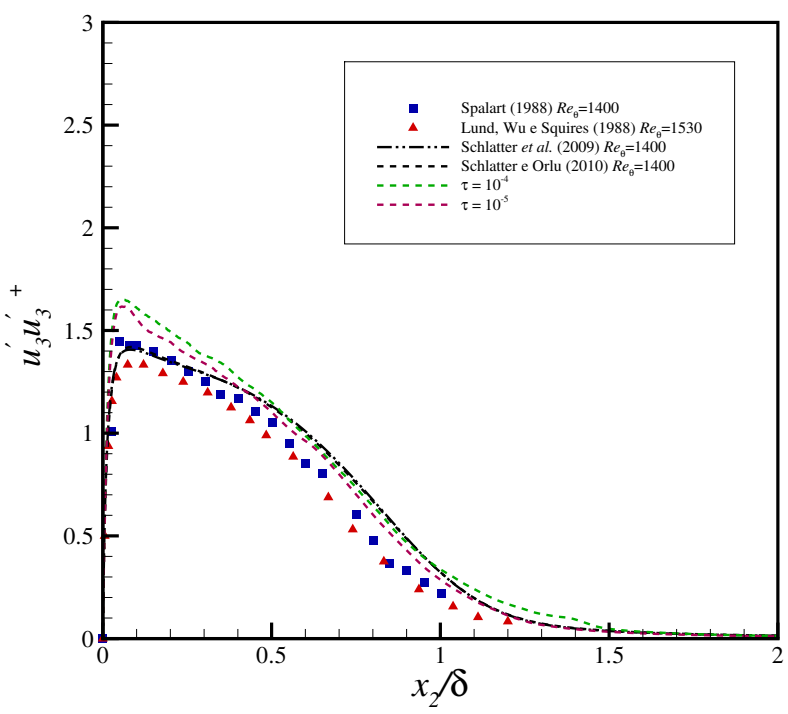

(b) $R e_{\theta}=1200$

Fonte: Elaborada pelo autor. 
Figura 22 - Tensor de Reynolds $u_{1}^{\prime} u_{2}^{\prime+}$ em função de $\frac{x_{2}}{\delta}$ para duas posições longitudinais $-R e_{\theta}=900$ e $R e_{\theta}=1200$. $\delta$ é a espessura da camada limite local.

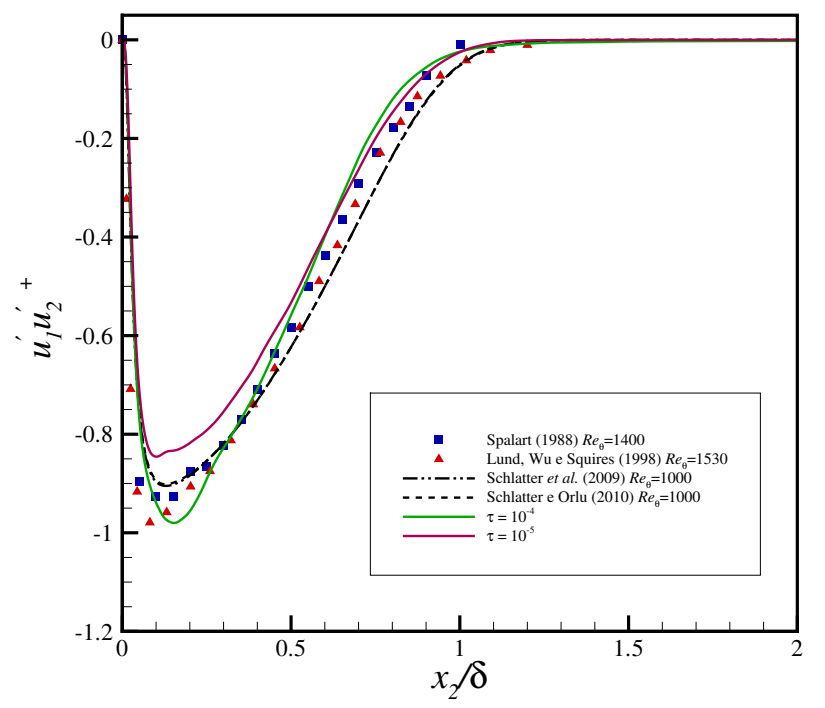

(a) $R e_{\theta}=900$

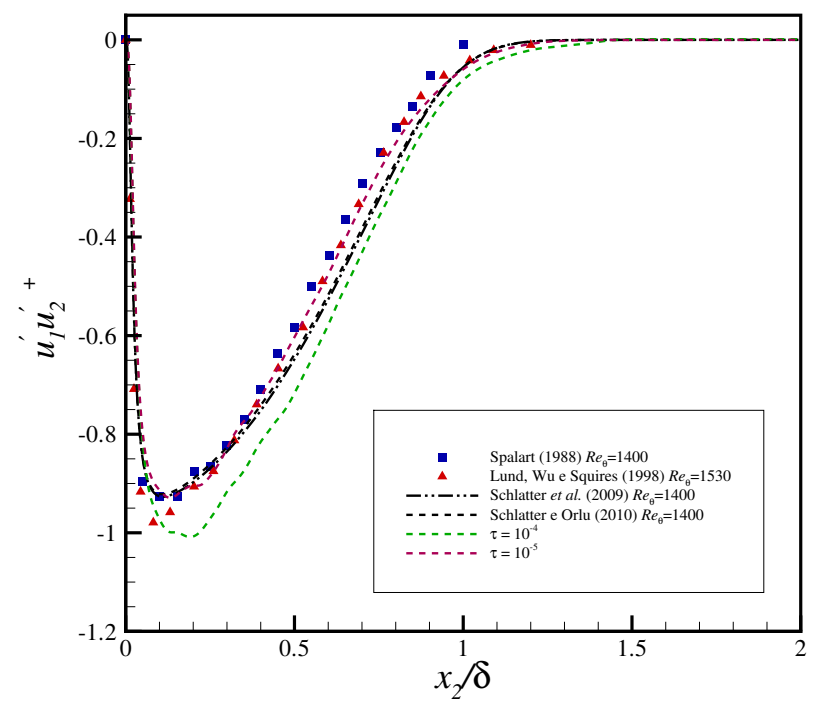

(b) $R e_{\theta}=1200$

Fonte: Elaborada pelo autor.

Figura 23 - Espectro de energia com função da frequência $(f)$ em duas posições dentro camada limite onde foi adotado $\tau=10^{-4}$ como parâmetro para o método RFG.

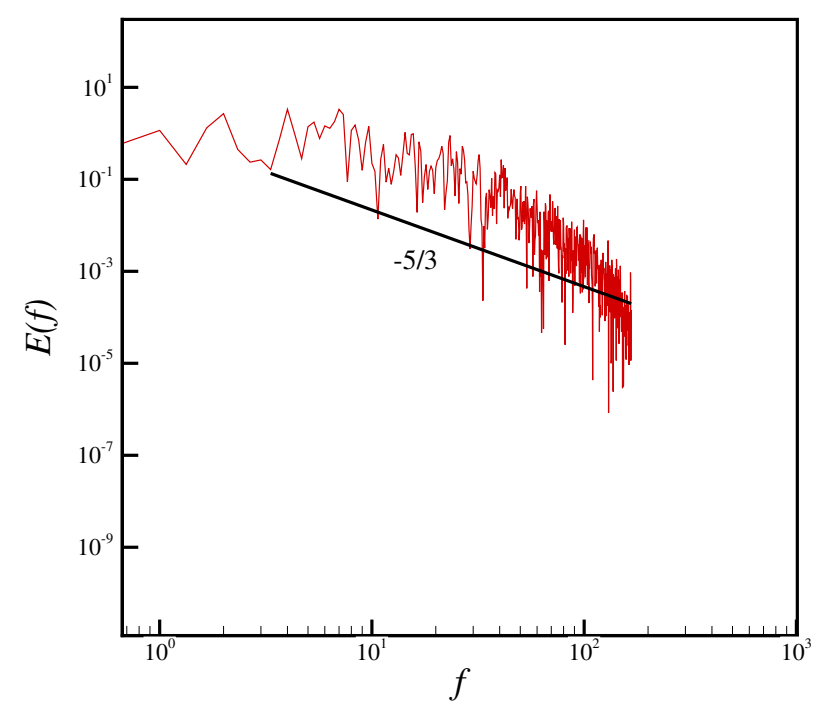

(a)

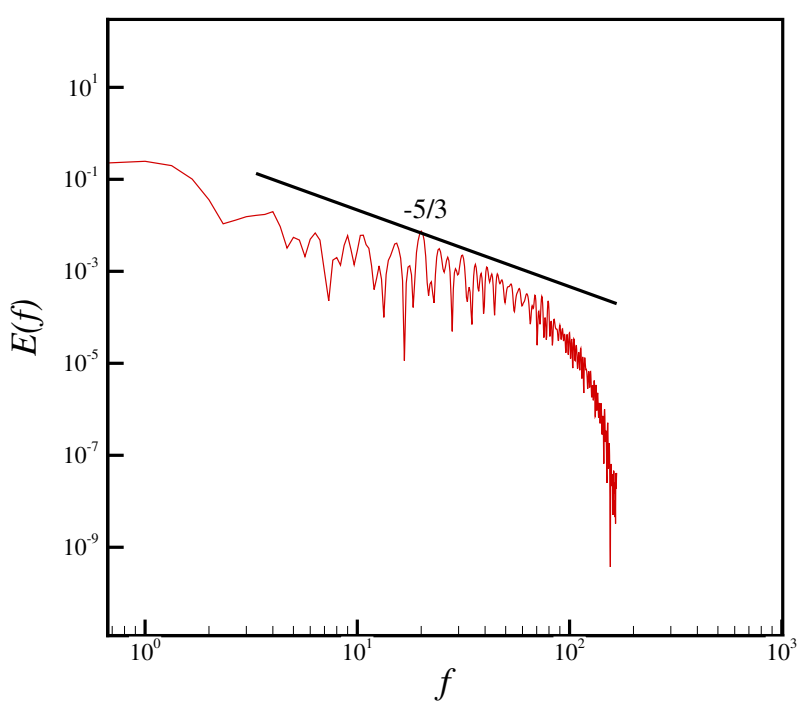

(b)

Fonte: Elaborada pelo autor. 
Figura 24 - Espectro de energia com função da frequência $(f)$ em duas posições dentro camada limite onde foi adotado $\tau=10^{-5}$ como parâmetro para método RFG.

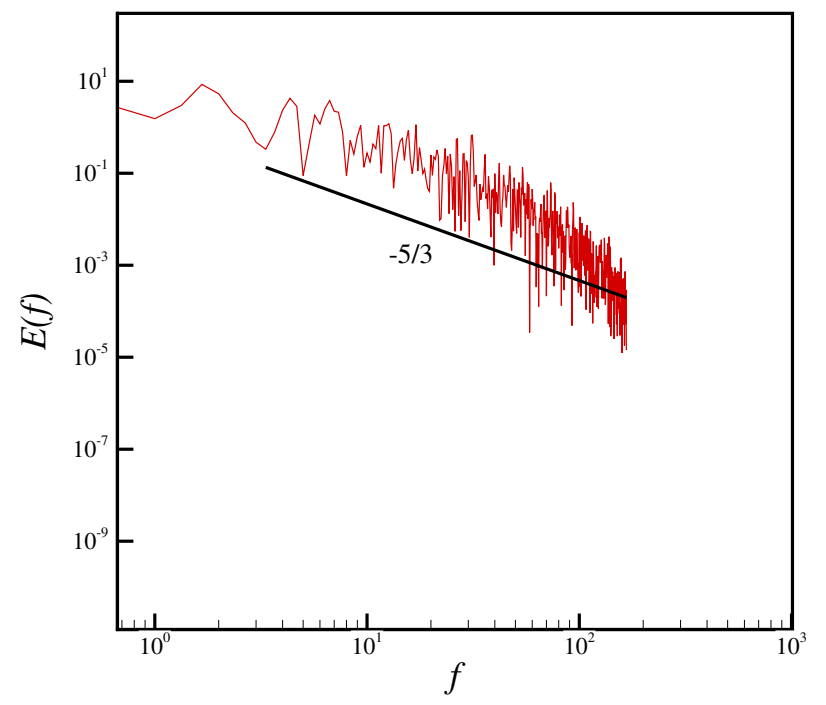

(a)

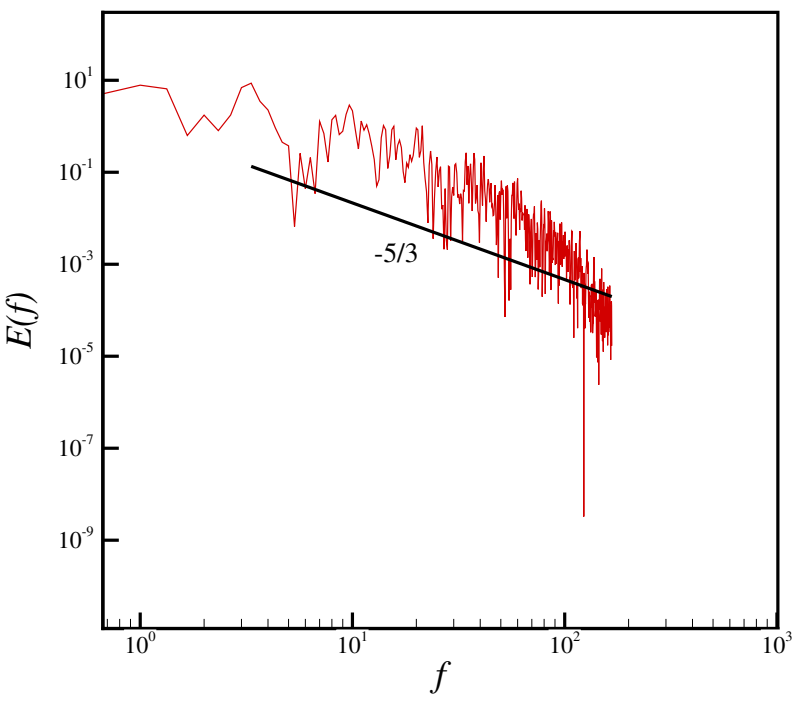

(b)

Fonte: Elaborada pelo autor.

\subsection{Cálculo dos parâmetros integrais da camada limite}

Basear-se somente no número de Re não é suficiente para caracterizar se a camada limite turbulenta atingiu o estado totalmente desenvolvido (FERNHOLZ; FINLEY, 1996; CHAUHAN; MONKEWITZ; NAGIB, 2009; SCHLATTER; ORLU, 2010). Como foi investigado no decorrer desse capítulo, deve-se levar em consideração as características da turbulência como, por exemplo, o espectro de energia, as velocidades médias e as quantidades turbulentas. Além disso, essa análise deve incluir o comportamento dos parâmetros integrais tais como espessura da deslocamento $\left(\delta^{*}\right)$, espessura de quantidade de movimento $(\theta)$, o fator de forma $\left(H=\frac{\delta^{*}}{\theta}\right)$ e o coeficiente de atrito $\left(C_{f}\right)$ (ver as definições dos parâmetros integrais na Seção 2.4).

O fator de forma $H$ é um jeito fácil frequentemente utilizado para caracterizar o estado de desenvolvimento de uma camada limite (SCHLATTER; ORLU, 2010). De acordo com Chauhan, Monkewitz e Nagib (2009), $H$ é um parâmetro muito importante que indica a qualidade da camada limite. $\mathrm{O}$ valor de $H$ cai substancialmente com a transição do regime laminar para o turbulento e valores altos apontam a proximidade do ponto de separação. O monitoramento da evolução do coeficiente de atrito $C_{f}$ aponta o nível de atividade turbulenta dentro da camada limite, tornando-se também um indicador de quão desenvolvido encontra-se o escoamento.

Nesse contexto, a simulação de camada limite com melhores resultados alcançados e que está descrita na seção anterior é examinada em função de $R e_{\theta}$ e dos parâmetros integrais $H$ e $C_{f}$. 
Essa simulação alcançou resultados numéricos bastante precisos para as quantidades turbulentas e espectro de energia (ver Seção 5.3.2 - malha refinada e $\tau=10^{-5}$ foram considerados. Os demais dados computacionais podem ser encontrados na Seção 5.3 .2 .

A Fig. 25 mostra a evolução do coeficiente de atrito local calculado. Para efeito de comparação, podem ser vistas nessa figura as correlações empíricas para $C_{f}$ dadas por $0.024 R e_{\theta}^{-1 / 4}$ e $2\left(\frac{1}{0.38} \log R e_{\theta}+4.08\right)^{-2}$ (OSTERLUND, 1999). Adicionalmente, os dados experimentais de Coles (1962) e os resultados DNS de Spalart (1988) e Schlatter e Orlu (2010) também são considerados.

A região de introdução de pertubações é claramente visível nos valores iniciais de $R e_{\theta}$, entretanto, pode-se observar que a presente simulação atinge o estado totalmente desenvolvido por volta de $R e_{\theta}=650$. Há ótima concordância dos resultados com a correlação empírica de Osterlund (1999). Além disso, uma margem de tolerância de aproximadamente 5\% é observada comparando o resultado numérico obtido com a simples relação, que é baseada na lei de potência, $0.024 R e_{\theta}^{-1 / 4}$. Observa-se, também, um desvio satisfatório de aproximadamente $7 \%$ para os dados de Spalart (1988) e Schlatter e Orlu (2010).

Figura 25 - Evolução do coeficiente de atrito local $C_{f}$ em função de $R e_{\theta}$.

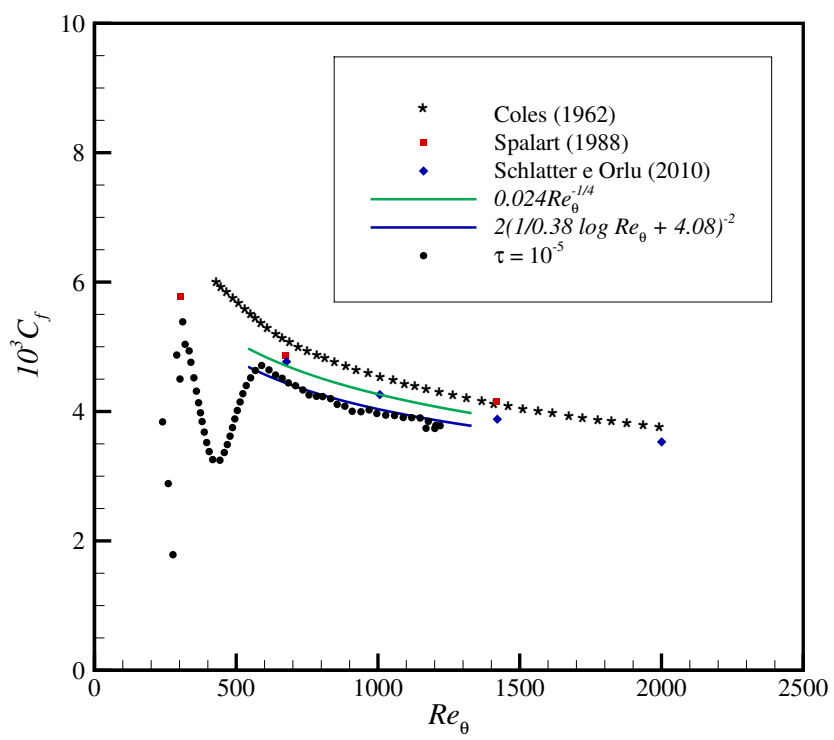

Fonte: Elaborada pelo autor.

O desenvolvimento longitudinal do fator de forma $H$ é mostrado na Fig. 26. Essa figura também apresenta o perfil empírico obtido por Monkewitz, Chauhan e Nagib (2007) juntamente com os dados de Coles (1962), Spalart (1988) e Schlatter e Orlu (2010). A região transição decorrente da introdução das flutuações de velocidade também é observada no início dos valores 
de $R e_{\theta}$. Os resultados da presente simulação LES concordam muito bem com literatura da área, estando dentro de uma tolerância de 3\% das soluções de referência consideradas.

Figura 26 - Evolução do fator de forma $H$ em função de $R e_{\theta}$.

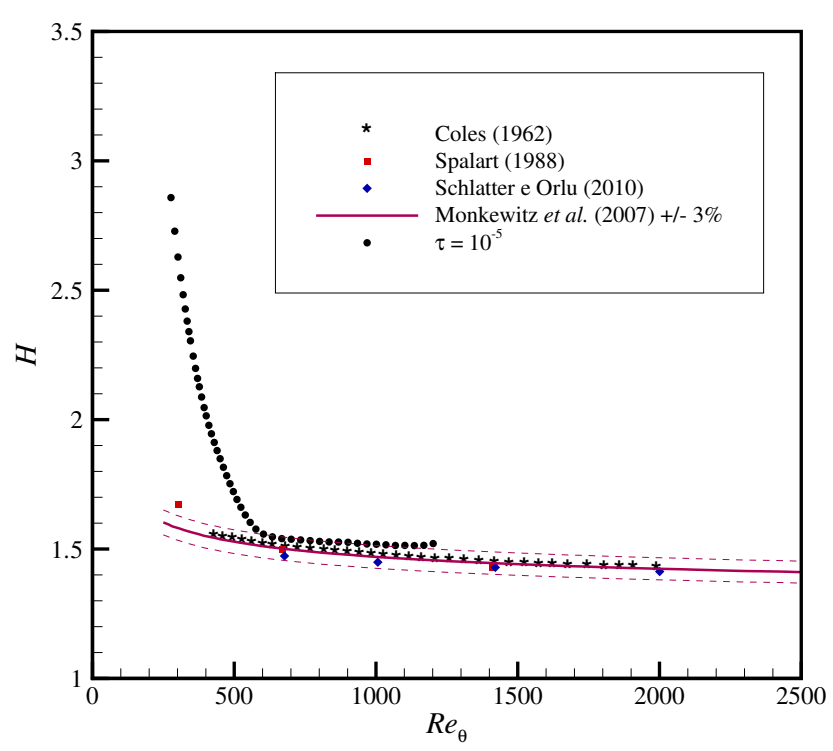

Fonte: Elaborada pelo autor.

\subsection{Visualização das estruturas turbulentas}

Essa seção mostra a comparação qualitativa da evolução da camada limite dentro do domínio computacional. Como feito na seção anterior, a simulação que atingiu maior qualidade nos resultados (Malha 3 e $\tau=10^{-5}$ ) é considerada aqui para visualização das estruturas turbulentas. Os outros dados computacionais são dados na Seção 5.3 .2 .

A Fig. 27 mostra os contornos de velocidade instantânea nas três direções em $x_{1}=2.999$. Fica claro a existência de estruturas vorticais na região próxima à parede.

Para visualização do desenvolvimento da camada limite turbulenta, a Fig. 28 apresenta o isocontorno da velocidade $u_{1}$ extraídas em 5 posições longitudinais e a Fig. 29 retrata a isosuperfície da magnitude da vorticidade colorida pela velocidade $u_{1}$. As regiões de relaminarização (ver Seção 4.5) adotadas nesse trabalho são omitidas nas figuras. Como esperado, as figuras mostram a dinâmica de estruturas coerentes em escoamentos com desenvolvimento espacial, podendo ser observado facilmente o crescimento longitudinal do tamanho da camada limite. Além disso, as estruturas de turbulência estão bem desenvolvidas e não mostram qualquer deterioração visual ou perturbação a jusante da entrada. 
Figura 27 - Contornos de velocidade instantânea em $x_{1}=2.999$.

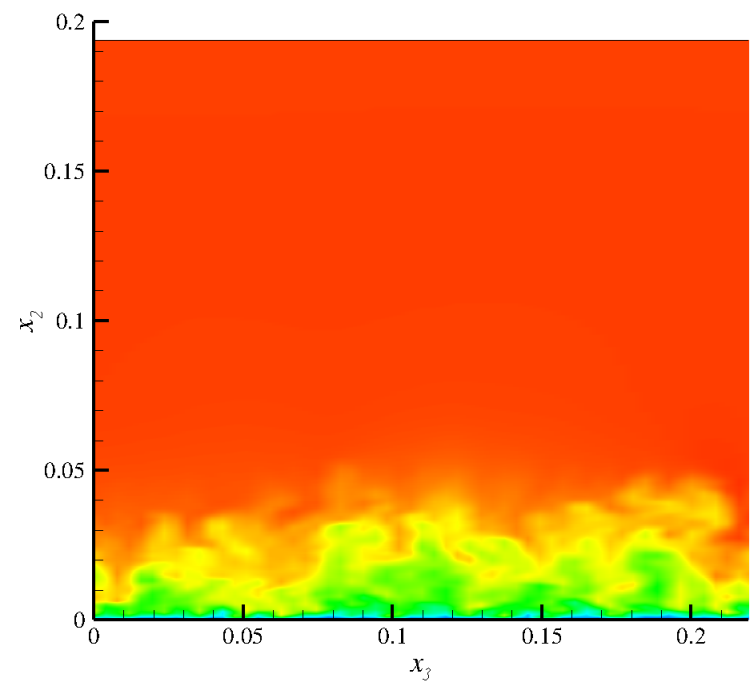

(a) velocidade $u_{1}$

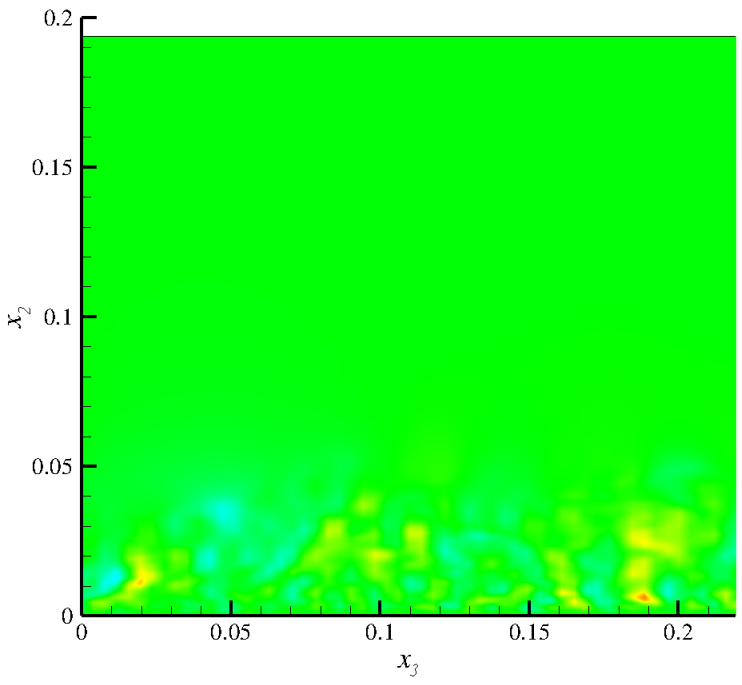

(b) velocidade $u_{2}$

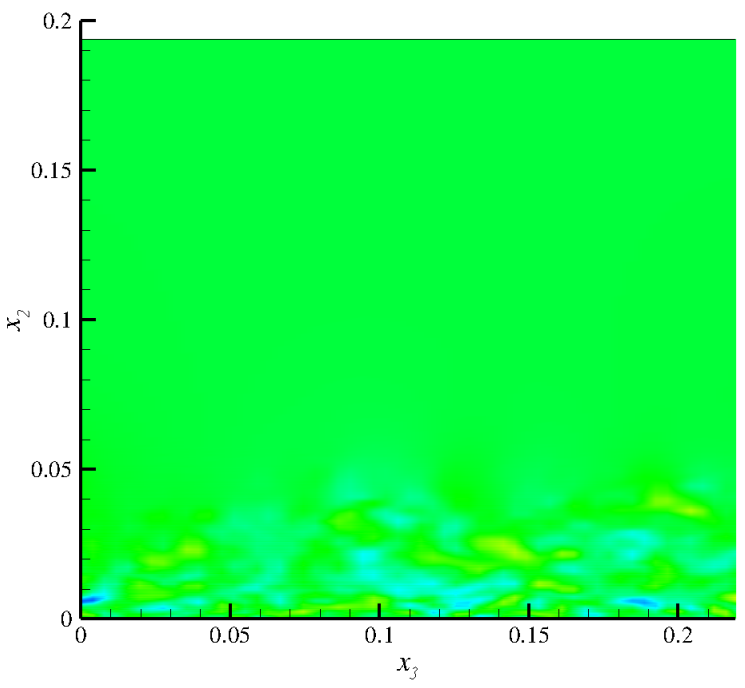

(a) velocidade $u_{3}$

Fonte: Elaborada pelo autor. 
Figura 28 - Isocontorno da velocidade $u_{1}$ para os resultados de camada limite turbulenta obtidos $\tau=10^{-5}$.

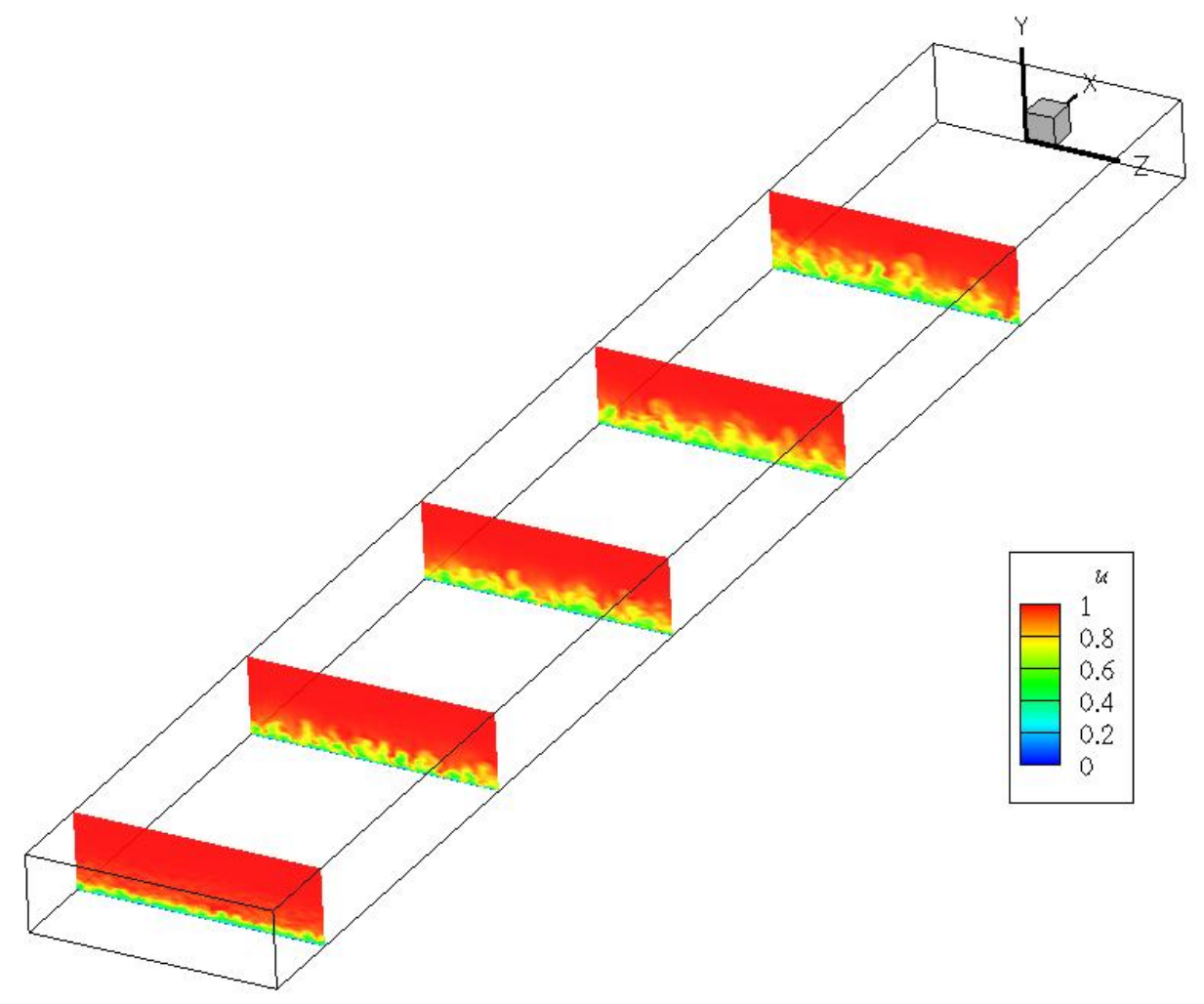

Fonte: Elaborada pelo autor.

\subsection{Comentários do capítulo}

Esse capítulo apresentou a validação do presente código LES para simulação de escoamentos em camada limite turbulenta sobre uma placa plana.

Primeiramente, o modelo submalha WALE garantiu comportamento assintótico apropriado da viscosidade turbulenta próxima à parede sólida. Ainda, o efeito da modelagem submalha pode ser comprovado através dos resultados numéricos que foram mostrados para três valores para a constante $C_{\mathrm{W}}: 0,0.325,0.5$. O valor $C_{\mathrm{W}}=0.5$ forneceu a quantidade de dissipação mais adequada na reprodução dos perfis de velocidade média e do tensor de Reynolds e, então, foi adotado nas simulações computacionais restantes.

Nos testes de refinamento de malha foi possível concluir que o código LES desenvolvido nesse trabalho mostrou notável melhora na qualidade dos resultados com refinamento da resolução computacional. Adotando mais modos de Fourier para resolução na direção transversal $(K=21)$, foram testadas três diferentes malhas nas direções $x_{1}$ e $x_{2}$ - Malha 1 (grossa), Malha 2 (intermediária) e Malha 3 (fina). Como resultado, a malha mais refinada, onde o primeiro ponto de malha na direção normal é localizado em $x_{2}^{+}<1$, o código computacional desenvolvido foi 
Figura 29 - Isosuperfícies da magnitude da vorticidade colorida pela velocidade $u_{1}$ para os resultados de camada limite turbulenta obtidos $\tau=10^{-5}$.

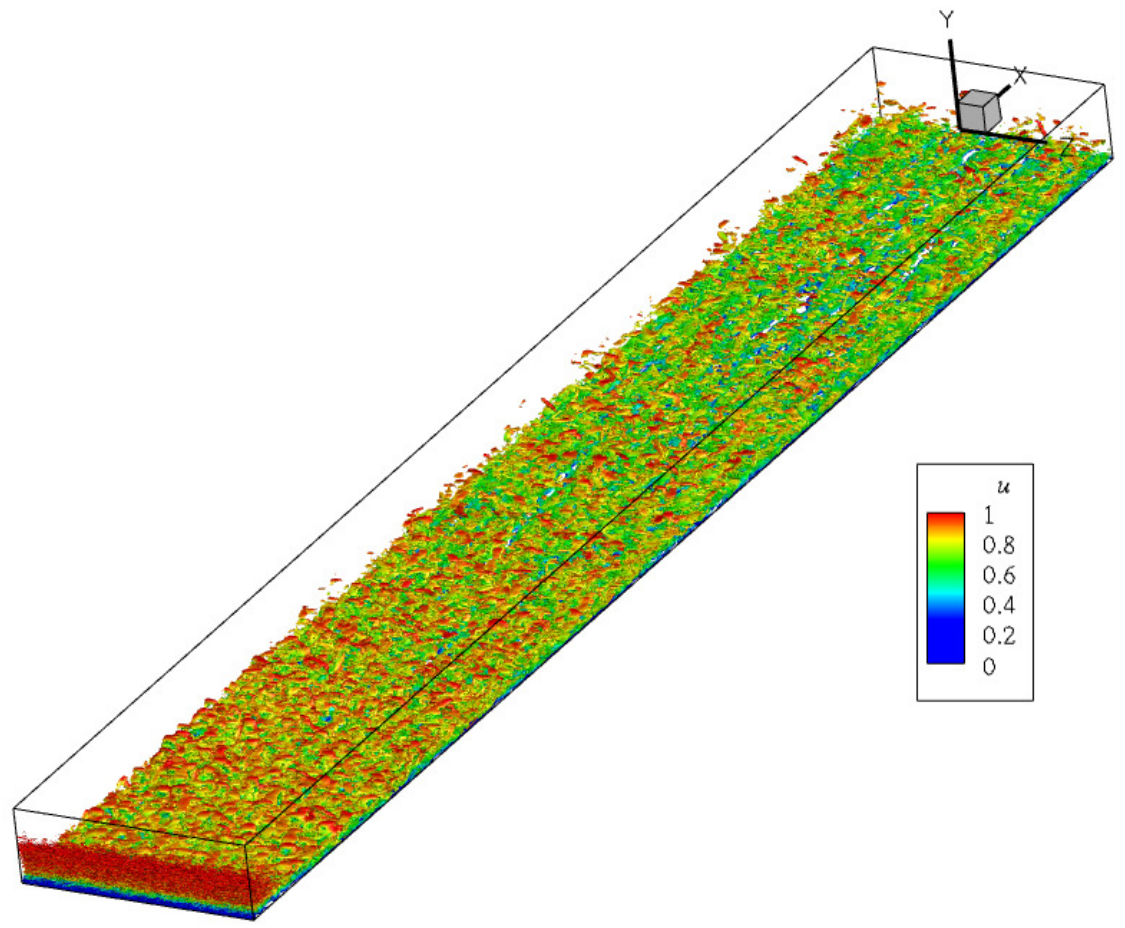

Fonte: Elaborada pelo autor.

capaz de reproduzir do perfil velocidade média $u^{+}$esperado pela teoria clássica de camada limite turbulenta. A partir desse ponto, a Malha 3 foi utilizada nos próximos testes.

Outra análise feita nesse capítulo foi investigar a sensitividade do método RFG com relação ao parâmetro de entrada $\tau$ (escala de tempo da turbulência). Na Seção 5.3.2, cinco diferentes valores de $\tau$ foram considerados: $\tau=10^{-3}, \tau=10^{-4}, \tau=10^{-5}$ e $\tau=10^{-6}$. Como resultado, quanto maior $\tau$, maiores as escalas de tempo e comprimento das flutuação geradas. Em contrapartida, vórtices de menor escala e o aumento da frequência da pertubação de velocidade são consequência da redução do valor de $\tau$. Além disso, a correta escolha do parâmetro de entrada $\tau$ para o algoritmo RFG implica em tempos computacionais diferentes para a simulação atingir um estado de equilíbrio desejado. As simulações realizadas com modos de Fourier $K=21$ (Malha 3) e $\tau=10^{-5}$ mostraram boa concordância com as soluções de referência, atingindo correta distribuição de energia e alta qualidade na reprodução dos perfis médios e dos componentes do tensor de Reynolds.

Por fim, a qualidade da camada limite em desenvolvimento obtida com a Malha 3 e $\tau=10^{-5}$ foi avaliada através dos parâmetros integrais $C_{f}$ e $H$. Os resultados mostraram grande concordância com as soluções de referência, principalmente para o perfil de $H$ - localiza-se dentro de uma tolerância de $3 \%$ das soluções de referência consideradas. Após a introdução 
das flutuações turbulentas, o estado totalmente desenvolvido é atingido sem longo período de adaptação, encontrando-se em aproximadamente $R e_{\theta}=650$. Isso confirma a eficiência do método RFG em fornecer condições iniciais turbulentas fisicamente consistentes.

O próximo capítulo apresenta as conclusões e as perspectivas desse trabalho. 
Essa pesquisa foi dedicada ao desenvolvimento de um código computacional de alta ordem para a simulação LES de escoamentos turbulentos em camada limite. A metodologia numérica é baseada no esquema de diferenças finitas em malhas colocalizadas, onde as derivadas nas direções longitudinal e normal são aproximadas por diferenças compactas de alta ordem. $\mathrm{O}$ presente código numérico contém estiramento de malha na direção normal e utiliza uma técnica de decomposição de domínio para a paralelização dos cálculos na direção longitudinal. Para a modelagem submalha adotou-se o modelo WALE.

Uns dos principais desafios encontrados nesse estudo foi a geração de condições iniciais turbulentas. Ao contrário de situações que envolvem canais, os escoamentos com desenvolvimento espacial não exibem homogeneidade na direção principal do movimento. Como consequência, o uso de condições de periodicidade e suas simplificações não podem ser colocadas em prática. Por essa razão, há a necessidade da especificação de flutuações turbulentas na entrada do domínio em todo passo de tempo. Além disso, a alta sensibilidade dos escoamentos turbulentos às condições iniciais torna crucial a imposição de flutuações turbulentas de forma fiel ao fenômeno físico.

Nesse contexto, as simulações de escoamento em camada limite realizadas nesse trabalho assumiram condições de periodicidade somente na direção transversal, onde um método espectral foi implementado. Ainda, após a realização de revisão bibliográfica sobre o tema e, pelos bons resultados encontrados na literatura, o método de RGF (SMIRNOV; SHI; CELIK, 2001) foi adotado para a geração de perturbações próximo ao contorno de entrada que tornam o escoamento turbulento.

A validação do presente código LES de alta ordem foi feito por meio de simulações de escoamentos em camada limite turbulenta em placa plana para $R e_{\theta}$ entre 900 a 1300 . A qualificação dos resultados numéricos foi determinada pela comparação com dados DNS e LES da literatura da área. 
O espectro de frequência com decaimento $-5 / 3$ confirmou que o modelo submalha WALE foi capaz de fornecer uma distribuição adequada de transferência de energia em um escoamento totalmente turbulento.

O estudo da sensitividade dos resultados em relação ao método RFG mostrou que a escolha da parâmetro de entrada $\tau$ é um fator importante para o sucesso da simulação, influenciando nos tempos computacionais para a obtenção de um camada limite turbulenta plenamente desenvolvida.

Nos testes de malha foi possível perceber a melhoria dos resultados com o refinamento da resolução espacial. A malha mais refinada foi capaz de reproduzir os perfis de velocidade média e componentes do tensor de Reynolds em excelente concordância com os dados DNS e LES (SPALART, 1988; LUND; WU; SQUIRES, 1998; SCHLATTER et al., 2009; SCHLATTER; ORLU, 2010). Ainda, o código numérico desenvolvido nessa pesquisa permitiu avaliar o comportamento do coeficiente de atrito e fator forma em boa concordância com os dados da literatura. Um curto período de adaptação após a imposição das flutuações de velocidade também foi evidenciado, reforçando a eficiência do método RFG para geração apropriada de perturbações para obtenção de uma camada limite turbulenta.

Dessa forma, pode-se concluir que o código LES de alta ordem proposto nessa pesquisa, que combina modelagem submalha WALE e o método de geração de flutuações turbulentas RFG, é uma ferramenta viável e muito promissora para a simulação de escoamentos turbulentos com desenvolvimento espacial.

\subsection{Trabalhos futuros}

Com o término do processo de validação do código para simulação de escoamentos turbulentos em camada limite, um interessante rumo dessa pesquisa seria a simulação computacional de um escoamento tridimensional sobre um degrau ascendente. O método de fronteiras imersas poderia ser utilizado para a introdução do degrau no domínio de cálculo.

Esse tipo de problema é fortemente influenciado pelas condições a montante da camada limite turbulenta que se choca com o degrau submerso no escoamento (SCHLICHTING, 1979, SIMPSON, 1989). A investigação de características como, por exemplo, a formação de bolhas de recirculação e a separação/recuperação da camada limite turbulenta sobre a geometria do degrau, podem ser de grande interesse prático para a indústria. De fato, as significativas alterações no transporte turbulento ocasionadas pela separação do escoamento podem causar a vibração de estruturas, a geração de som e limitação do funcionamento de asas de avião e turbinas eólicas, entre outros. Várias alturas de degrau e condições da camada limite poderiam ser investigadas. 


\section{REFERÊNCIAS}

BOERSMA, B. J. A 6th order staggered compact finite difference method for the incompressible Navier-Stokes and scalar transport equations. Journal of Computational Physics, v. 230, p. 4940-4954, 2011. Citado na página 50.

BOUSSINESQ, J. Essai sur la theorie des eaux courantes. Memoires Presentes par Divers Savants a l'Academie des Sciences, p. 1-660., 1877. Citado na página25.

CHAUHAN, K. A.; MONKEWITZ, P. A.; NAGIB, H. M. Criteria for assessing experiments in zero pressure gradient boundary layers. Fluid Dynamics Research, v. 41, n. 1-23, 2009. Citado na página 76 .

COLES, D. E. The turbulent boundary layer in a compressible fluid. Rand. Rep. R403-PR, ARC 24473 : Appendix A : A manual of experimental practice for low-speed flow. [S.1.], 1962. Citado na página 77 .

DEARDORFF, J. W. Numerical integration of neutral and unstable planetary boundary layers. Journal of the Atmospheric Sciences, p. 91-115, 1972. Citado na página 26.

. Three-dimensional numerical study of the height and mean structure of a heated planetary boundary layer. Boundary-Layer Meteorology, v. 7, p. 81-106, 1974. Citado na página 36.

ECA, L.; HOEKSTRA, M.; HAY, A.; PELLETIER, D. Verification of RANS solvers with manufactured solutions. Engineering with Computers, v. 23, p. 253-270, 2007. Citado na página 56 .

FERNHOLZ, H. H.; FINLEY, P. J. The incompressible zero-pressure-gradient turbulent boundary layer: An assessment of the data. Progress in Aerospace Sciences, v. 32, p. 245-311, 1996. Citado na página 76 .

FERZIGER, J. H.; PERIC, M. Computational Methods for Fluid Dynamics. [S.1.]: SpringerVerlag Berlin Heidelberg New York, 1997. Citado na página 50.

GERMANO, M.; PIOMELLI, U.; MOIN, P.; CABOT, W. H. A dynamic subgrid-scale eddy viscosity model. Physics of Fluids, v. 4, p. 1760-1765, 1991. Citado 2 vezes nas páginas 36 e 39.

HUANG, S. H.; LI, Q. S.; WU, J. R. A general inflow turbulence generator for large eddy simulation. Journal of Wind Engineering and Industrial Aerodynamics, v. 98, p. 600-617, 2010. Citado na página 68 .

JARRIN, N.; BENHAMADOUCHE, S.; LAURENCE, D.; PROSSER, R. A synthetic-eddymethod for generating inflow conditions for large-eddy simulations. International Journal of Heat and Fluid Flow, v. 27, p. 585-593, 2006. Citado na página 29.

KEATING, A.; PIOMELLI, U.; BALARAS, E.; KALTENBACH, H. J. A priori and a posteriori tests of inflow conditions for large-eddy simulation. Physics of Fluids, v. 16, p. 4696-4712, 2004. Citado 4 vezes nas páginas 19, 20, 28, e 29. 
KLEIN, M.; SADIKI, A.; JANICKA, J. A digital filter based generation of inflow data for spatially developing direct numerical or Large Eddy Simulations. Journal of Compututational Physics, v. 186, p. 652-665, 2003. Citado 2 vezes nas páginas 29 e 30.

KLOKER, M. A robust high-resolution split-type compact FD scheme for spatial direct numerical simulation of boundary-layer transition. Applied Scientific Research, v. 59, p. 353-377, 1998. Citado na página 50 .

KOLMOGOV, A. N. The local structure of turbulence in incompressible viscous fluid for very large Reynolds number. Doklady Akademii Nauk, v. 30, p. 9-13, 1941. Citado na página 24.

KRAICHNAN, R. H. Diffusion by a random velocity field. Physics of Fluids, v. 13, p. 22-31, 1970. Citado 3 vezes nas páginas 20,30 e 42 .

KUBAN, L.; LAVAL, J. P.; ELSNERN, W.; TYLISZCAK, A.; MARQUILLIE, M. LES modeling of converging-diverging turbulent channel flow. Journal of Turbulence, v. 13, n. 11, p. 1-19, 2012. Citado na página 60.

LAUNDER, B.; SPALDING, D. The numerical computation of turbulent flows. Computer Methods in Applied Mechanics and Engineering, v. 3, p. 269-289, 1974. Citado na página 26.

LE, H.; MOIN, P.; KIM, J. Direct numerical simulation of turbulent flow over a backward-facing step. Journal of Fluid Mechanics, v. 330, p. 349-374, 1997. Citado na página 30.

LELE, S. Compact finite difference schemes with spectral-like resolution. Journal of Computational Physics, v. 103, p. 16-42, 1992. Citado 2 vezes nas páginas 50 e 55.

LESIEUR, M.; MÉTAIS, O. New trends in Large-Eddy Simulations of turbulence. Annual Review Fluid Mechanics, v. 28, p. 45-82, 1996. Citado 7 vezes nas páginas 19, 27, 28, 35, 37, 38 e 39.

LILLY, D. K. The representation of small-scale turbulence in numerical simulation experiments. In: IBM Scientific Computing Symposium on Environmental Sciences. [S.l.: s.n.], 1967. Citado 2 vezes nas páginas 36 e 39 .

A proposed modification of the Germano subgrid-scale closure method. Physics of Fluids, v. 3, p. 633-635, 1992. Citado na página 39.

LINNICK, M. N.; FASEL, H. F. A high-order immersed interface method for simulating unsteady incompressible flows on irregular domains. Journal of Computational Physics, v. 204, p. 157192, 2005. Citado na página 50 .

LUND, T. S.; KALTENBACH, H. J. Experiments with explicit filtering LES using a finite difference method. [S.1.], 1995. Citado na página 61.

LUND, T. S.; WU, X.; SQUIRES, K. D. Generation of turbulent inflow data for spatiallydeveloping boundary layer simulations. Journal of Computational Physics, v. 140, p. 233-258, 1998. Citado 6 vezes nas páginas 28, 29, 60, 61, 64, e 84.

MEITZ, H. L. Numerical Investigation of Suction in a Trasitional Flat-Plate Boundary Layer. Tese (Doutorado) - The University of Arizona, 1996. Citado na página 55. 
MENEVEAU, C.; KATZ, J. Scale-invariance and turbulence models for Large Eddy Simulation. Annual Review Fluid Mechanics, v. 32, p. 1-32, 2000. Citado na página 35 .

MONKEWITZ, P. A.; CHAUHAN, K. A.; NAGIB, H. M. Self-consistent high-Reynolds-number asymptotics for zero-pressure-gradient turbulent boundary layers. Physics of Fluids, v. 19, n. 115101, p. 1-12, 2007. Citado na página 77 .

NICOUD, F.; DUCROS, F. Subgrid-scale stress modelling based on the square of the velocity gradient. Flow, Turbulence and Combustion, v. 62, p. 183-200, 1999. Citado 2 vezes nas páginas 40 e 60 .

ORSZAG, S. A.; PATTERSON, G. S. Numerical simulation of three-dimensional homogeneous isotropic turbulence. Journal Physical review Letters, v. 28, p. 76-79, 1972. Citado na página 26.

OSTERLUND, J. M. Experimental studies of zero pressure-gradient turbulent boundarylayer flow. Tese (Doutorado) - Department of Mechanics, Royal Institute of Technology, Stockholm, 1999. Citado na página 77 .

PAMIES, M.; WEISS, P.-E.; GARNIER, E.; DECK, S.; SAGAUT, P. Generation of synthetic turbulent inflow data for large eddy simulation of spatially evolving wall-bounded flows. Physics of Fluids, v. 21, 2009. Citado na página 29.

PETRI, L. A.; SARTORI, P.; ROGENSKI, J. K.; SOUZA, L. F. Verication and validation of a Direct Numerical Simulation code. Computer Methods in Applied Mechanics and Engineering, 2015. Citado na página 56.

PIOMELLI, U. Large-eddy simulation: achievements and challenges. Progress in Aerospace Sciences, v. 35, p. 335-362, 1999. Citado 2 vezes nas páginas 35 e 39.

PIOMELLI, U.; BALARAS, E. Wall-layer model for Large Eddy Simulations. Annual Review Fluid Mechanics, v. 34, p. 349-374, 2002. Citado na página 67.

POPE, S. Turbulent flows. [S.1.]: Cambridge University Press, 2000. Citado 6 vezes nas páginas 19, 23, 27, 33, 36, e 37.

PRONK, F. T. Comparison of Inflow generation methods for Large-Eddy Simulation. Dissertação (Mestrado) - Delft University of Technology, 2012. Citado na página 24.

RAI, M. M.; MOIN, P. Direct numerical simulation of transition and turbulence in a spatially evolving boundary layer. Journal Computational Physics, v. 109, p. 169-192, 1993. Citado na página 61 .

REYNOLDS, O. An experimental investigation of the circumstances which determine whether the motion of water shall be direct or sinuous, and of the law of resistance in parallel channels. Philosophical Transactions of the Royal Society, v. 174, p. 935-982, 1883. Citado na página 26 ,

ROACHE, P. J. Verification of codes and calculations. AIAA Journal, v. 36, p. 696-702, 1998. Citado na página 56.

RODI, W.; FERGIZER, J. H.; BREUER, M.; POURQUIÉ, M. Status of large eddy simulation: results of a workshop. Journal of Fluids Engineering, v. 119, p. 248-262, 1997. Citado na página 39. 
ROGENSKI, J. K. Desenvolvimento e otimização de um código paralelizado para simulação de escoamentos incompressíveis. Dissertação (Mestrado) - Instituto de Ciências Matemáticas e de Computação (ICMC-USP), 2011. Citado 4 vezes nas páginas 49, 51, 53 e 54.

SAGAUT, P. Large eddy simulation for incompressible flows. [S.1.]: Springer Verlag, 2006. Citado 8 vezes nas páginas 19, 28, 29, 35, 37, 38, 39, e 67.

SALARI, K.; KNUPP, P. Code verification by the Method of Manufactured Solutions. Sandia National Laboratories, 2000. Citado na página 56.

SCHLATTER, P.; LI, Q.; BRETHOUWER, G.; JOHANSSON, A. V.; HENNINGSON, D. S. Simulations of spatially evolving turbulent boundary layers up to $R e_{\theta}=4300$. International Journal of Heat and Fluid Flow, v. 31, n. 3, p. 251-261, 2009. Citado 3 vezes nas páginas 60. 64 e 84.

SCHLATTER, P.; ORLU, R. Assessment of direct numerical simulation data of turbulent boundary layers. Journal Fluids Mechanics, v. 659, p. 116-126, 2010. Citado 7 vezes nas páginas $34,60,64,73,76,77, \mathrm{e} 84$.

SCHLICHTING, H. Boundary-layer theory. [S.1.]: McGraw-Hill, IncH., 1979. Citado 7 vezes nas páginas 24, 25, 26, 31, 32, 43, e 84 .

Silveira Neto, A. Turbulêcia. In: I Escola de Primavera em Transição e Turbulência. [S.1.: s.n.], 1998. Citado 4 vezes nas páginas 26, 27, 28 e 36 .

SILVESTRINI, J. H. Simulação direta numérica e de grandes escalas de escoamentos turbulentos e transicionais. In: II Escola de Primavera em Transição e turbulência. [S.l.: s.n.], 2000. Citado 3 vezes nas páginas 27, 28, e 39.

SIMENS, M. P.; JIMÉNEZ, J.; HOYAS, S.; MIZUNO, Y. A high-resolution code for turbulent boundary layers. Journal of Computational Physics, v. 228, n. 11, p. 4218-4231, 2009. Citado na página 34 .

SIMPSON, R. L. Turbulent boundary-layer separation. Ann. Rev. Fluid Mechanics, v. 21, p. 205-232, 1989. Citado na página 84 .

SMAGORINSKY, J. General circulation experiments with the primitive equations. Monthly Weather Review, v. 91, p. 99-164, 1963. Citado 2 vezes nas páginas 36 e 39.

SMIRNOV, A. Random flow generation procedure - technical Manual. [S.1.], 2004. Citado na página 43 .

SMIRNOV, A.; SHI, S.; CELIK, I. Random flow generation technique for Large Eddy Simulations and particle-dynamics modeling. Journal of Fluids Engineering, v. 123, p. 359-371, 2001. Citado 7 vezes nas páginas 20, 29, 30, 35, 41, 42 e 83 .

SOUZA, J. F. A.; OLIVEIRA, L. R. de; AZEVEDO, J. L. L. de; S., I. D.; MATA, M. M. Uma revisão sobre turbulência e sua modelagem. Revista Brasileira de Geofísica, v. 29, n. 1, p. 21-41, 2011. Citado 2 vezes nas páginas 32 e 33 .

SOUZA, L. F. Instabilidade centrífuga e transição para turbulência em escoamentos laminares sobre superfícies côncavas. Tese (Doutorado) - Instituto Tecnológico de Aeronáutica (ITA), 2003. Citado 3 vezes nas páginas 49, 52 e 54. 
SOUZA, L. F. Numerical evaluation of time integration schemes in a disturbed flow simulation. In: 18th International Congress of Mechanical Engineer. Ouro Preto - MG: [s.n.], 2005. Citado na página 50 .

SOUZA, L. F.; MENDONÇA, M. T.; MEDEIROS, M. A. F. The advantages of using high-order finite differences schemes in laminar-turbulent transition studies. International Journal for Numerical Methods in Fluids, v. 48, p. 565-592, 2005. Citado na página 50.

SPALART, P. R. Direct simulation of a turbulent boundary layer up to $\operatorname{Re}_{\theta}=1410$. Journal Fluids Mechanics, v. 187, p. 61-98, 1988. Citado 8 vezes nas páginas 29, 33, 60, 64, 65, 73, 77. 84 .

SPITALERI, R. M. Full-FAS multigrid grid generation algorithms. Applied Numerical Mathematics, v. 32, p. 483-494, 2000. Citado na página 54.

STUBEN, K.; TROTTENBERG, U. Nonlinear multigrid methods, the full approximation scheme. In: __. [S.1.]: Koln-Porz, 1981. (Lecture Notes in Mathematics), cap. 5, p. 58-71. Citado na página 54 .

TANI, I. History of boundary-layer theory. Annual Reviews Fluid Mechanics, v. 9, p. 87-111, 1977. Citado 2 vezes nas páginas 25 e 30.

TAYLOR, G. I. Statistical theory of turbulence. Proceedings of the Royal Society of London, v. 151, p. 421-444, 1935. Citado na página 26.

TENNEKES, H.; LUMLEY, J. L. A first course in turbulence. [S.l.]: The MIT Press Cambridge, 1972. Citado 4 vezes nas páginas 23, 27, 28, e 32.

TUTAR, M.; CELIK, I.; YAVUZ, I. Modelling of effect of inflow turbulence on large eddy simulation of bluff body flows. Mathematical and Computational Applications, v. 11, n. 3, p. 225-234, 2006. Citado 2 vezes nas páginas 30 e 41 .

VEDOVOTO, J. M. Mathematical and numerical modeling of turbulent reactive flows using a hybrid LES / PDF methodology. Tese (Doutorado) - Universidade Federal de Uberlandia, 2011. Citado 2 vezes nas páginas 30 e 41 .

VEDOVOTO, J. M.; NETO, A. S.; SILVAB, L. F. F.; MURAC, A. Influence of synthetic inlet turbulence on the prediction of low Mach number flows. Computer \& Fluids, v. 106, p. 135-153, 2015. Citado na página 60.

WHITE, F. M. Fluid mechanics. [S.1.]: McGraw-Hill, 2002. Citado na página 32

WILCOX, D. C. Turbulence modeling for CFD. [S.1.]: DCW Industries, 1994. Citado 8 vezes nas páginas $19,23,27,28,32,35,36$ e 39 .

WRAY, A.; HUSSAINI, M. Y. Highly accurate compact methods and boundary conditions. Proc. Royal Soc. London, v. 392, p. 373-389, 1994. Citado na página 50

WU, X.; MOIN, P. Direct numerical simulation of turbulence in a nominally zero-pressuregradient flat-plate boundary layer. Journal Fluids Mechanics, v. 630, p. 5-41, 2009. Citado na página 33 .

ZHANG, J. Acceleration of five-point red-black gauss-seidel in multigrid for poisson equation. Applied Math. and Comp., v. 80, p. 73-93, 1996. Citado na página 54. 
